Distribution Categories:

$\mathrm{UC}-20,-20 \mathrm{a},-20 \mathrm{~b},-20 \mathrm{c}$,

$-20 \mathrm{~d},-20 \mathrm{e},-20 \mathrm{f},-20 \mathrm{~g}$

ANL/FPP- $78-1$

ARGONNE NATIONAL LABORATORY

9700 South Cass Avenue

Argonne, Illinois 60439

FUSION POWER PROGRAM

QUARTERLY PROGRESS REPORT

January-March 1978

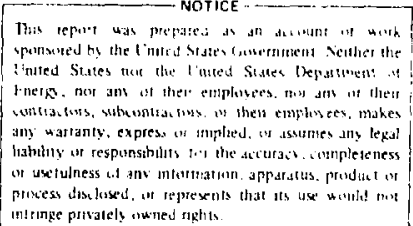

Charles C. Baker, Director

Joseph B. Darby, Jr., Associate Director

Samuel D. Harkness, Associate Director 
This quarterly report describes fusion-related activities in research, development and reactor design, analysis and safety conducted within the Fusion Power Program and within other DOE-funded programs at Argonne National Laboratory.

The last six quarterly reports issued were:

$\begin{array}{ll}\text { ANI/CTR-76-5 } & \text { July-September } 1976 \\ \text { ANL/FPP-76-6 } & \text { October-December } 1976 \\ \text { ANL/FPP-77-1 } & \text { January-March } 1977 \\ \text { ANL/FPP-77-2 } & \text { April-June } 1977 \\ \text { ANL/FPP-77-4 } & \text { July-September } 1977 \\ \text { ANL/FPP-77-7 } & \text { October-December } 1977\end{array}$

ABSTRACT

This quarterly report summarlzes the Argonne National Laboratory work periormed for the Office of Fusion Energy during the January-March 1978 quarter in the following research and development areas: materials; energy storage and transfer; tritium containment, recovery and control; advanced reactor design; systems studies; neutronics; atomic data; reactor safety; and other work related to fusion power. 
TABLE OF CONTENTS

Page

I. FUSION REACTOR MATERIALS . . . . . . . . . . . . . . . 1

A. Plasma Materials Interactions .............. 1

1. Surface Damage of 316 Stainless Steel Irradiated with

${ }^{4} \mathrm{He}^{+}$to High Doses.............. 1

2. Depth Distribution of Bubbles in ${ }^{4} \mathrm{He}^{+}$-Ion Irradiated Nickel and the Mechanism of Blister Formation .... 3

3. Correlation of Blister Diameter and Blister Skin

Thlckness for Helium Bombarded V............ 5

4. Sputtering Yields for Deuterium on Gold . . . . . . . 11

5. Fast-neutron Sputtering of Gold . . . . . . . . 14

B. Dosimetry and Damage Analysis . . . . . . . . . . 18

1. Experiments at ${ }^{9} \mathrm{Be}(\mathrm{d}, \mathrm{n})$ Accelerator Neutron Sources . - 18

2. Review of the Fusion Materials Irradiation Test

Facility (FMIT) Dosimetry Program . . . . . . . 18

3. Dosimetry Standardization ........... 20

4. Fission Reactor Dosimetry ........... 20

C. Alloy Development ................. 23

1. Hydrogen Permeation and Materials Behavior in Alloys of Interest to the Fusion Power Program . . . . . . . 23

2. Microstructure of Irradiated Fusion Reactor Firstwall Materials . . . . . . . . . . . . 26

D. Special Purpose Materlals . . . . . . . . . . 37

1. Ion-1mplantation Damage in Amorphous and Crystalline

$\mathrm{Nb}_{40} \mathrm{Ni}_{60} \cdot . . \cdot . \cdot . \cdot . \cdot . \cdot . \cdot . \cdot . \cdot 37$

II. EXPERTMENTAL POWER REACTOR . . . . . . . . . . . . 46

A. First-Wall/Limiter Design .............. 46

B. Impurity Control . . . . . . . . . . . . 49

C. Model Equilibrium Field Coll System . . . . . . . . . 50 
III. FUSION SYSTEMS ENGINEERING ............... 53

A. Fusion Reactor Systems Studies . . . . . . . . . . 53

1. Systems Studies of Fusion Reactor Tritium Facilities . . 56

B. Development of Blanket Processing Technology for Fusion

Reactors .................. 56

1. Lithium Processing Test Loop (LPTL) . . . . . . . 56

2. Supporting Studies ............. 60

C. Safety Studies of Fusion Concepts . . . . . . . . . . 60

1. Analysis of Tritium Soaking Mechanisms ........ 60

D. MACKLIB-IV, A New Library of Nuclear Response Functions . . 63

E. Energy Storage and Power Supply Requirements for Commercial Fusion Reactors ............ 66

F. Blanket/Shield Design Evaluation for Commerclal Fusion

Reactors .................... 66

1. Blanket/Shield Design Study . . . . . . . . 66

2. An Analysis of the Relationship Between Avallable

Materials Properties and Allowable Fusion Reactor

Design Conditions ............. 71

3. Fusion Reactor Blanket Design Study . . . . . . . 81

4. Evaluation of Steam as a Potential Coolant for Nonbreeding Blanket Designs............ 83

G. Cross Section Measurements, Evaluations and Techniques . . 87

1. Fast-Neutron Total and Scattering Cross Sections of Elemental Titanium . . . . . . . . . . . 87

2. Nuclear Data for High-Energy Neutron-Damage Sources . 87

IV. MAGNETIC SYSTEMS . . . . . . . . . . . . . . 88

A. Energy Storage and Transfer Program . . . . . . . . 88

1. Homopolar Generator ........... 88

2. Inductor-Converter Bridge ............ 88 
TABLE OF CONTENTS (Cont1nued)

Page

B. Negative Ion Source Development . . . . . . . . . . 90

1. Direct Extraction $\mathrm{H}^{-}$Source . . . . . . . . . 90

V. APPLIED PLASMA PHYSICS .................... 91

A. Disparate Clump Approximation in Neoclassical Transport

Theory ...................... 91

B. Theoretical Spectroscopic Data for Silver-Like Ions . . . . 92

FPP AND FPP-RELATED DOCUMENTS AUTHORED BY ARGONNE PERSONNEL • • • • • • 94 
I-1. Scanning electron micrograph of Type 316 stainless steel irradiated at $\backsim 450^{\circ} \mathrm{C}$ with $100-\mathrm{keV}^{4} \mathrm{He}^{+}$ions to a total

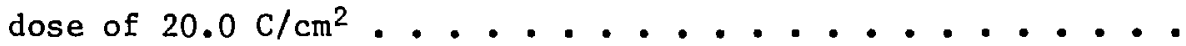

I-2. Bright field TEM of annealed polycrystalline $\mathrm{Ni}$ irradiated at $500^{\circ} \mathrm{C}$ with $500-\mathrm{keV}{ }^{4} \mathrm{He}^{+}$for a dose of $5 \times 10^{17}$ tons $/ \mathrm{cm}^{2}$, and histogram showing swelling $(\Delta V / V)$ as a function of depth from the irradiated surface for the micrograph . . . . .

I-3. Bright field TEM of annealed polycrystalline $\mathrm{Ni}$ irradiated at $500^{\circ} \mathrm{C}$ with $20-\mathrm{keV}{ }^{4} \mathrm{He}^{+}$for a dose of $2.9 \times 10^{17}$ ions $/ \mathrm{cm}^{2}$, and histogram showing swelling as a function of depth from the irradiated surface for the micrograph . . . . . . . 6

I-4. Histrogram of the size distribution of blisters in annealed polycrystalline vanadium irradiated at room temperature with $100-\mathrm{keV}{ }^{4} \mathrm{He}^{+}$to a total dose of $0.5 \mathrm{c} / \mathrm{cm}^{2}$, and a typical scanning electron micrograph that was used to construct the histogram ......................

I-5. A double logarithmic plot of blister diameter against mean blister skin thickness, $t$, for annealed polycrystalline and monocrystalline vanadium surfaces . . . . . . . . . .

I-6. Scanning electron micrograph of annealed polycrystalline vanadium irradiated at room temperature with $60-\mathrm{keV}{ }^{4} \mathrm{He}^{+}$ to a dose of $0.5 \mathrm{c} / \mathrm{cm}^{2}$, showing nearly spherical blisters . . 12

I-7. Microphotodensitometer trace of autoradiograph (in direction parallel to cylinder axis) . . . . . . . . . . 15

I-8. Cascade 1ifetime and thermal-spike lifetime versus primary recoll energy, as calculated by Sigmund. Also plotted is damage energy distribution for our neutron-energy spectrum versus primary recoil energy ...............

I-9. Error analysis of the unfolded neutron spectrum for $E_{d}=$ $30 \mathrm{MeV}$ at $4 \mathrm{~mm}$ from the source...................... 19

I-10. Unfolded spectrum for LPTR - E7 with error analysis . . . . 21

I-11. Unfolded spectrum for LPTR - C4 with error analysis . . . . 22

I-12. Hydrogen permeation rate versus hydrogen pressure for 316-SS at 517, 897 and $1015 \mathrm{~K}$. . . . . . . . . 24

I-13. Schematic of ANL dua1-ion irradiation system . . . . . . 26 
I-14. Temperature dependence of swelling and cavity size in

I-15. Temperature dependence of the dislocation and cavity number densities in Fe-20N1-15Cr........... 28

I-16. Dose dependence of cavity size in Fe-20N1-15Cr . . . . . 29

I-17. Dose dependence of cavity number density in $\mathrm{Fe}-20 \mathrm{~N} 1-15 \mathrm{Cr} . . .30$

I-18. Dose dependence of dislocation density in Fe-20Ni-15Cr . . . 31

I-19. Dose dependence of swelling in Fe-20N1-15Cr . . . . . . . 32

I-20. Absorption contrast micrographs of $\mathrm{V}-15 \mathrm{Cr}$ specimens Irradiated at $650^{\circ} \mathrm{C}$ to different dose levels . . . . . . 33

I-21. Dislocation contrast micrographs of $\mathrm{V}-15 \mathrm{Cr}$ specimens irradiated at $650^{\circ} \mathrm{C}$ to different dose levels . . . . . . 33

I-22. The same area of the 27-dpa specimen shown in Figure I-14 imaged under strong dislocation contrast and absorption contrast ................... 34

I-23. Average void stze observed in $\mathrm{V}-15 \mathrm{Cr}$ as a function of

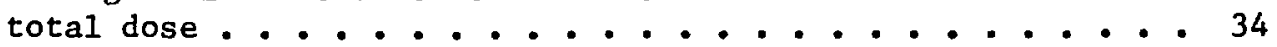

I-24. Void number density and calculated total swelling for $\mathrm{V}-15 \mathrm{Cr}$ as a function of total dose. The total swelling of the unalloyed $\mathrm{V}$ stock is also shown . . . . . . . . 35

I-25. Cr concentration versus depth profiles for an unirradiated control and two irradiated specimens . . . . . . . . 36

I-26. Microstructure of $\mathrm{Nb}_{4} \mathrm{Ni}_{60}$ after irradiation to $20 \mathrm{dpa}$ at

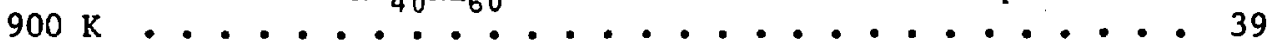

I-27. Specimen preannealed to $973 \mathrm{~K}$ for 10 minutes in vacuum and specimen appearance after irradiation to dose $>6 \mathrm{dpa}$ at room temperature or $900 \mathrm{~K}$. . . . . . . . . . . .

I-28. Specimen preannealed to $950 \mathrm{~K}$ for 10 minutes in vacuum and microstructure after irradiation to $20 \mathrm{dpa}$ at $900 \mathrm{~K}$ but for a depth near the tail of the ion-damage curve at $\sim 2$ dpa ............................ 
I-29. Specimen preannealed at $930 \mathrm{~K}$ for 10 minutes in vacuum and dark-fleld micrograph of the structure after irradiation to $20 \mathrm{dpa}$ at $900 \mathrm{~K}$ but for sectien depth at the tall of the damage curve at $v 1 \mathrm{dpa}$. . . . . . . . . . 44

II-1. Schematic of EPR 11miters ...............47

II-2. Detall of limiter geometry .............. 47

II-3. Calculated thermal response of surface of graphite limiters that cover a fraction of first-wall area ..........48

II-4. Calculated thermal response of stainless steel first wall with and without 1-cm thick graphite limiter . . . . . . .

II-5. Equilibrium-fleld coll model for a $6-\mathrm{m}$ major radius reactor with $9 \mathrm{~T}$ toroldal colls for a somewhat elongated D-shaped plasma with toroldal beta of $8 \%$, plasma current of $9.8 \mathrm{MA}$ and aspect ratio of 3.5 . . . . . . . . . . . 51

III-1. Dependence of the cost of energy on the downtime for (a) SS structure, and (b) vanadiun structure with lifetime ratio and the range $1-6$. . . . . . . . . . . 55

III-2. Time-temperature histories and impurity concentration profiles for the first 2000 hours of LPTL operation . . . . . . 57

III-3. Dlagram of the IPTL cold trap presently in use . . . . . . 59

III-4. Alr detritiation curves for a typlcal cleanup operation using the bench-scale test chamber . . . . . . . . 61

III-5. Calculated species concentrations with time for the curves In Figure III-4 . . . . . . . . . . . . . 62

III-6. Neutron kerma factor for berylllum . . . . . . . . . 64

III-7. Neutron kerma factors for ${ }^{235} \mathrm{U},{ }^{238} \mathrm{U}$ and ${ }^{232} \mathrm{Th} . . . . . .65$

III-8. Plot of breeding ratio versus breeding zone thickness for three breeding materials . . . . . . . . 69

III-9. Effect of fractional burnup and doubling time upon required breeding ratio .............. 70

III-10. A comparison of the expected fatigue lives of annealed, coldworked and Irradlated type 316 stalnless steel . . . . . 74 
$\underline{\text { Page }}$

III-11. Comparison of expected crack growth propertles with those needed to achieve a $10 \mathrm{MW}-\mathrm{yr} / \mathrm{m}^{2}$ wall $11 \mathrm{fe}$........ 76

III-12. Average effective stresses expected in a 11thium-cooled module as a function of wall loading . . . . . . . . . 77

III-13. Evaluation of expected crack growth properties in terms of a time dependent first wall stress history ....... 79

III-14. The effect of wall thickness of the crack growth rates required to achleve a $10 \mathrm{MW}-\mathrm{yr} / \mathrm{m}^{2} 11 \mathrm{fe} . . . . . . . . . .80$

III-15. A comparison of crack growth rates in air and in sodium . . 81

III-16. Effect of fractional burnup and doubling time upon required breeding ratio for a $3000 \mathrm{MW}(\mathrm{th})$ tokamak reactor . . . 82

III-17. Schemat1c of EPR blanket/superheater . . . . . . . . . 86

IV-1. HOPE-1 - voltage across the drum, current through the drum and speed of the drum as a function of time . . . . . 89 
I-1. Sputtering ylelds (atoms/ion) ............. 14

I-2. Integral fluxes for LPTR ............... 2 .

I-3. Lattice spacings and intensitles from the electron dif-

fraction pattern of partially crystaline specimens

annealed at temperatures within the first exothermic peak . . 39

III-1. Reference reactor parameters . . . . . . . . . 54

III-2. Reference parameters for the heat transfer and transport

system . . . . . . . . . . . . . . . . 54

III-3. Comparison of neutron kerma factors in MACKLIB-IV and

MACKLIB for several materials in selected energy groups . . 65

III-4. Basic machine design ... . . . . . . . . . . 67

III-5. Reference materials considered in blanket design study . . . 68

III-6. "Fuel Pin" fusion reactor breeding scenarios for $3000 \mathrm{MW}(\mathrm{th})$ plant ...................... . 84

$\mathrm{V}-1$. Theoretical data on wavelength $\lambda$, absorption oscillator strength $f$, and transition rate $A$ for $\mathrm{W}^{27^{+}}$and $\mathrm{Au}^{32^{+}}$. . . 93 


\section{FUSION REACTOR MATERIALS}

\section{A. Plasma Materials Interactions}

1. Surface Damage of 316 Stainless Steel Irradiated witl: ${ }^{4} \mathrm{He}^{+}$ to High Doses

M. Kaminsl i' and S. K. Das, Physics Division

Surface blistering of metals (e.g., Nb) by implantation with helium ions in the 9 to $15 \mathrm{keV}$ energy range has been shown 1,2 to discppear for sufficiently high doses ( $\sim 1$ to $3 \mathrm{r} / \mathrm{cm}^{2}$ ). In more recent studics ${ }^{3}$ of $100-\mathrm{keV}$ helium implanted $\mathrm{Nb}$, again, the disappearance of blisters was reported for the high dose of $20 \mathrm{c} / \mathrm{cm}^{2}$. The authors ${ }^{3}$ observed a sponge-like surface structure which they considered to be an equilibrium surface structure, and they concluded that blistering is a transient phenomenon. However, since sponge-like surfaces have been observed 4,5 at much lower doses $\left(e . g ., 1 \mathrm{c} / \mathrm{cm}^{2}\right)$ but for high target temperatures (homologous temperature $\sim 0.5$ ) it appeared possible that the results reported in Ref. (3) were not typical for high dose implantations but for high target temperatures (e.g., target heating by deposited beam power $30-100 \mathrm{~W} / \mathrm{cm}^{2}$ ). To clarify this point we have conducted systematic studies of the surface damage of fcc (A1), bcc (V, Nb, Mo) and hcp (Be) metals and stainless steel under $100-\mathrm{keV}$ helium ion irradiation for high doses of $20 \mathrm{c} / \mathrm{cm}^{2}$ at controlled target temperatures and under high vacuum conditions. For limitation of space only, results for 316 stainless steel held at $450^{\circ} \mathrm{C}$ will be discussed here and compared to earlier reported results 6 for $\mathrm{Nb}$ held. at $400^{\circ} \mathrm{C}$. The results for the other metals will be reported in a full length paper elsewhere.

Figure I-1 shows, at three magnifications, the seriously exfoliated surfaces of 316 stainless steel. An "equilibrium surface structure" has not been formed. Instead, in many areas ("deep holes", 0.1 to $1.0 \%$ of irradiated area) 15 skins have been lost, each of $\sim 0.55 \pm 0.05 \mu \mathrm{m}$ skin thickness (Figure I-1c), and in addition, two skin layers appear to have been lost completely. Under the assumption that two skins have been lost, and by adding the loss of skins in the area of the deep holes, a lower limit for the surface erosion yield has been estimated as $\sim 0.1$ atoms/ion. In turn, an estimate of the upper limit for the erosion yield (assuming the complete loss of 15 skins) gives a value

I J. G. Martel, R. St. Jacques, B. Terreault, G. Veilleux, J. Nucl. Mat. 53 (1974) 142 .

2 J. Roth, R. Behrisch and B. M. Scherzer, J. Nucl. Mat. 57 (1975) 365.

3 R. Behrisch, M. Risch, J. Roth and B. M. Scherzer, Proc. 9th Symp. of Fusion Technology (Pergamon 1976) 531.

4 W. Bauer and G. J. Thomas, Nucl. Metallurgy 18 (1973) 255.

5 M. Kaminsky and S. K. Das, Proc. 4th Conference, Scientific and Industrial Applications of Small Accelerators, Denton, Texas (IEEE, New York 1976) 238.

6

M. Kaminsky, Proc. Seventh International Conference on Atomic Collisions in Solids, Moscow, U.S.S.R., (September, 1977). 

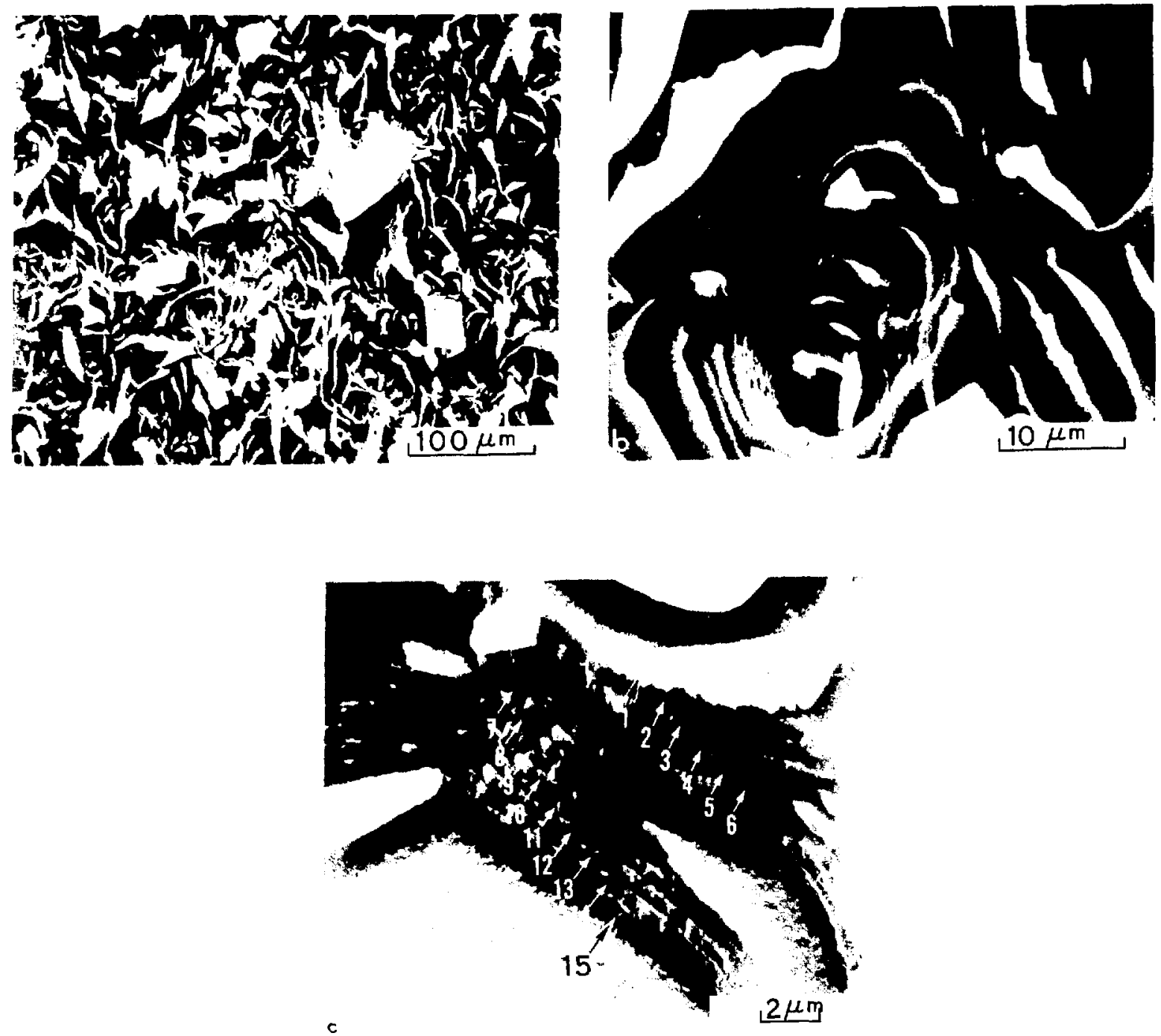

Figure I-1. I-1(a)-(c) shows scanning electron micrograph of Type 316 stainless steel irradiated at $\sim 450^{\circ} \mathrm{C}$ with $100-\mathrm{keV}{ }^{4} \mathrm{He}^{+}$ions to a total dose of $20.0 \mathrm{c} / \mathrm{cm}^{2}, F i g . ~ I-1(b)$ shows an enlarged view of one of the holes created due to multiple exfoliation and Fig. I-1(c) snows $a_{1}$ : even higher magnification micrograph of another hole. Notice that the thickness of each exfoliated layer marked by arrows $1-15$ are nearly the same. 
of 0.7 atoms/ion. It should be noted that even the lower limit value for the erosion yield is one order of magnitude larger than the physical sputtering yield value calculated according to Smith. ${ }^{7}$ We already reported 6 that for polycrystalline $\mathrm{Nb}$ irradiated at $400^{\circ} \mathrm{C}$ with $100-\mathrm{keV}{ }^{4} \mathrm{He}^{+}$to a dose of 20 $\mathrm{C} / \mathrm{cm}^{2}$ no "sponge-like" equilibrium surface could be observed. Instead, in many areas more than 3 skins (each of $\sim 0.3 \mu \mathrm{m}$ thickness) had been lost and the surface exfoliation process had not been stopped.

The results reported here do not support the claim ${ }^{3}$ made for $100-\mathrm{keV}$ ${ }^{4} \mathrm{He}^{+}$implantation of solids to high doses of $20 \mathrm{c} / \mathrm{cm}^{2}$ that blistering will be a transient phenomenon, and that an equilibrium surface structure ("spongelike") will be formed. Instead, we observe a continuous exfoliation process of the irradiated surfaces.

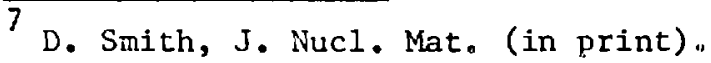

2. Depth Distribution of Bubbles in ${ }^{4} \mathrm{He}^{+}$-Ion Jrradiated Nickel and the Mechanism of Blister Formation

G. Fenske, S. K. Das, M. Kaminsky, Physics Division, and G. H. Miley*

While the radiation blistering phenomenon has been widely studied, the mechanism of blister formation is still not well understood. 8 The present studies on depth distribution of helium bubbles in nickel were carried out in order to obtain a better understanding of the radiation blistering process. Particularly, the aim was to understand the experimental observation 8,9 that the blister skin thickness for many metals irradiated with $\mathrm{He}^{+}$ ions of energies lower than $20-\mathrm{keV}$ is a factor of two or more larger than the calculated projected range.

High purity (99.995\%) annealed polycrystalline nickel foils were irradiated at $500^{\circ} \mathrm{C}$ with either $20-$ or $500-\mathrm{keV}^{4} \mathrm{He}^{+}$ions to total doses of $2.9 \times 10^{17}$ and $5 \times 10^{15}$ ions $/ \mathrm{cm}^{2}$, respectively. Thin foils suitable for transmission electron microscopy were prepared from the irradiated samples by a transverse sectioning technique described elsewhere. 10 The technique allows one to obtain depth distribution of cavities (e.g. bubbles, voids) from a single specimen.

Figure I-2(a) shows a typical bright field transmission electron micrograph (TEM) of the plated and irradiated regions (the interface between the two is marked by arrows) of the 500-keV irradiated sample. The cavities seen at the interface and in the plating are probably due to the trapped hydrogen bubbles generated in the nickel strike solution. The swelling $(\Delta V / V)$ due to the cavities (voids or bubbleș) were measured from enlarged

\footnotetext{
* University of Illinois - Urbana.

8 S. K. Das, M. Kaminsky, Adv, in Chemistry 158 (1976) 112.

9 S. K. Das, M. Kaminsky, G. Fenske, J. Nucl. Materials (in print).

${ }^{10}$ G. Fenske, S. K. Das and M. Kaminsky, to be published.
} 


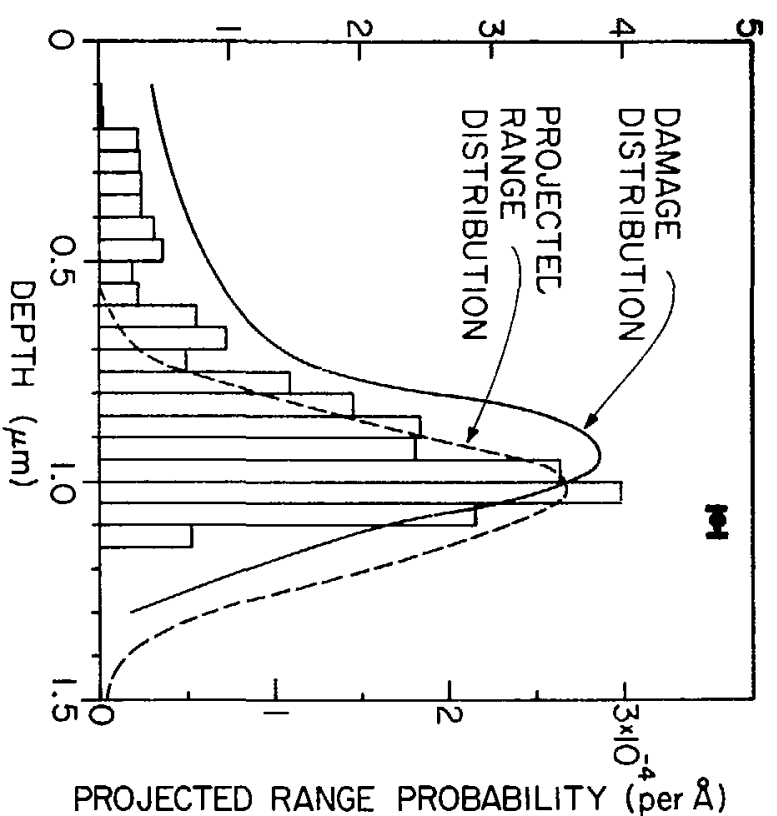

PROJECTED RANGE PROBABILITY (per $\AA$ )

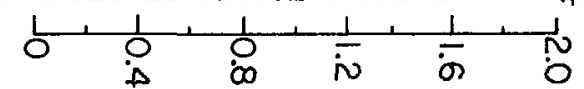

ENERGY DEPOSITED INTO DAMAGE (eV/Å)

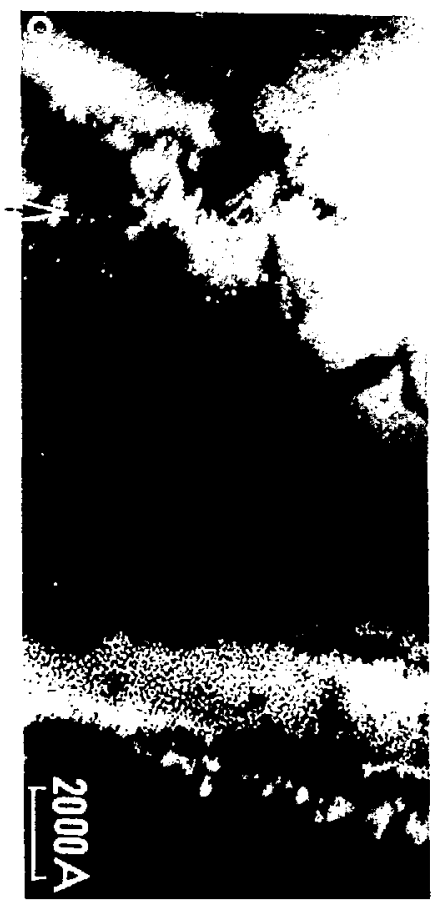


micrographs as a function of depth at $500 \AA$ intervals and is shown in Fig. I-2(b). The solid and dashed curves show the depth distribution of unergy deposited into damage, and the projected range calculated according to Bricell, respectively. Also, the experimentally measured blister skin thickness is plotted with the error bars. It can be seen that the peak in the swelling agrees well with the peak in the projected range distribution and with the blister skin thickness.

Figure I-3(a) shows a bright field of TEM of the 20-keV irradiated sample and the corresponding histogram of the swelling as a function of depth is shown in Figure I-3(b). The dashed curve represents the calculated projected range probability distribution. The measured blister skin thickness is shown by the horizontal bar. Here it can be seen that the depth at which the swelling peak occurs is at a much larger depth than the peak in the calculated projected range distribution, but agrees well with the blister skin thickness. These results suggest that the separation of blister skin occurs at a depth where the volume fraction of the helium bubbles is at a maximum. The critical dose for blister formation is reached when interbubble fracture has been initiated in the region of maximum swelling where the interbubble distance has become sufficiently small.

11. K. Brice, Ion Implantation Range and Energy Deposition Distribution, Vol. 1, (Plenum, New York, 1975).

3. Correlation of Blister Diameter and Blister Skin Thickness for Helium Bombarded V

M. Kaminsky and S. K. Das, Physics Division

Different models have been proposed to explain the formation of surface blisters on helium-bombarded surfaces. Such models are based on (a) gas bubble coalescence and the build-up of internal gas pressure, 12-1: or (b) the percolation of helium in the lattice,20-21 and/or (c) the build-up of

12 M. Karninsky, Adv. in Mass Spectrometry 3 , 69 (1964).

13 W. Primak and J. Luthra, J. Appl. Phys. 37, 2287 (1966).

${ }^{14}$ R. S. Blewer and J. Maurin, J. Nucl. Mat. 44, 260 (1972).

15 S. K. Das and M. Kaminsky, J. App1. Phys. 44, 25 (1973).

${ }^{16}$ S. K. Das and M. Kaminsky, Proc. of Third Conf. on Application of Small Accelerators, CONF-741040-P1 (1974).

${ }^{17}$ G. M. McCracken, Japan J. Appl. Phys. Suppl. 2, Pt. 1, 269 (1974).

$18 \mathrm{~J}$. H. Evans, J. Nucl. Mat. 61,1 (1976).

19. Auciello, Radiation Effects, 30, 11 (1976).

20 W. D. Wilson, C. L. Bisson and D. E. Amos, J. Nucl. Mat. 53, 154 (1974).

${ }^{21}$. J. Thomas and W. Bauer, Radiation Effects, 17, 221 (1973). 

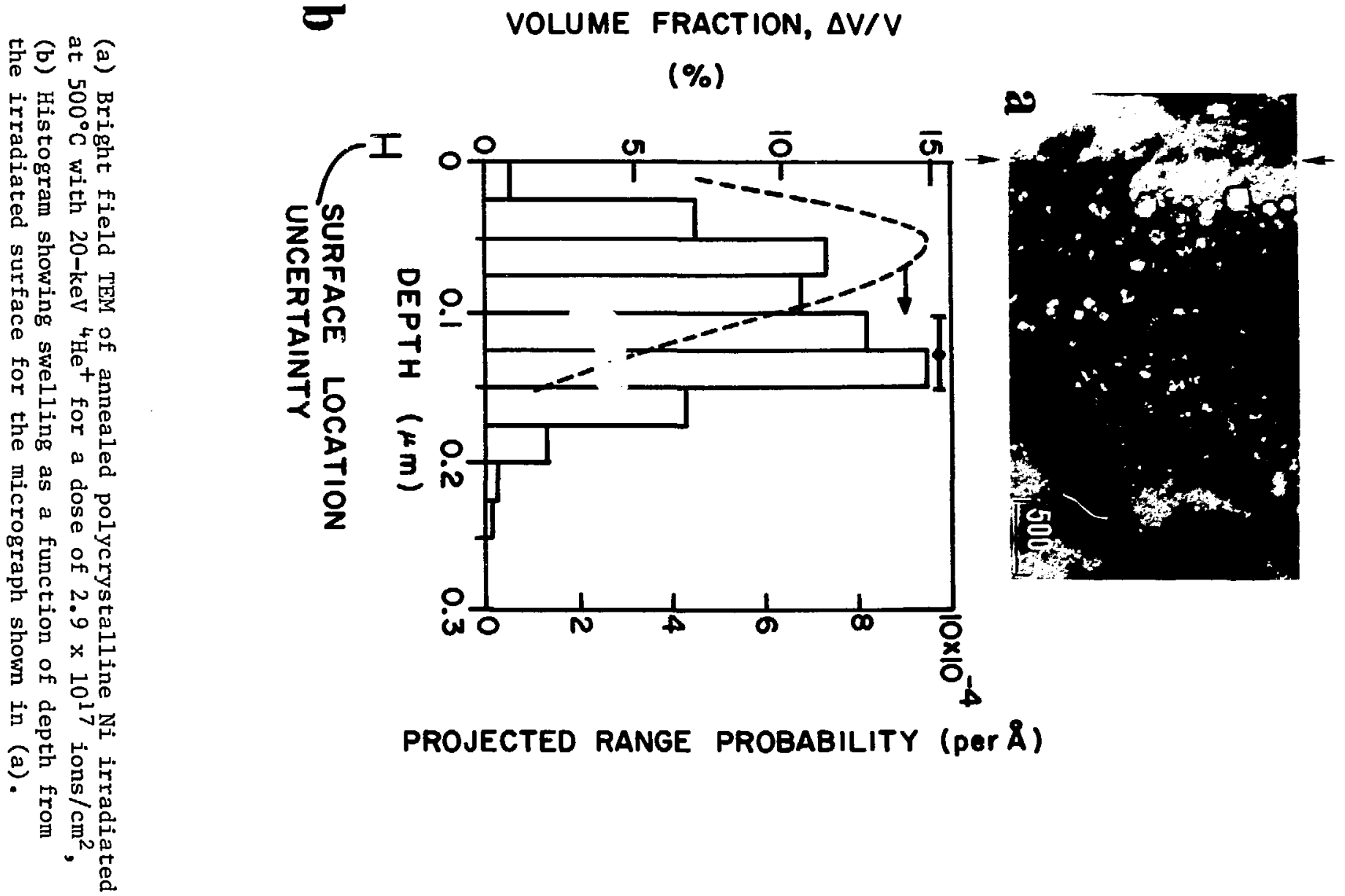
stresses in the implanted layer. ${ }^{22-25}$ Some models of the latter type suggest that large lateral stresses introduced in an ion-implanted surface layer may cause elastic instability and buckling of the implant layer, and result in a relationship $D_{\text {up }} \propto \mathrm{t}^{1.5}$ between the most probable blister diameter, $D_{\text {mp }}$, and the blister skin thickness, $t$. This relationship was initially suggested by Roth, 23 and then by Risch, et a1.,24 for helium blistering of Nb. Subsequently, EerNisse, et a1.,25 claimed that this relationship should apply also to metals such as Be, Ti, V, Mo, Pd, and 4301 stainless steel. However, since EerNisse et al., showed for several metals (e.g., Ti and $V$ ) only one data point on a $D_{m p}$ vs $t^{1.5}$ plot, the applicability of this relationship for a wide range of $D_{m p}$ and $t$ values for these metals needed to be tested.

In this paper we report a systematic study of the correlation between blister diameter and skin thickness for annealed polycrystalline and monocrystalline vanadium $(100)$ surfaces blistered by ${ }^{4} \mathrm{He}^{+}$ion irradiation in the energy range from $20 \mathrm{keV}$ to $500 \mathrm{keV}$. In order to make such a correlation meaningful it is important to consider that the blister diameter depends on parameters such as target temperature, total dose, target microstructure (e.g. cold worked or annealed), and the crystallographic orientation of the surface of monocrystals, as we have discussed earlier. ${ }^{26}$ Furthermore, we have shown earlier 27,28 that the blister skin thickness correlates very well with the calculated projected range for ${ }^{4} \mathrm{He}^{+}$ion irradiation of vanadium for the energy range from $20 \mathrm{keV}$ to $1000 \mathrm{keV}$.

Both the polycrystalline and the monocrystalline vanadium targets were obtained from Materials Research Corporation (Marz Grade). Back-reflection Laue photographs of the monocrystalline vanadium targets showed the orientation of the surface normal of the target to be within $1^{\circ}$ parallel to the [100] direction. The foils received a fine metallographic polish. Subsequently, they were annealed at $1200^{\circ} \mathrm{C}$ for two hours in a vacuum of $\sim 3 \times 10^{-7}$ torr, and then eiectropolished. The irradiations were carried out with mass analyzed ${ }^{4} \mathrm{He}^{+}$ions either from a low-energy d.c. accelerator (for energies $<100 \mathrm{keV}$ ) or from a 2-MV Van de Graaff accelerator (for energies $\geq 100 \mathrm{keV}$ ), and the ior beam was incident parallel to the surface normal. During the

22 R. Behrisch, J. Bottiger, W. Eckstein, V. Littmark, J. Roth and B. M. U. Scherzer, App1. Phys. Lett. 27, 199 (1975).

$23 \mathrm{~J}$. Roth, Applications of Ion Beams to Ma"erials, eds. G. Carter, J. S. Colligon and W. A. Grant (The Institute of Physics, London 1976), p. 280.

24

M. Risch, J. Roth and B. M. U. Scherzer, to appear in Proc. of International Conference on Plasma-Wall Interactions, Julich, W. Germany, (October, 1976).

E. P. EerNisse and S. T. Picraux, J. Appl. Phys. 48, 9 (1977).

26 s. K. Das and M. Kaminsky, Adv. in Chemistry Series 158 (editor M. Kaminsky, American Chemical Society, Washington, D.C. 1976) 112.

27

M. Kaminsky, S. K. Das and G. Fenske, J. Nucl. Mat. 59, 86 (1976).

28

M. Kaminsky and S. K. Das, Scientific and Industrial Applications of Sma11 Accelerators, Fourth Conference - 1976, Nenton, Texas (pub1ished by The Institute for Electrical and Electronic Engineers, Inc.) p. 238. 
irradiation the ion flux was kept fow $\left(5 \times 10^{13}\right.$ to $1 \times 10^{1 / 4}$ ions $\mathrm{cm}^{-2} \mathrm{~s}^{-1}$ ) to minimias surlace heating, and the targets were held at room temperature. The total dose for cach irradiation was chosen so as to avoid blister cualescence for ${ }^{4} \mathrm{He}^{+}$ion energies greater than $40 \mathrm{keV}$ and to minimize sputtering of blister skin for energies at $20 \mathrm{kev}$. The irradiated surfaces were examined in a Cambridge Stereoscan $\$ 4-10$ scanning electron microscope. and ten or more inicrographs werv taken for each irradiation. The size distribution of blisters were meisured from the micrographs witl the aid of a zeiss particle-size analyzer. The blister skin thicknesses were measured from ruptured edges of blister skins and compared with the values we had published earlier. 28 A very close agreement between these sets of values was observed.

Figure 1-4(a) shows a typical histogram of the distribution of blister diameters observed for annealed polycrystilline vanadium after irradiation with 100-keV " $\mathrm{He}^{+}$to a dose of $0.5 \mathrm{c} / \mathrm{cm}^{2}$. Figure $\mathrm{I}-4$ (b) illustrates the dependence of the blister dianeter on grain orientation, the blister diameters, being larger for the grain shown on the left of the micrograph than for the onte on the right. In order to obtain statistically meaningful values for the most probable blister diameter, $D_{\text {mpl }}$, at least 10 such micrographs were cvaluated to obtiatn one histogram of the type shown in. Figurear-4(a). For asample, for $100-\mathrm{keV}^{4} \mathrm{He}^{+}$irradiation of annealed polycrystalline vanadium [Fis. [-4(a)] the observed minimum diameler was 2.1 m, the maximun diameter $8.1 \mathrm{~mm}$, the averaye diameter $3.9 \mathrm{~mm}$, the most probable diancter $2.9 \mathrm{jm}$, and the standard deviation $1.5 \mu \mathrm{m}$. Figures $\mathrm{I}-5(\mathrm{a})$ and (b) show a plot of blister diameters versus mean blister skin thickness for vanadfum irradiated by ${ }^{4} \mathrm{He}^{+}$ions of various energies and correlation between mean skin thickness and ${ }^{4} \mathrm{He}^{+}$ion energy, respectively. The filled and open circles are $D_{m p}$ values for annealed polycrystalline $V$ and monocrystalline $V(100)$ surfaces, respectively. The $D_{a v}$ aro also shown ( $x$ ) Eor annealed polycrystalline vanadium. The bars shown for a given t value indicate the smallest and the largest blister diameter observed for that thickness for both polycrystalline and monocrystalline vanadium. A power function it (by the method of least squares) of $D_{m p}$ with $t_{0}$ ives the relationship $\mathrm{D}_{\mathrm{mp}}=6.3 \mathrm{t}^{0.85}$ for polycrystalline $\mathrm{V}$, and $\mathrm{D}_{\mathrm{mp}}=7.4$ L0.94 for monocrystalline $V(100)$, where $D_{m p}$ and $t$ are given in units of micrometers. The coefricient of determination, $r$, for the above two $f$ its was 0.97 and 0.96 , respectively (note, $r^{?} \simeq 1$ indicates better fit than $r^{?} \simeq 0$. For discussion of fitting method used, see Ref. 29). If both polycrystalline and monocrystalline dita ire fitted together one obtains the relationship $\mathrm{D}_{\mathrm{mp}}=6.7$ t0.89 (with $\mathrm{r}^{2}=0.96$ ) which is shown as a solid line in Fig. I-5. Power curve fits for $D_{a v}$ and $D_{m i n}$ with $t$ give the relationships $D_{a v}=9.2$ $t^{1.02}$ (with $\mathrm{r}^{2}=0.96$ ) and $\mathrm{D}_{\min }=3.8$ t0.98 (with $\mathrm{r}^{2}=0.92$ ), respectively. In no case does one obtain the relationship $D \propto t^{1.5}$ as suggested by EerNisse and Picraux.25 According to the lateral stress model25 the pre-exponential factor in the $d, t$ relationship can be represented by $(\mathrm{KE})^{\frac{1}{2}}\left(2.5 \times 10^{-4}\right.$ $\left.\left(1-p^{2}\right) \sigma_{y}\right)^{-\frac{1}{2}}$. Here, $E$ is the Young's modulus (for $V: F=1.3 \times 10^{12}$ dynes $\left.\mathrm{cm}^{-2}\right), \mathrm{P}$ is Poisson's ratio $(\mathrm{V}: \mathrm{p}=0.35), \mathrm{o}_{\mathrm{y}}$ is the yield strength (V: $1.17 \times 10^{9}$ dynes $\mathrm{cm}^{-2}$ ), and $\mathrm{K}$ is a geometric factor which ranges from 1.4 to 4.9 for elastic edge conditions ranging from a simply supported edge to a clamped edge, respectively. The values listed in parenthesis are

29 S. K. Das, M. Kaminsky and G. Fenske, to be submitted to J. Appl. Phys. 

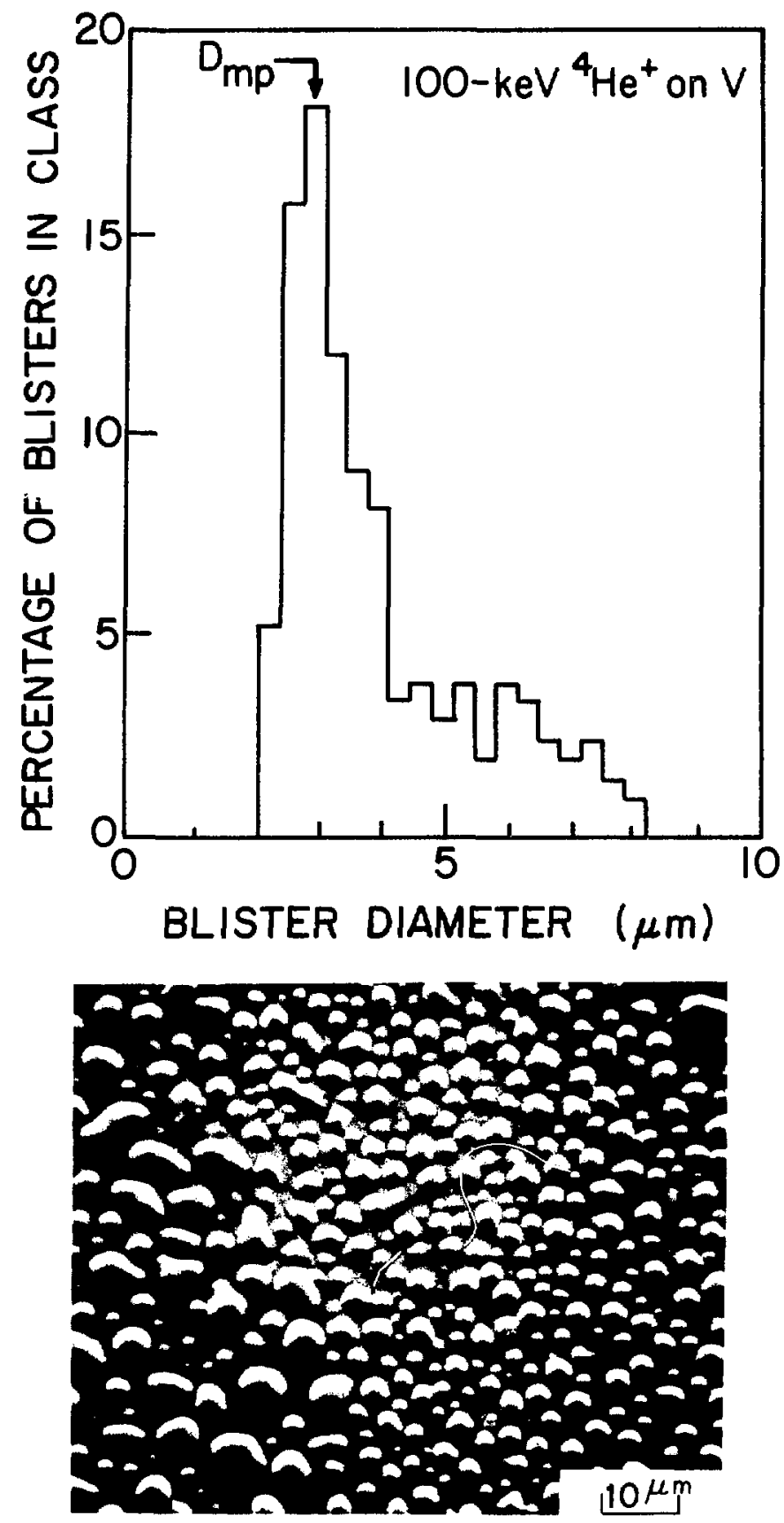

Figure I-4. (a) histogram of the size distribution of blisters in annealed polycrystalline vanadium irradiated at room temperature with $100-\mathrm{keV}{ }^{4} \mathrm{He}^{+}$to a total dose of $0.5 \mathrm{c} / \mathrm{cm}^{2}$. (b) A typical scanning electron micrograph which was used to construct the histogram in Figure $I-4(a)$. 

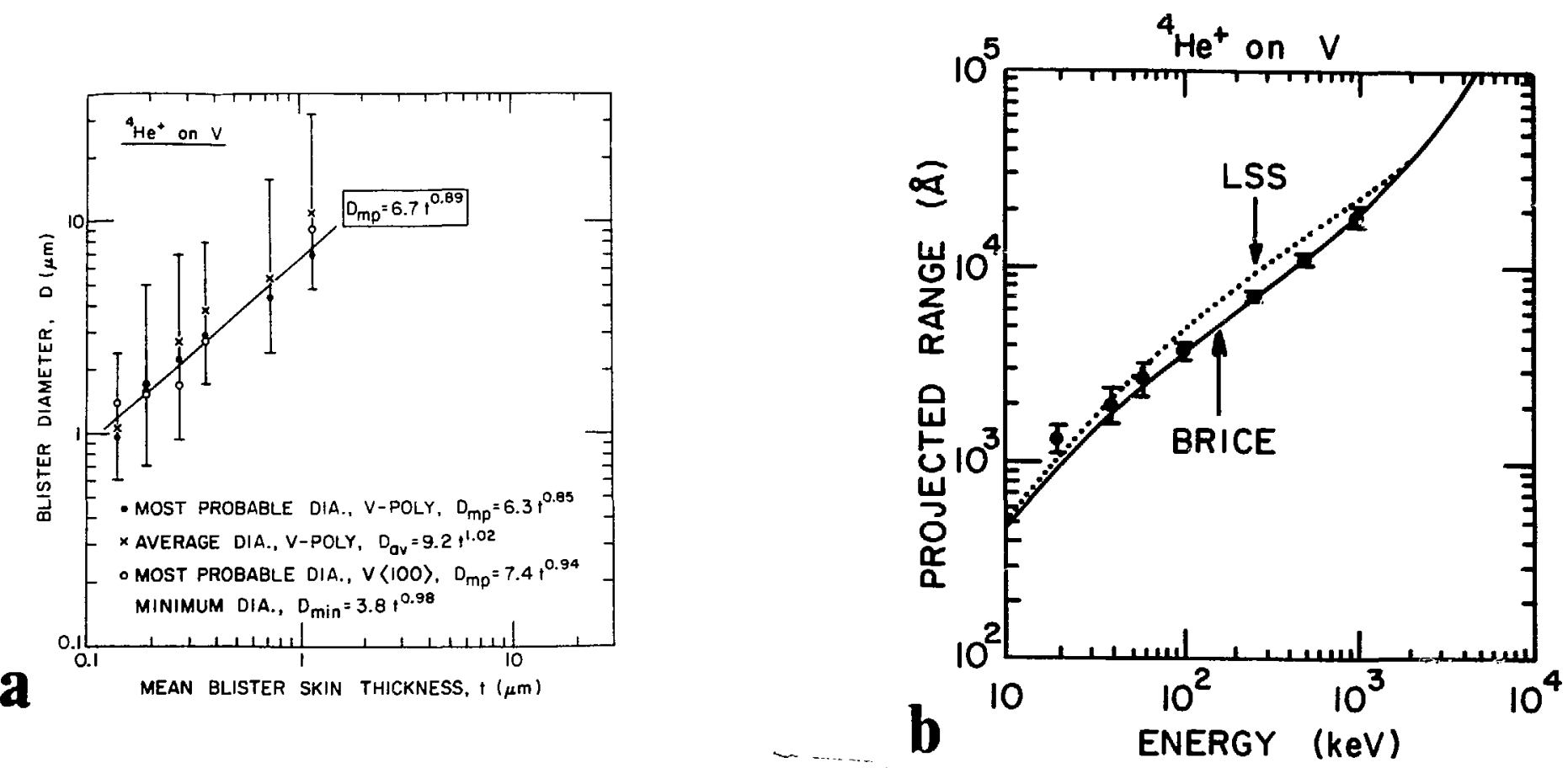

Figure I-5. (A) A double logarithmic plot of blister diameter against mean blister skin thickness, $t$, for annealed polycrystalline and monocrystalline vanadium surfaces. For annealed polycrystalline $V$ the $D_{m p}$ values ( $1 \mathrm{n} \mu \mathrm{m}$ ) and the standard deviation (In $\mu \mathrm{m}$ - 11sted in parenthesis) are: $1.0(0.3), 1.7(0.5), 2.2(1.0), 2.9(1.5), 4.4(2.0), 7.0(10.0)$. The corresponding values for $V(100)$ targets are: $1.4(0.3), 1.5(0.8), 1.7(1.0), 2.8(2.0), 9.2(4.3)$.

(B) Calculated projected ranges of ${ }^{4} \mathrm{He}^{+}$lons in vanadium as a function of projectlle energy. The dotted curve was calculated according to Lindhard, et al, and the solfd curve according to Brice. Measured skin thickness values are indicated by . 
characteristic for annealed vanadium 30,31 and may differ from those for irradiated vanadium.

For vanadium the experimentally determined relationship $D_{m p}=6.3 t^{0.85}$ does not agree with those calculated according to the lateral stress mode1 25 for the two extreme values of the $K$ factor $(1.4$ and 4.9$), D_{m p}=27.4 t^{1.5}$ and $D_{m p}=51.3 t^{1.5}$, respectively. We also find significant disagreement between predicted and experimentally determined $d, t$ relationships for metals such as $\mathrm{Be}, \mathrm{Ni}$ and $\mathrm{Nb}$, as discussed elsewhere. 29,32

Finally, we would like to mention our observation of nearly spherical blisters on $V$ surfaces irradiated with ${ }^{4} \mathrm{He}{ }^{+}$ions under certain conditions. Figure I-6 shows an example for annealed polycrystalline $V$ irradiated at room temperature with $60-\mathrm{keV}{ }^{4} \mathrm{He}^{+}$ions to a dose of $0.5 \mathrm{c} / \mathrm{cm}^{2}$. Observation of such blisters at various tilt angles shows that the diameter of the blister base is smailer than the diameter of the blister sphere. The arrows in Fig. I-6 point to cracks in the blister skin. The measured skin thickness is $0.22 \pm 0.06 \mu \mathrm{m}$, a value which agrees well with the one we had published earlier. 28 In our opinion such spherical blisters cannot be caused by elastic buckling of the implanted layer as invoked in the stress model but result from surface deformation by internal gas pressure. For discussions of additional supportive evidence for blister formation in metals by internal gas pressure the reader is referred to Refs. $12-18$, and 29 and 32 .

30 Metals Handbook. Vol. 1 (American Soc. for Metals, Metals Park, Ohio) 1961.

31 C. R. Tipton, Jr., editor, Reactor Handbook. Vol. 1 (Interscience Publishers, New York 1960).

32 S. K. Das, M. Kaminsky, and G. Fenske, submitted to J. Nuc1. Mat.

4. Sputtering Yieids for Deuterium on Gold

D. M. Gruen and Ch. Steinbruchel, Chemistry Division

We have carried out measurements of sputtering yields for $\mathrm{D}^{+}$and $\mathrm{Ar}^{+}$ on $\mathrm{Au}$ in the $1 \mathrm{keV}$ energy range using matrix isolation spectroscopy.

The purpose of this work was to provide reliable data for deuterium sputtering yields, particularly at low energies where very little information is available in the literature. Such data will be useful for characterizing first-wall fusion reactor materials and for testing theories of sputtering. In addition, our results establish that matrix isolation spectroscopy is a viable experimental technique for measuring low sputtering yields.

Our apparatus consists of a stainless-steel vacuum chamber which is evacuated by a separate pumping station. The vacuum chamber is equipped with a target holder, with a sputter ion gun, and with a closed-cycle helium refrigerator. The ion gun is connected to the vacuum chamber via an orifice. The target is mounted at an angle of 45 degrees with respect to the ion gun and to the collection plate attached to the refrigerator. Material is sputtered from the target into an argon matrix which is formed on the 

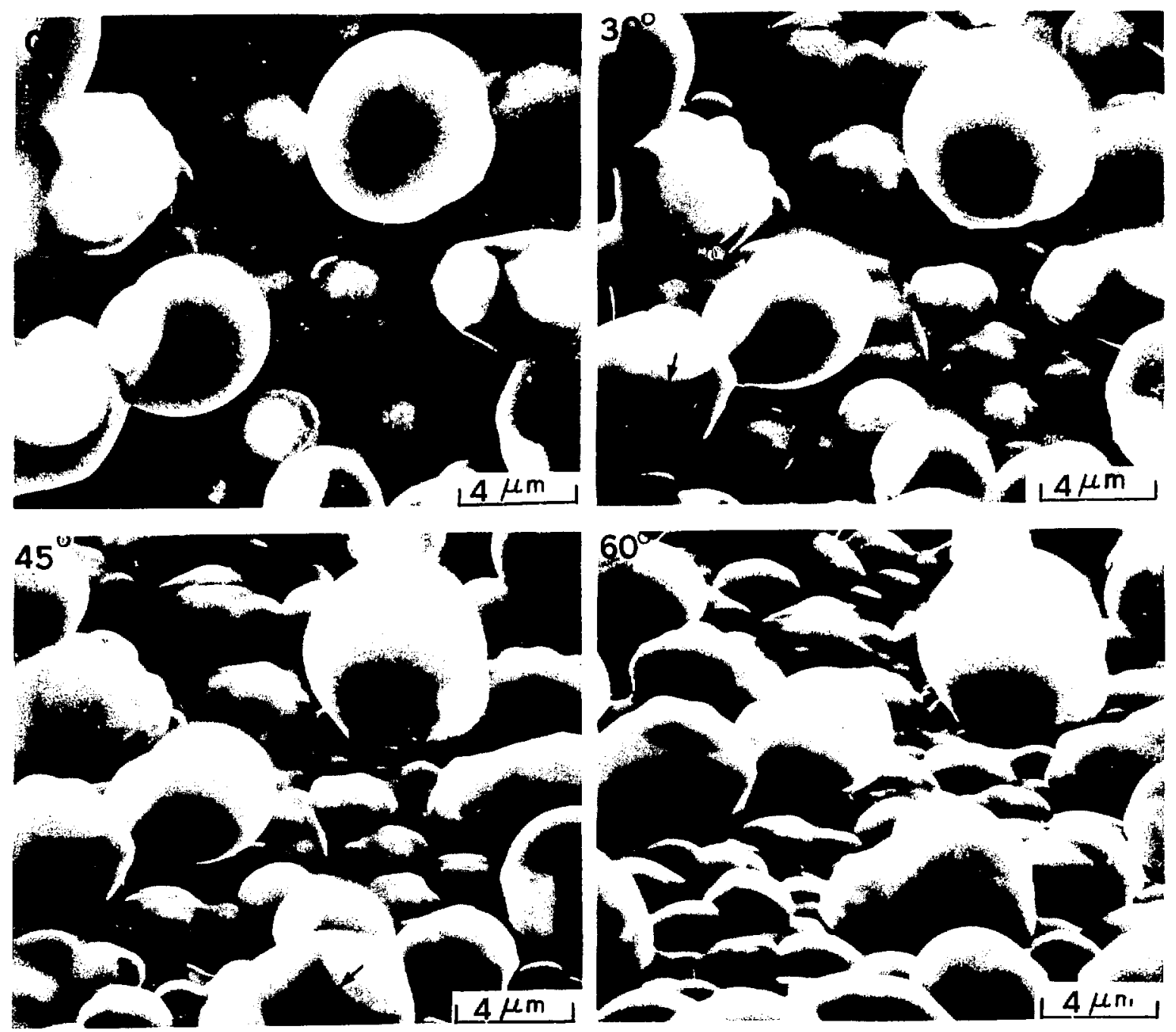

Figure I-6. Scanning electron micrograph of annealed polycrystalline vanadium irradiated at room temperature with $60-\mathrm{keV}{ }^{4} \mathrm{He}^{+}$ to a dose of $0.5 \mathrm{c} / \mathrm{cm}^{2}$, showing nearly spherical blisters. The numbers in the top left-hand corner refer to the various tilt angles at which the micrographs were taken. 
collection plate by gas flowing onto this plate from two nearby jets. The amount of metai collected in the matrix is determined from optical absorption spectra recorded in the UV-visible region. Pressures are monitored by a cold-cathode gauge in the main chamber and by an ion gauge in the ion gun.

After the initial pump-down and with the helium refrigerator cold, the ion gun is outgassed until the pressure in the ion gun is $1 \cdot 10^{-6}$ torr or less, at which point the pressure in the main chamber is $\sim 3 \cdot 10^{-8}$ torr. The target is then sputter-cleaned for 30 minutes, with the pressure in the ion gun at $\sim 5 \cdot 10^{-5}$ torr. At this time argon matrix gas is introduced (typical flow rate $\sim 0.2 \mathrm{~cm}^{3} / \mathrm{min}$ ), and sputtered atoms are collected in the matrix. During matrix deposition the pressure in the main chamber is $21 \cdot 10^{-7}$ for sputtering with $\mathrm{Ar}^{+}$and $\omega 5 \cdot 10^{-6}$ for sputtering with $\mathrm{D}_{2}^{+}$. The ion current to the target is measured with the target biased positively by 90 volts so as to suppress secondary electrons. (Ion current densities are typically 1-10 $\left.\mathrm{\mu A} / \mathrm{cm}^{2}\right)$. Under the conditions described the matrix-to-metal atom ratio is $\sim 10^{5}$ to $10^{4}$ so that the metal in the matrix is virtually exclusively in the form $f$ single atoms. A sufficient amount of metal can be collected in 10-60 minutes. Matrix absorption spectra are recorded on a Cary $17 \mathrm{H}$ spectrometer. Amounts of metal sputtered are taken to be proportional to the areas under the absorption peaks characteristic of Au atoms. (The spectra obtained in this work are identical to spectra reported previously 33 for $\mathrm{Au}$ in Ar.) Amounts of metal are reproducible typically to within $\sim 5 \%$ for a given ion beam exposure.

Our results are presented in Table $I-1$. The numbers for the sputtering yields $S$ are based on the assumption that $S=1.0$ for Ar on Au at $1 \mathrm{keV} .34,35$ Furthermore, as usual, sputtering by $\mathrm{D}_{2}^{+}$is taken to be equivalent to sputtering by $\mathrm{D}^{+}$at half the energy and twice the flux. There is considerable disagreement in the literature on the values of $\mathrm{S}$ for $\mathrm{Ar}^{+}$on $\mathrm{Au}$, with values at $1 \mathrm{keV}$ ranging from 1 to $5.34-38$ We favor the lowest value because it compares more favorably with theoretical estimates 39 and because it leads to more reasonable values of $S$ for $D^{+}$sputtering on Au. 40

33 D. M. Gruen, S. L. Gaudioso, R. L. McBeth, and J. L. Lerner, J. Chem. Phys. $\underline{60}, 89$ (1974).

34 o. Almén and G. Bruce, Nucl. Instrum. Methods 11, 257 (1961).

35 H. Patterson and D. H. Tomlin, Proc. Roy. Soc. London A265 474 (1962).

36 C. H. Weijsenfeld, Philips Res. Rept. Suppl. No. 2 (1967).

37 H. Oechsner, Z. Physik 261, 37 (1973).

38 N. Laegreid and G. K. Wehner, J. App1. Phys. $\underline{32}, 365$ (1961).

39 W. M. Stacey, Jr., et al., "Impurity Control in Tokamak Reactors," Argonne National Laboratory, ANL/FPP/TM-91 (August, 1977).

40 C. F. Finfge1d, U.S. AEC Report ORO-3557-15 (1975). 
Table I-1, Sputtering Yields (atoms/ion)

\begin{tabular}{|c|c|c|c|c|c|}
\hline \multirow[b]{2}{*}{$\begin{array}{l}\text { Energy } \\
(\mathrm{keV})\end{array}$} & \multicolumn{2}{|c|}{$\mathrm{Ar}^{+}$} & \multicolumn{2}{|c|}{$\mathrm{D}^{+}$} & \multirow[b]{2}{*}{$\begin{array}{l}\text { Stacey } \\
\text { (theory) }\end{array}$} \\
\hline & $\begin{array}{l}\text { Present } \\
\text { data }\end{array}$ & $\begin{array}{l}\text { Stacey, et al. } \\
\text { (theory) }\end{array}$ & $\begin{array}{l}\text { Present } \\
\text { data }\end{array}$ & Finfgeld 40 & \\
\hline 0.25 & & & 0.013 & & \\
\hline 0.5 & 0.47 & 0.22 & 0.045 & 0.02 & 0.01 \\
\hline 0.75 & & & 0.058 & & \\
\hline 1.0 & 1.0 & 0.43 & 0.080 & 0.03 & 0.015 \\
\hline 1.5 & 1.3 & & & & \\
\hline 2.0 & 1.6 & 0.85 & & & \\
\hline
\end{tabular}

Two conclusions can be drawn from the figures in Table I-1. Firstly, our values of $\mathrm{S}$ for $\mathrm{D}^{+}$on $\mathrm{Au}$ are somewhat higher than, but comparable to, those of Finfgeld. 40 Second $1 y$, the model by Stacey, et al., 39 which was derived from Sigmund's theory 41 to account for sputtering by light ions, tends to underestimate sputtering yields on gold. In addition, our results show matrix isolation spectroscopy to be a sensitive technique for determining sputtering yields. On the basis of the experimental conditions employed in this work we estimate that we should be able to measure sputtering yields as low as $10^{-3}$. The reproducibility of our data should enable us to measure ion fractions as well. We are in the process of modifying our apparatus in order to perform such measurements.

41 P. Sigmund, Phys. Rev. 184, 383 (1969).

\section{Fast-neutron Sputtering of Gold}

M. A. Kirk and R. A. Conner, Materials Science Division

The sputtering or ejection of surface atoms due to high-energy particle irradiation has been the subject of considerable experimental investigation for approximately the past 20 years. The reason fur much of the interest in sputtering has been the recognized close connection between the physics of both sputtering and radiation-damage phenomena in the bulk. The emphasis of the majority of this work has been on the bombardment of metal surface with energetic ions. Little previous work has been published on the sputtering of solids by fast-neutron bombardment because of the great difficulty encountered in performing this type of experiment in a radiation environment under well-controlled conditions.

Many of these difficulties have been overcome, as can be ascertained from the experiments briefly reported here. These results represent the most accurate and reproducible determination of sputtering yield and the

Work Funded by Basic Energy Sciences. 
first detailed picture of the spatial distribution of sputtered atoms due to fast-neutron irradiation. A far more detailed comparison with other experimental results and sputtering theory also has been accomplished as a result of an extensive determination of neutron flux and energy spectrum for the irradiation facility and calculations of damage parameters based on this neutron-energy spectrum.

Single crystals of gold were activated prior to sputtering in a core position in the ANL $\mathrm{CP}-5$ reactor. Following activation, the crystals were annealed and then remotely transferred to a sputtering capsule. This capsule was evacuated, sealed, and transferred to the cryogenic fast-neutron irradiation facility in $\mathrm{CP}-5$ for the sputtering irradiations. High-purity aluminum foils were used to collect the sputtered gold atoms. The gold samples were centrally located in the cylindrical sputtering capsules, with collector foils adjacent to the cylinder wall. Following sputtering, the collector foils were removed and investigated by autoradiographic and $\gamma-$ counting techniques to reveal the spatial distribution and determine the total yield of sputtered gold atoms, respectively.

A calibrated microphotodensitometer trace of a representative autoradiograph is shown in Figure $\mathrm{I}-7$. The data closely correspond to a theoretically random distribution of sputtered atoms. The asymmetry was caused by a crystal holder shield and was reproduced in the theoretical distribution. This constitutes rather strong evidence for a sticking coefficient close to unity.

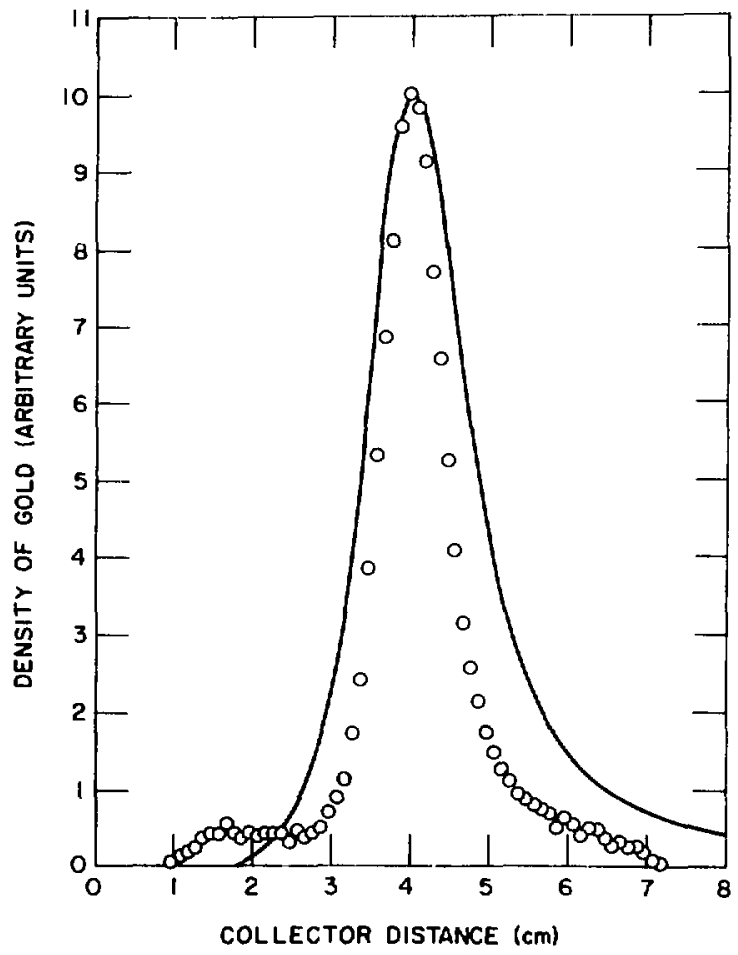

Figure I-7. Microphotodensitometer trace of autoradiograph (in direction parallel to cylinder axis). Solid curve corresponds to directionally random sputtering. 
Gamma counting of the $411.8-\mathrm{keV}$ peak for ${ }^{198} \mathrm{Au}$ was performed on $\mathrm{Ge}(\mathrm{L} 1$ ) detectors. Tolal sputtered gold concentrations were corrected for goldimpurity backgrounds in the collector foils and calibrated by the active fractions found for the gold single crystals. The extent of contamination by pieces of radioactive gold was usually found to be quite 1imited (10\% of total sputtering yield) and could be subtracted by the use of autoradiographs and selected area $\gamma$-counting. A blank run produced similar contamination but no central gold stripe due to sputtering. It was concluded that this small amount of contamination was due to handling and not sputtering.

In conjunction with these sputtering experiments, a neutron flux and energy spectrum was carefully determined for the cryogenic fast-neutron irradiation facility in the $\mathrm{CP}-5$ reactor. The absolute differential neutron-energy spectrum was determined by a 20-foil activation technique using the most recent version of the SAND-II computer code, 42 which iteratively determines the best neutron spectrum fit to the foil activities. Total cross sections and recoil and damage energy distributions were calculated for gold with the differential neutron energy spectrum and the DIScS computer code. 43 This information was then used in the analysis of the gold-sputtering data reported here.

In three sputtering experiments, an average value of the sputtering ratio of $8.0 \times 10^{-6}$ sputtered gold atom per incident neutron ( $\mathrm{E}>0.1 \mathrm{MeV}$ ) was determined with an absolute error (including absolute flux error) of 1 38\%. This can be compared with recent sputtering experiments on gold with $14-\mathrm{MeV}$ neutrons by scaling with calculated damage energy. The result of this scaling is an expected sputtering ratio of $\sim 4 \times 10^{-5}$ for neutrons produced by fusion. This roughly agrees with the lower limit of the range of values found for these $14-\mathrm{MeV}$ neutron experiments 44 and strengthens the conclusion that neutron sputtering should not be a significant problem for the first wall of the containment vessel in a fusion reactor.

To explain these experimental results, three mechanisms of sputtering are considered. Sputtering along crystallographic directions by focused collision sequences is eliminated as a significant mechanism when both the autoradiographic and total yield data are considered. It was concluded that sputtering was dominated by high-energy recoil cascades which intersect the crystal surface. However, a calculation of sputtering by the linear cascade theory of Sigmund4l yields about one half the sputtering ratio found experimentally. This difference is greater than the sum of the errors of measured and calculated sputtering ratios and is believed to be significant. A correction to this theory could include a nonlinear or thermal-spike contribution to the sputtering. The autoradiographic evidence indicates a sufficiently high-energy density within the cascade that could produce thermal sputtering, since the crystal structure is apparently lost during the lifetime of the cascade. Thus, the controlling factor is the lifetime of the cascade or resultant thermal spike.

42 W. N. McElroy, S. Berg, T. B. Crockett, and R. J. Tuttle, Nucl. Sci. Eng. 36, 15 (1969).

43

G. R. Odette and L. R. Doiron, Nuc1. Tech. 29, 346 (1976).

44 o. K. Harling, M. T. Thomas, R. L. Brodzinski, and L. A. Rancitelli, J. Nucl. Mater. 63, 422 (1976). 
Another theoretical calculation due to Sigmund ${ }^{45}$ is displayed in Figure I-8. Calculations of cascade and thermal-spike lifetimes are plotted versus primary recoil energy along with the damage energy distribution for gold in our neutron-energy spectrum. This comparison of damage energy distribution and calculated thermal-splke lifetime indicates only a small effect on the thermal-spike contribution to sputtering. A more recent theoretical calculation of thermal-spike effects by Kelly 46 appears to yield a longer spike lifetime and would be in better agreement with the experimental results reported here.

A thermal-spike mechanism has long been proposed to explain many radiation-damage effects associated with the high-energy collision cascade. However, direct experimental evidence for this concept is minimal. Sputtering experiments provide a means to investigate the collision cascade during its time of development $\left(10^{-13} \mathrm{~s}\right)$ and include any influence from the development of a thermal spike over $10^{-12}$ to $10^{-11} \mathrm{~s}$ ). We are pursuing this aspect further with additional sputtering experiments on a lighter mass material (NiCo), since this is predominantly a mass-dependent effect.

\footnotetext{
45 P. Sigmund, Appl. Phys. Lett. 25, 169 (1974). 46

R. Kelly, Rad. Effects 32, 91 (1977).
}

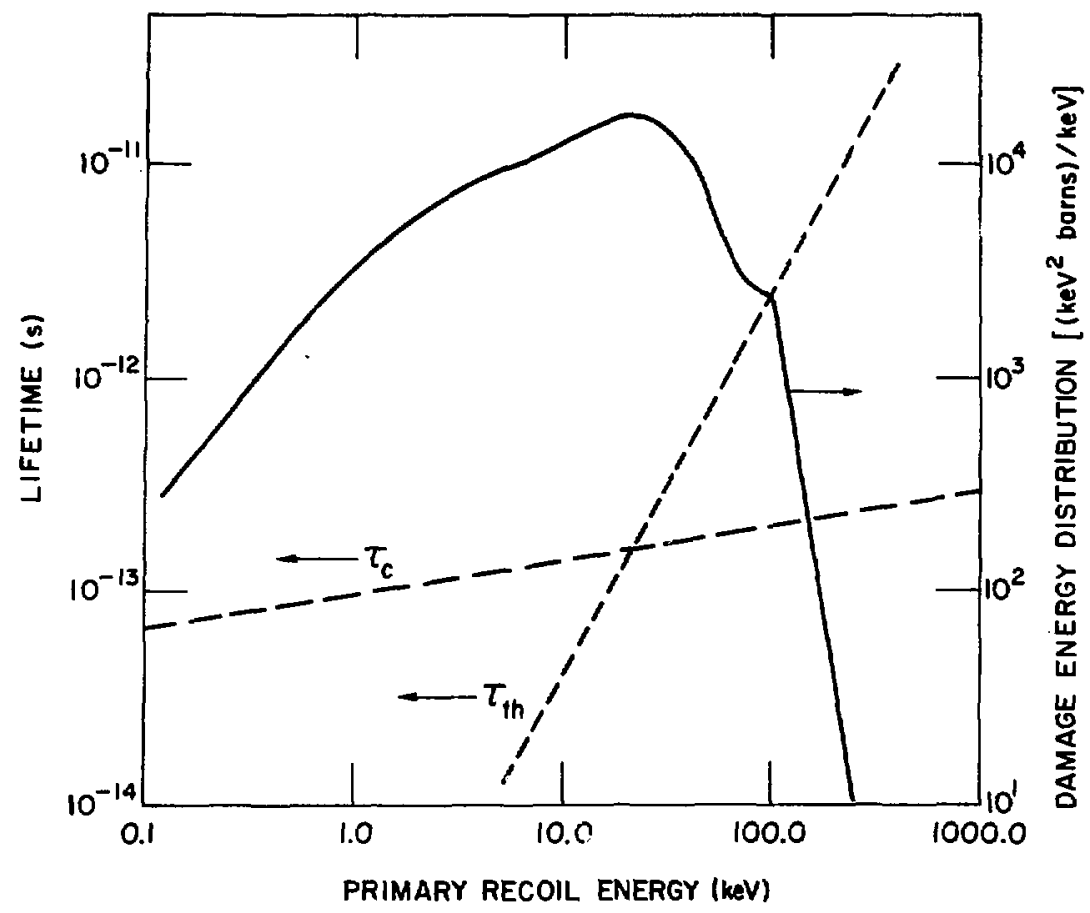

Figure I-8. Cascade lifetime $\left(\tau_{c}\right)$ and thermal-spike lifetime ( $\tau_{t h}$ ) vs primary recoil energy, as calculated by Sigmund. Also plotted is damage energy distribution for our neutron-energy spectrum vs primary recoil energy. 
B. Dosimetry and Damage Analysis.

L. R. Greenwood and R. R. Heinrich, Chemical Engineering Division

1. Experiments at ${ }^{9} \mathrm{Be}(\mathrm{d}, \mathrm{n})$ Accelerator Neutron Sources

Dosimetry was provided for D. Styris (PNL) at the University of California Cyclotron at Davis during February, 1978. Neutrons were produced by stropping a $40 \mathrm{MeV}$ deuteron beam in a thick beryllium target. Tensile specimens were irradiated at about $4 \mathrm{~mm}$ and $40 \mathrm{~mm}$ from the source. Dosimetry packages were placed at each position. Each package was $2^{\prime \prime} \times 0.25$ " and contained $\mathrm{Al}, \mathrm{Fe}, \mathrm{Ni}, \mathrm{Co}, \mathrm{Nb}, \mathrm{In}$, and $\mathrm{Au}$. Nickel foils were placed at the front and rear of each package to measure attenuation and geometric effects. The foils were cut into ten subsections and are now being counted at ANL and LLL. An error analysis has been completed for our previous work at $E_{\mathrm{d}}=30 \mathrm{MeV}$ reported last quarter. This analysis is instructive since it repressents the state-of-the-art for high energy dosimetry. Figure I-9 shows the unfolded spectrum at $4 \mathrm{~mm}$ from the source. The dashed lines represent one standard deviation error limits based on a Monte Carlo analysis. The code SANDANL determines the error in the flux due to errors in the activation cross-sections, the measured foil activities, and the starting input spectrum. The errors are derived from experience gained with integral cross-section tests and input spectra are taken from time-of-flight measurements as well as previous unfolding experiments.

As can be seen in Fig. I-9 the error in the differential flux is typically $10-20 \%$ except at low energies ( $<1 \mathrm{MeV}$ ) and very high energies ( $>25 \mathrm{MeV}$ ). Unfortunately, there are very few reactions which have any sensitivity in these energy regions. However, only $8 \%$ of the total flux is below $1 \mathrm{MeV}$ and only $5 \%$ is above $25 \mathrm{MeV}$. Hence, these regions do not contribute significantly to materials damage effects.

Covariance effects are also very important and must be calculated in order to assess errors in integral parameters. The rror in the total flux is only $\pm 12 \%$ and above $4 \mathrm{MeV}$ the error is only $\pm 5 \%$. These error limits are quite accurate in a relative sense; however, absolute errors are somewhat uncertain since cross-section errors are only estimated.

Integral cross-section tests performed at the ANL Tandem Van de Graaff accelerator using the $\mathrm{Be}(\mathrm{d}, \mathrm{n})$ reaction at $\mathrm{E}_{\mathrm{d}}=14-16 \mathrm{MeV}$ have been accepted by Nuclear Technology for publication. Preprints are available from L. Greenwood. Work is nearly complete on similar integral tests at the Oak Ridge Cyclotron (ORIC) at $\mathrm{E}_{\mathrm{d}}=40 \mathrm{MeV}$ and will be reported next quarter.

\section{Review of the Fusion Materials Irradiation Test Facility (FMIT) Dosimetry Program}

Plans are now being formulated for a proposed materials irradiation facility to be built at HEDL by 1983. This facility will consist of a linac accelerator to produce up to 0.1 amps of $40 \mathrm{MeV}$ deuterons. The beam will then be stopped in a flowing, liquid lithium target producing neutron fluxes of $10^{15} \mathrm{n} / \mathrm{cm}^{2}-\mathrm{s}$ in the experimental volume near the source. 


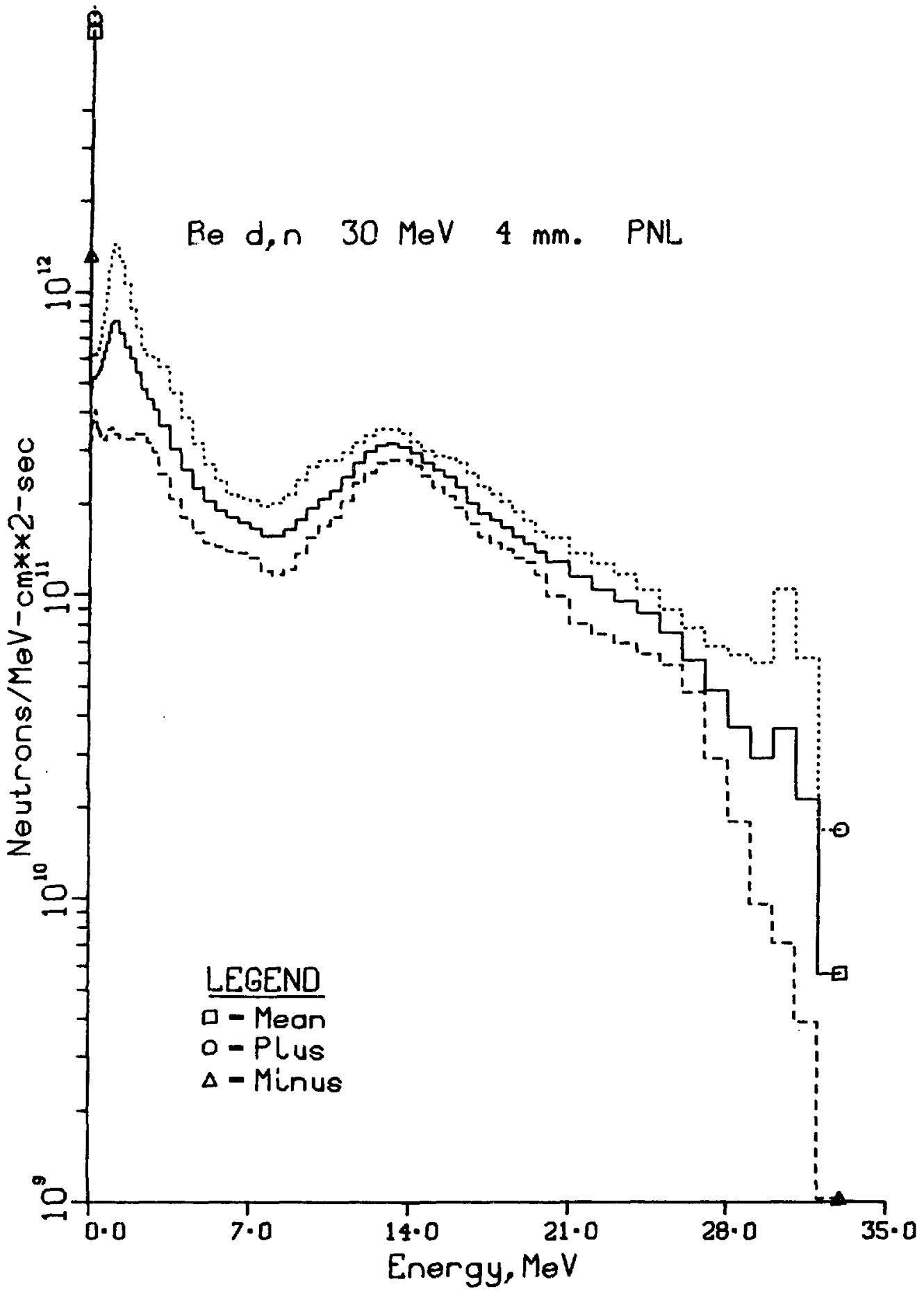

Figure I-9. Error analysis of the unfolded neutron spectrum for $E_{d}=30 \mathrm{MeV}$ at $4 \mathrm{~mm}$ from the source. The dashed and dotted lines represent one standard deviation. 
Plans have been drafted by the FMIT Project for conducting dosimetry at this facility. The Subtask Group on Environmental Characterization (L. R. Greenwood, Chairman) of the Damage and Fundamental Studies Task Group of MFE was asked to review the proposed program. A meeting was held at ANL on March 9-10, 1978, including Subtask Group members and outside consultants. A formal report was then drafted and has been submitted to DOE. Copies of the report are available upon request to L. R. Greenwood (ANL).

\section{Dosimetry Standardization}

The DAFS Task Group Program Plan includes the standardization of dosimetry procedures in order to reduce uncertainties in damage analysis and correlation studies. Reactor dosimetry has been largely standardized thanks to the Interlaboratory Reaction Rate (ILRR) Program. However, no formal program exists at present for ex-reactor irradiations.

Recent1y, committee E-10 of the ASTM has formed a Task Group B on "Procedures for Performing Ex-Reactor Neutron Irradiations," L. Greenwood, Chairman. A draft of the recommended practice has been written and is available on request. The plan is to complete work on these recommendations in time for the upcomming ASTM meeting in Richland, Washington in July, 1978 .

\section{Fission Reactor Dosimetry}

Spectral analysis has been provided for the Livermore Pool-Type Reactor (LPTR) at the request of $J$. Kinney (LLL). The irradiation and counting of the dosimeters was done at Livermore. Activation results were then sent to ANL for analysis. Data were obtained for 11 reactions, including cadmium covers on $\mathrm{Co}, \mathrm{Au}, \mathrm{Cu}$, and $\mathrm{Sc}$. The spectrum is about $40 \%$ thermal so that self-shielding effects are very large for the $(n, \gamma)$ reactions in the resonance region.

The results for positions $\mathrm{E} 7$ and $\mathrm{C} 4$ in LPTR are given in Table $\mathrm{I}-2$ and are shown in Figures $\mathrm{I}-10$ and I-11. A complete error analysis was performed, as shown in the data. Errors are large in the intermediate region between $10^{-2}$ and $1.5 \mathrm{MeV}$ due to poor foil coverage. Thermal and fast fluxes, however, are quite well-established. The thermal values agree reasonably well with calculations done at Livermore; however, the fast flux values are somewhat higher. The reasons for the differences are now being explored.

Table I-2. Integral Fluxes for LPTR

(Flux $\times 10^{13}$ neutrons $/ \mathrm{cm}^{2}-\mathrm{s}$ )

\begin{tabular}{lll}
\hline $\begin{array}{l}\text { Energy } \\
(\mathrm{MeV})\end{array}$ & $\begin{array}{c}\text { E7 } \\
\text { Flux } \pm \%\end{array}$ & F1ux $\pm \%$ \\
\hline Total & $5.92 \pm 10$ & $24.7 \pm 36$ \\
$>5.5 \times 10^{-7} \star$ & $2.72 \pm 5$ & $8.68 \pm 5$ \\
$>0.11$ & $1.90 \pm 26$ & $11.1 \pm 64$ \\
$>1.5$ & $0.33 \pm 24$ & $2.06 \pm 16$ \\
$>2.5$ & $0.13 \pm 7$ & $0.91 \pm 7$ \\
$>4.1$ & $0.034 \pm 9$ & $0.24 \pm 6$ \\
\hline * LLL reports thermal fluxes of $1.9 \times 10^{13}$ for $\mathrm{E7}$ and $7.1 \times 10^{13}$ for C4.
\end{tabular}




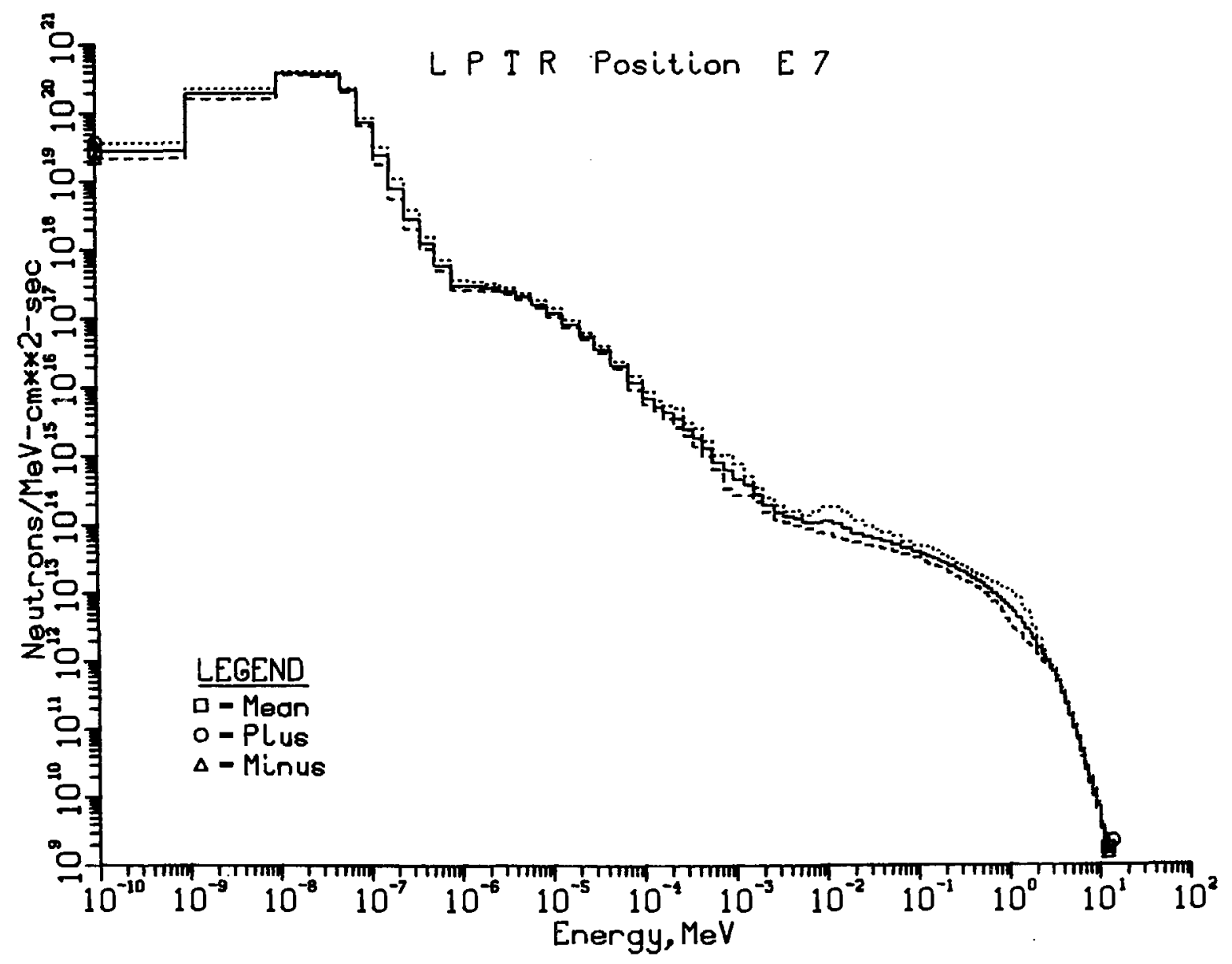

Figure I-10. Unfolded spectrum for LPTR - E7 with error analysis. 


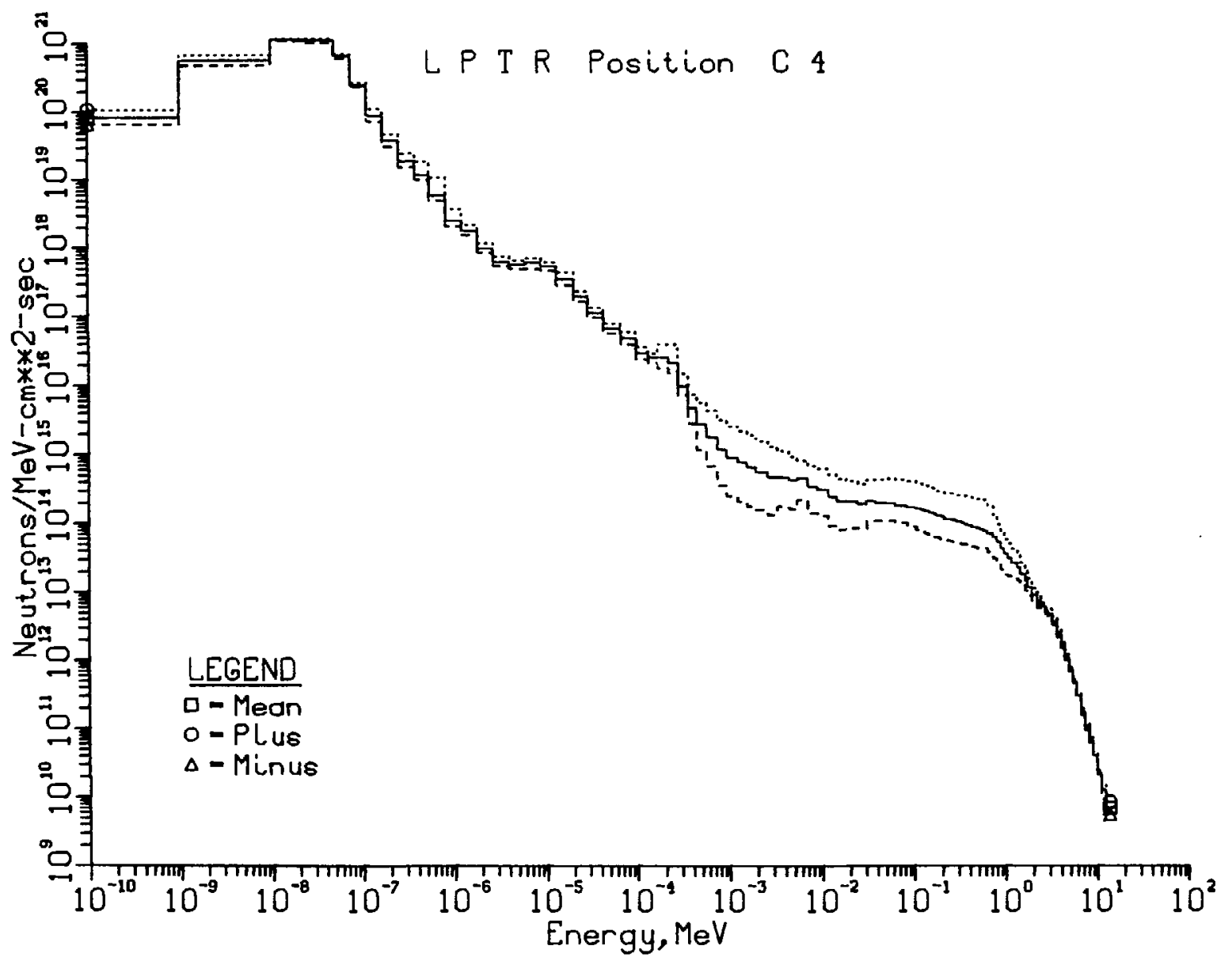

Figure I-11. Unfolded spectrum for LPTR - C4 with error analysis. 


\section{Alloy Development}

\section{Hydrogen Permeation and Materials Behavior in Alloys of Interest to the Fusion Power Program}

Recent emphasis in this program has been directed towards (1) studies of hydrogen permeation in representative austenitic and nickel-base alloys and (2) construction of a small ( 0.5-1iter capacity) stainless-steel-clad vanadium alloy lithium loop. Progress in these two areas during the second quarter of FY-1978 is summarized below.

\section{a. Hydrogen Permeation Studies \\ E. H. Van Deventer and V. A. Maroni, Chemical Engineering Division}

During this reporting period, we completed the permeation study of $316-S S$ and initiated permeation measurements on Incone1-718. The hydrogen permeability of 316 -SS has now been thoroughly studied over the temperature range from 420 to $1020 \mathrm{~K}$ using hydrogen driving pressures that ranged from $10^{-3}$ to $10^{4} \mathrm{~Pa}\left(10^{-5}\right.$ to $10^{2}$ torr). The least-squares refined results of 28 separate measurements may be represented by the equation

$$
\phi_{316-S S}=0.182 \exp (-15,175 / R T)
$$

where $\Phi$ is in units of $\mathrm{cm}^{3}(\mathrm{STP}) / \mathrm{m} \cdot \mathrm{s} \cdot \mathrm{kPa}^{\frac{1}{2}}, \mathrm{R}$ is equal to 1.987 , and $\mathrm{T}$ is in $K$. The parameters in equation (1) are only slightly different from preliminary values reported in the preceding progress report. 47 (The previously given equation was based on both an estimated membrane area and a smaller data set.)

In order to extend the investigations into the $10^{-3}$ to $10^{-1} \mathrm{~Pa}$ range, it was necessary to make pressure measurements with an ion gauge (instead of the capacitance manometer normally used above $10^{-1} \mathrm{~Pa}$ ) and to operate in the dynamic cleaning mode, 47 wherein a throttled ion pump is used in combination with a uranium hydride bed to provide continuous impurity removal at constant hydrogen pressure. With this approach, we were able to maintain the purity of the low pressure hydrogen in the upstream compartment at $>90 \%$ to temperatures of $1020 \mathrm{~K}$. Although the uncertainty in the corrected ion gauge readings is greater than the uncertainty normally incurred with capacitance manometer measurements, the hydrogen pressures recorded with the ion gauge were considered to be sufficiently accurate for deducing pressure dependence effects in the $10^{-3}$ to $10^{-1} \mathrm{~Pa}$ range. However, the data collected with the ion gauge were not used in the determination of equation (1).

The combined results of all pressure dependence tests done on the 316-SS sample are shown in Figure I-12. A near-to-half-power dependence is observed at each of the indicated temperatures and the results appear to be unaffected by the presence of a $1 \mathrm{mCi}$ gamma-source lodged in the upstream compartment. 47 It should be pointed out, however, that the ionizing

C. C. Baker, et al., "Fusion Power Program Quarterly Progress Report: October-December, 1977", Argonne National Laboratory Report ANL/FPP-77-7 (1978). 


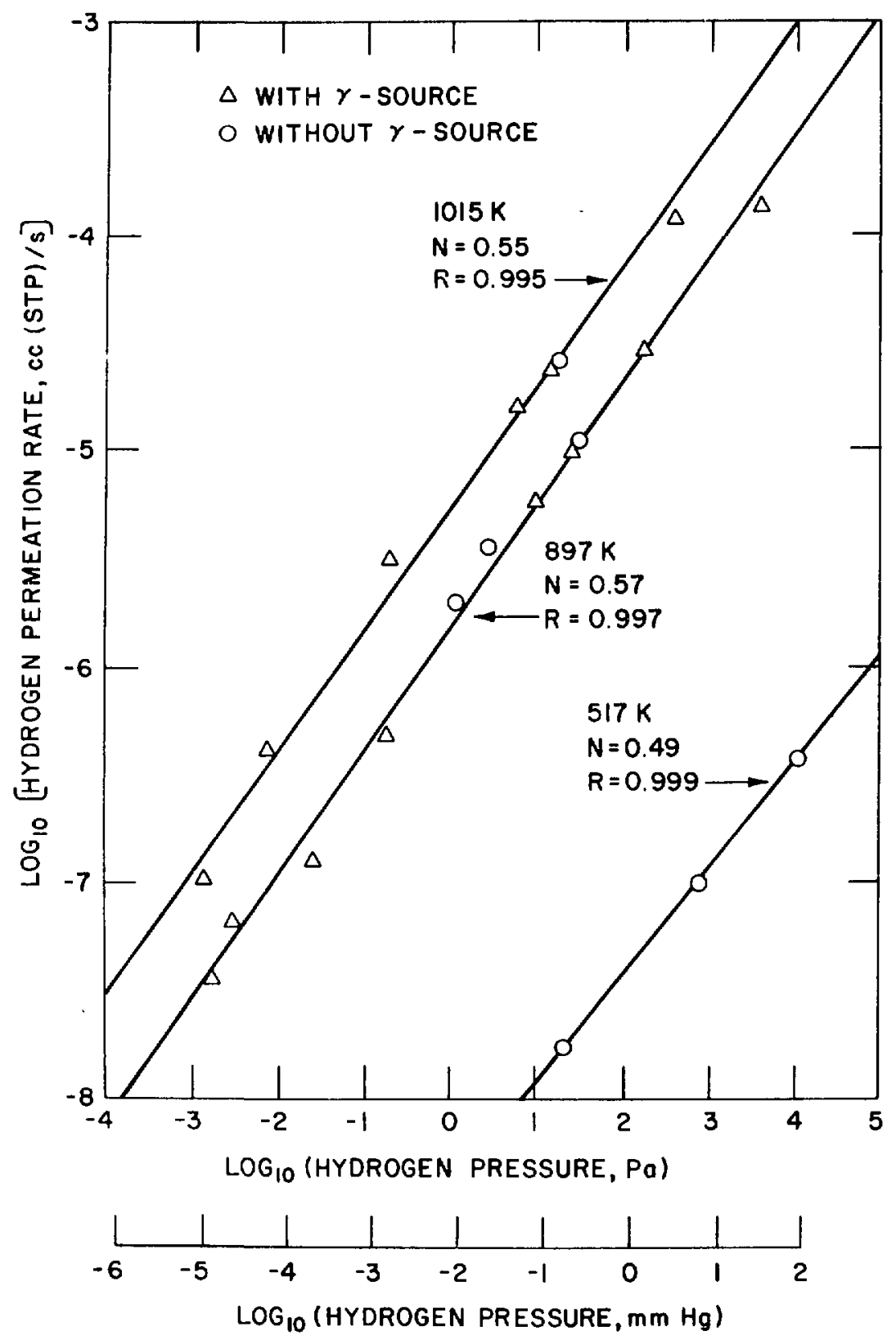

Figure I-12. Hydrogen permeation rate versus hydrogen pressure for 316-sS at 517,897 , and $1015 \mathrm{~K}$. 
potential of this source $\left(\sim 10^{-14} / \mathrm{s} \text { at } 1 \mathrm{~cm}\right)^{48}$ is many orders of magnitude lower than the estimated ionizing potential in the radiation field near a fusion reactor first wall ( $10^{-4} / \mathrm{s}$ at $\left.1 \mathrm{~cm}\right) .48$

Permeation measurements are presently underway on a sample of Inconel718. Results obtained to date are in very good agreement with a recently published study 49 done at much higher hydrogen pressures (i.e., $\geq 10^{5} \mathrm{~Pa}$ ) than are normally used in our work. Baseline measurements have been completed for the as-received alloy at temperatures in the range 360 to $1050 \mathrm{~K}$ using hydrogen pressures from $10^{-1}$ to $10^{4} \mathrm{~Pa}$. Some evidence of deviations from a half-power dependence on pressure was observed at the lower end of the pressure range studied. This is believed to be due to irreversible formation of oxide layers that are stabilized by the $\sim 0.5 \%$ aluminum normally present in Inconel-718. Deliberate oxidation of the sample will be performed to further investigate this effect. Details of the Incone1-718 study will be presented in the next progress report.

Two titanium base alloys (Ti-6Al-4V and Ti-5A1-6Sn-2Zr-1Mo-0.25Si) have been received from John Davis at McDonnell Douglas Astronautics Company (MDAC). Initial attempts to electron-beam weld these alloys into the stainless steel couplings normally used in our permeation work 50 were unsuccessful due to weld embrittlement. Subsequent conversations with John Davis of MDAC confirmed that these titanium alloys cannot be welded to 300-series stainless steel. Methods of preparing suitable permeation assemblies for these alloys are being investigated.

48 L. R. Greenwood, Argonne National Laboratory, personal communication. 49

W. M. Robertson, Metall. Trans. 8A, 1709 (1977).

E. H. Van Deventer, T. A. Renner, R. H. Pelto, and V. A. Maroni, J. Nucl. Mater. 64, 241 (1977).

b. Tests of Vanadium Alloy Performance in a Liguid Lithium Environment

D. L. Smith, Materials Science Division, and V. A. Maroni Chemical Engineering Division

Work on the stainless steel-clad vanadium alloy (V-15Cr) 11thtum loop is continuing. All that remains to the fabrication of this system is to tack-weld the flowmeter leads into position and to complete their closure with the cladding. Plans have been made to assemble the high-vacuum gas handling system that will be used to monitor and control the atmosphere in the interface region between the vanadium alloy and the cladding. Set up of the loop, including the attachment of heaters and insulation, is expected to be completed during the third quarter of FY-1978. 


\section{Microstructure of Irradiated Fusion Reactor First-wall Materials}

S. C. Agarwal, G. Ayrault and F. V. Nolf1, Jr., Materials Science Division

In order to study the effects on microstructure of radiation damage and simultaneous displacement damage and helium production that will occur in structural materials in fusion reactors (FRs), the following investigations were performed.

\section{a. Dual-ion Irradiation of an $\mathrm{Fe}-15 \mathrm{Cr}-20 \mathrm{Ni}$ Alloy}

Annealed specimens of this experimental austenitic alloy were irradiated simultaneously with a $3.0-\mathrm{MeV}{ }^{5}{ }^{8} \mathrm{Ni}^{+}$beam and a degraded $0.95-\mathrm{MeV}{ }^{3} \mathrm{He}^{+}$beam at the ANL Dual-ion Irradiation Facility, Fig. I-13, and subsequently examined by transmission electron microscopy (TEM). Nominal dose levels ranged from 3-25 dpa, the dose rate was $\sim 3 \times 10^{-3} \mathrm{dpa} \cdot \mathrm{s}^{-1}$, the irradiation temperature was $700^{\circ} \mathrm{C}$, and the nominal $\mathrm{He}(\mathrm{appm}): \mathrm{dpa}$ ratios were $5: 1,15: 1$, and 50:1 (a 15:1 He:dpa ratio is considered typical for FR operation). For comparative studies, specimens preinjected at room temperature with 15 appm $\mathrm{He}$ and irradiated only with $\mathrm{Ni}$ ions were also included. The doses and irradiation temperatures were the same as above. A temperature dependence study was also carried out in the range $600-800^{\circ} \mathrm{C}$ in order to determine any shift in the swelling peak associated with the high heliun levels. For this study, the dose and He:dpa ratio were held constant at $12 \mathrm{dpa}$ and 15:1, respectively.

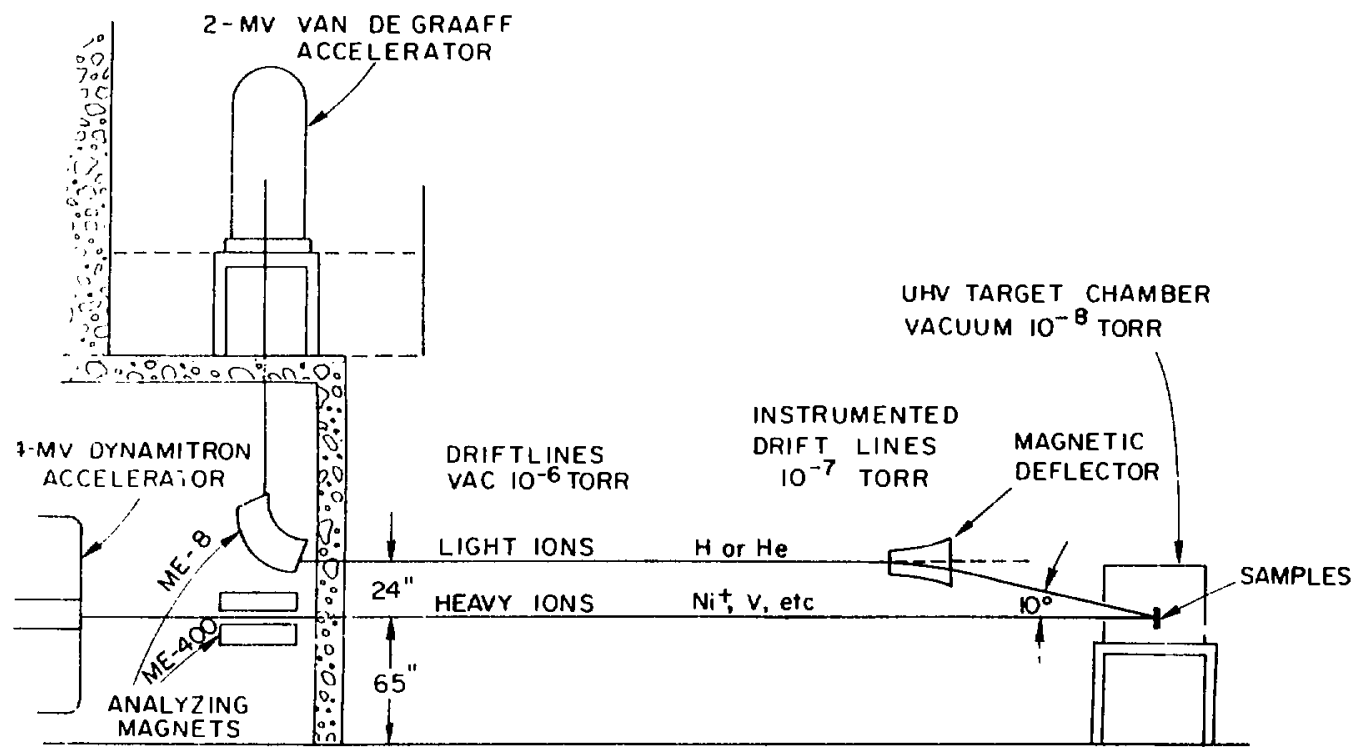

OUAL ACCELERATOR SYSTEM FOR SIMULTANEOUS BOMBARDMENT AND HELIUM INJECTION

Figure 1-13. Schematic of ANL dual-ion irradiation system. 
From the temperature dependence study, peaks in both the swelling curve and cavity size were observed to occur at $\sim 650^{\circ} \mathrm{C}$ indicating an apparent weak effect of helium on the swelling peak temperacures, Figure I-14 (the peak swelling temperature for this alloy is $\sim 700^{\circ} \mathrm{C}^{51}$ when preinjected with 15 appm $\mathrm{He}$ and $\mathrm{N} 1$-ion-irradiated at $10^{-2} \mathrm{dpa} \cdot \mathrm{s}^{-1}$ ). Both the cavity number density and dislocation density decrease with increasing temperature and show a plateau in the vicinity of the peak swelling temperature, Figure I-15. In the dose dependence study, a strong dependence of cavity microstructure on He:dpa ratio was observed, Figure I-16. A bimodal size distribution of cavities was fiund to persist to $\sim 25$ dpa in the $50: 1$ specimens and to $\sim 6$ dpa in the 15:3 specimens. For both He:dpa ratios, the cavity number density decreased with increasing dose, Figure I-17, and was generally higher for the 50:1 He:dpa ratio. In contrast, the dislocation density was nearly independent of dose and He:dpa ratio, Figure I-18. This study also showed that up to $\approx 6 \mathrm{dpa}$, the swelling is comparable for both the He:dpa ratios thus far examined $(15: 1,50: 1)$, and that above 6 dpa swelling is lower in the higher He:dpa ratio specimens, Figure I-19.

${ }^{51}$ W. G. Johnston, et al., "The Effect of Metallurgical Variables on Void Swelling," GE R\&D Report 76CRD019, Schenectady, N.Y., (1976).

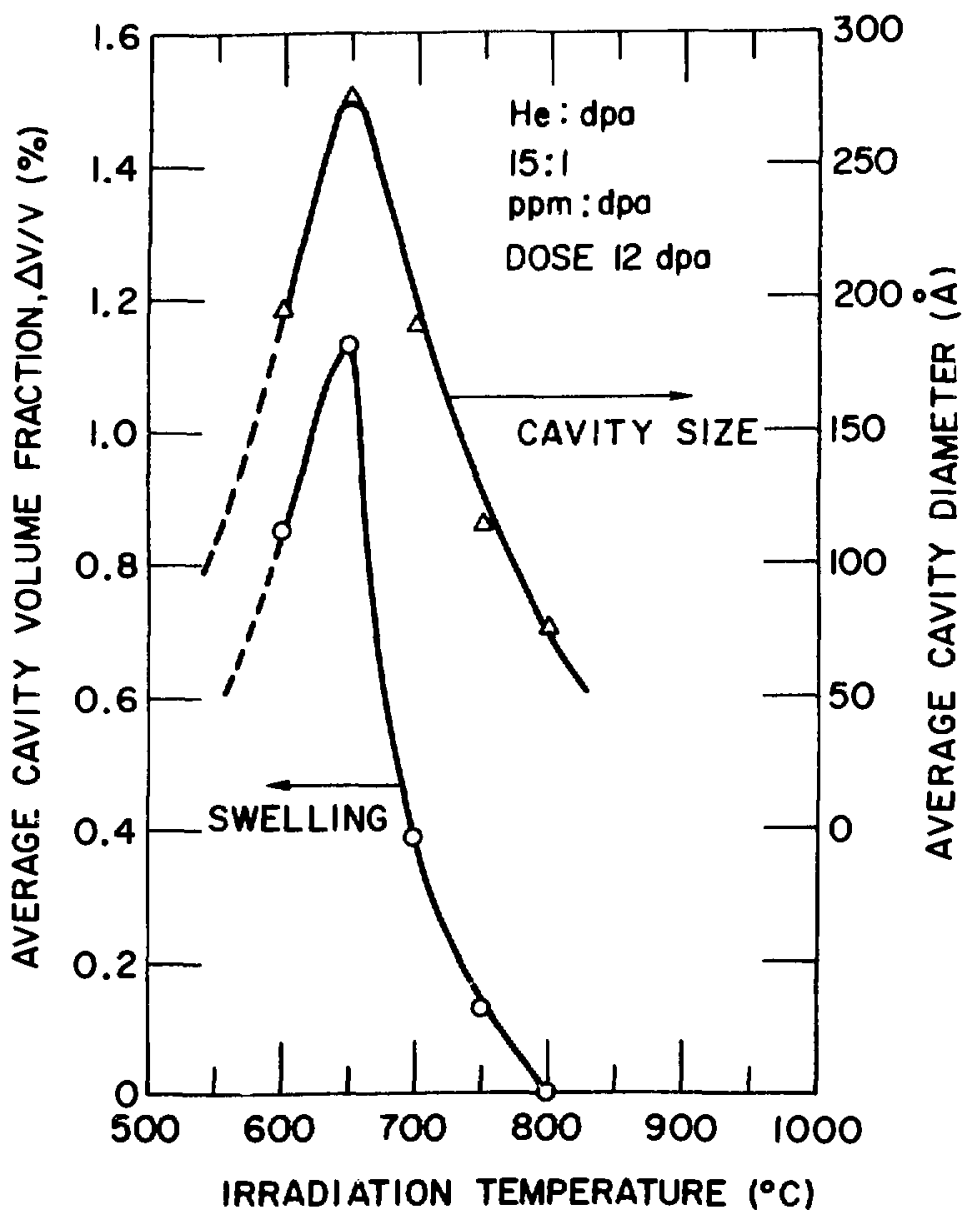

Figure I-14. Temperature dependence of swelling and cavity size in Fe-2ONi-15Cr (dose rate $=3 \times 10^{-3} \mathrm{dpa} \cdot \mathrm{s}^{-1}$ ). 


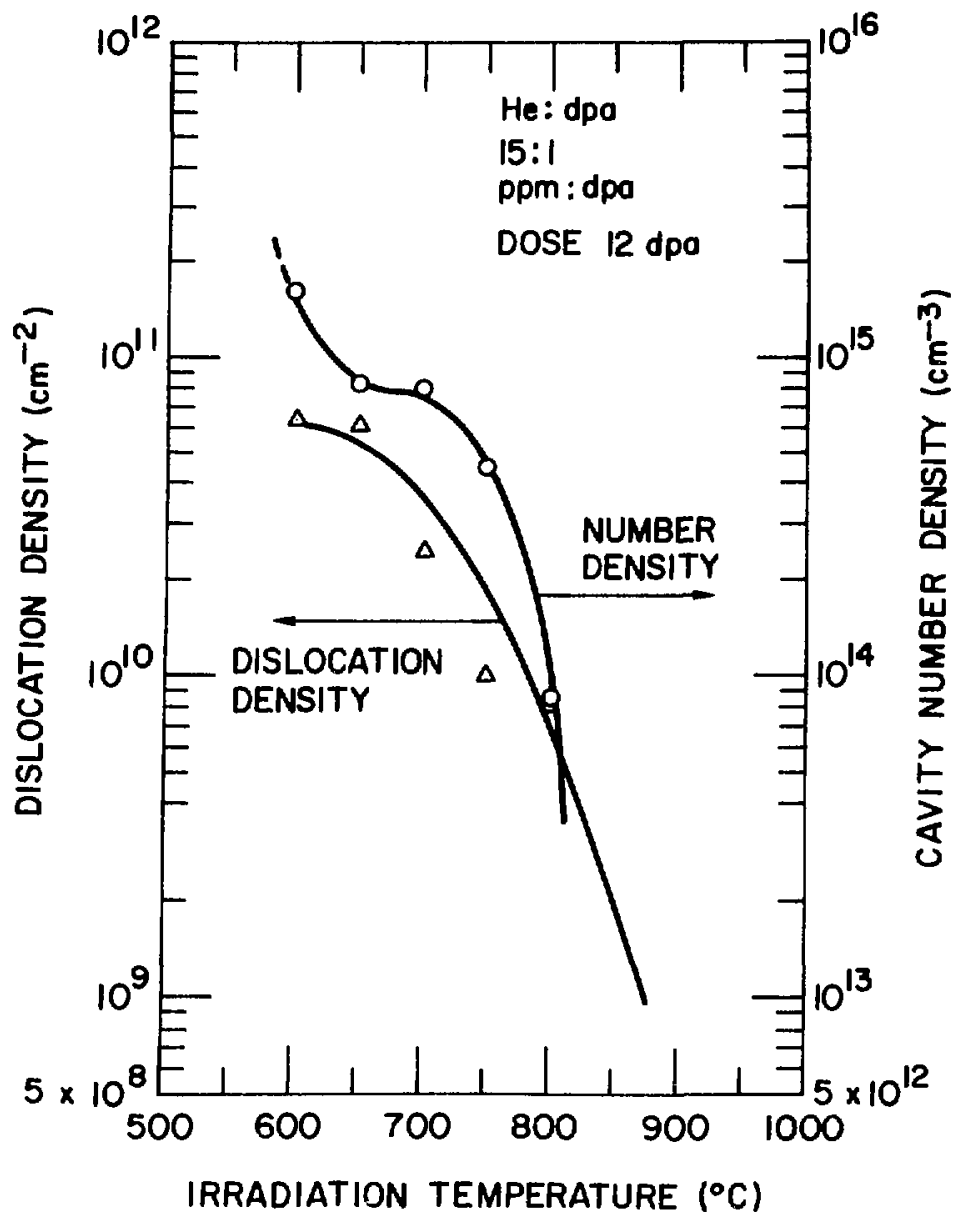

Figure I-15. Temperature dependence of the dislocation and cavity number densities in $\mathrm{Fe}-20 \mathrm{Ni}-15 \mathrm{Cr}$ (dose rate $=3 \times 10^{-3} \mathrm{dpa} \cdot \mathrm{s}^{-1}$ ).

The results of the present work suggest the following conclusions:

(a) The total swelling, and cavity sizes and number densities are sensitive to the He:dpa ratio.

(b) At all doses to $25 \mathrm{dpa}$, the cavity number densities are substantially higher in the 50:1 specimens than in the 15:1 specimens suggesting that He is enhancing cavity nucleation significantly. Both sets of number densities decrease with increasing dose (to $25 \mathrm{dpa}$ ) indicating that coarsening of the cavity distribution is occurring. 


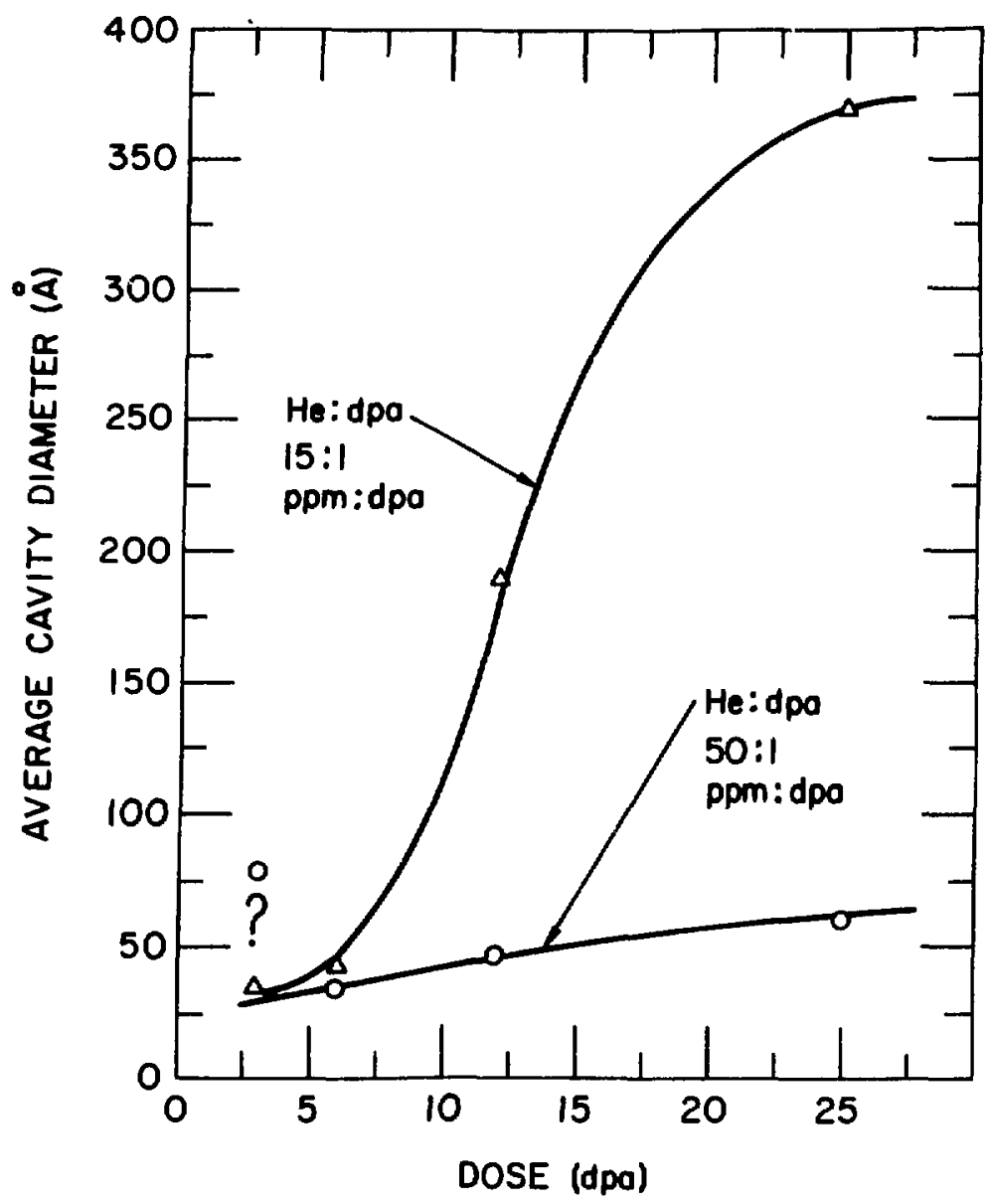

Figure I-16. Dose dependence of cavity size in $\mathrm{Fe}-20 \mathrm{Ni}-15 \mathrm{Cr}$ (dose rate = $3 \times 10^{-3} \mathrm{dpa} \cdot \mathrm{s}^{-1}$ temperature $-700^{\circ} \mathrm{C}$ ).

(c) The 50:1 specimens swell less than the 15:1 specimens; this is associated with higher number densities and smaller cavities in the $50: 1$ specimens.

(d) There is no evidence for significant shifts in the peak swelling temperature induced by helium injected at a ratio of 15:1.

(e) At 12 dpa and 15:1 He:dpa ratio, cavity growth is inhibited at temperatures above the swelling peak $\left(650\right.$ to $\left.800^{\circ} \mathrm{C}\right)$. 


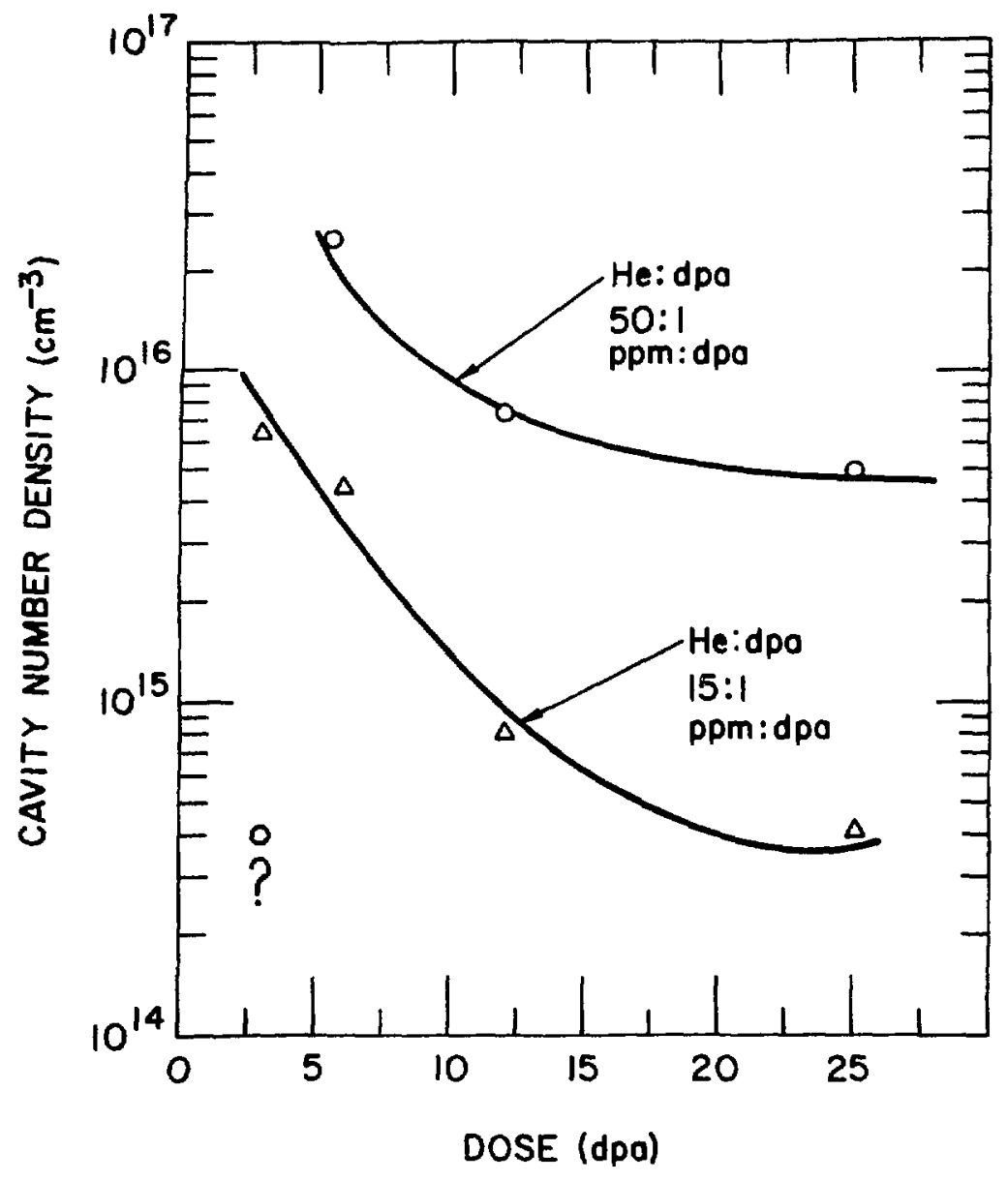

Figure I-17. Dose dependence of cavity number density in $\mathrm{Fe}-20 \mathrm{Ni}-15 \mathrm{Cr}$ (dose rate $=3 \times 10^{-3} \mathrm{dpa} \cdot \mathrm{s}^{-1}$, temperature $=700^{\circ} \mathrm{C}$ ).

b. Irradiation-induced Swelling and Segregation in a V-15 wt \% Cr Alloy

A promising refractory alloy for FR applications is $\mathrm{V}-15 \mathrm{Cr}-5 \mathrm{Ti}$ which has good radiation response, creep strength, and is more fabricable than binary $\mathrm{V}-\mathrm{Cr}$ alloys. Studies of a V-15Cr binary alloy enable determination of the effects of $\mathrm{Cr}$ versus $\mathrm{Ti}$ on these properties so that alloy modifications for optimum performance can be made. Annealed specimens of this experimental refractory alloy were irradiated with $3.5-\mathrm{MeV} 51 \mathrm{~V}^{+}$ions at $650^{\circ} \mathrm{C}$ to peak dose levels of 5 to $60 \mathrm{dpa}$. Specimens were also irradlated for a temperature dependence study $\left(450-650^{\circ} \mathrm{C}\right)$ at a fixed dose of 25 dpa, both with single-ion $\left(3-\mathrm{MeV}{ }^{51} \mathrm{~V}^{+}\right)$and dual-ion $\left(3-\mathrm{MeV}^{51} \mathrm{~V}^{+}\right.$and $0.95-\mathrm{MeV}$ degraded ${ }^{3} \mathrm{He}^{+}$) beams. 


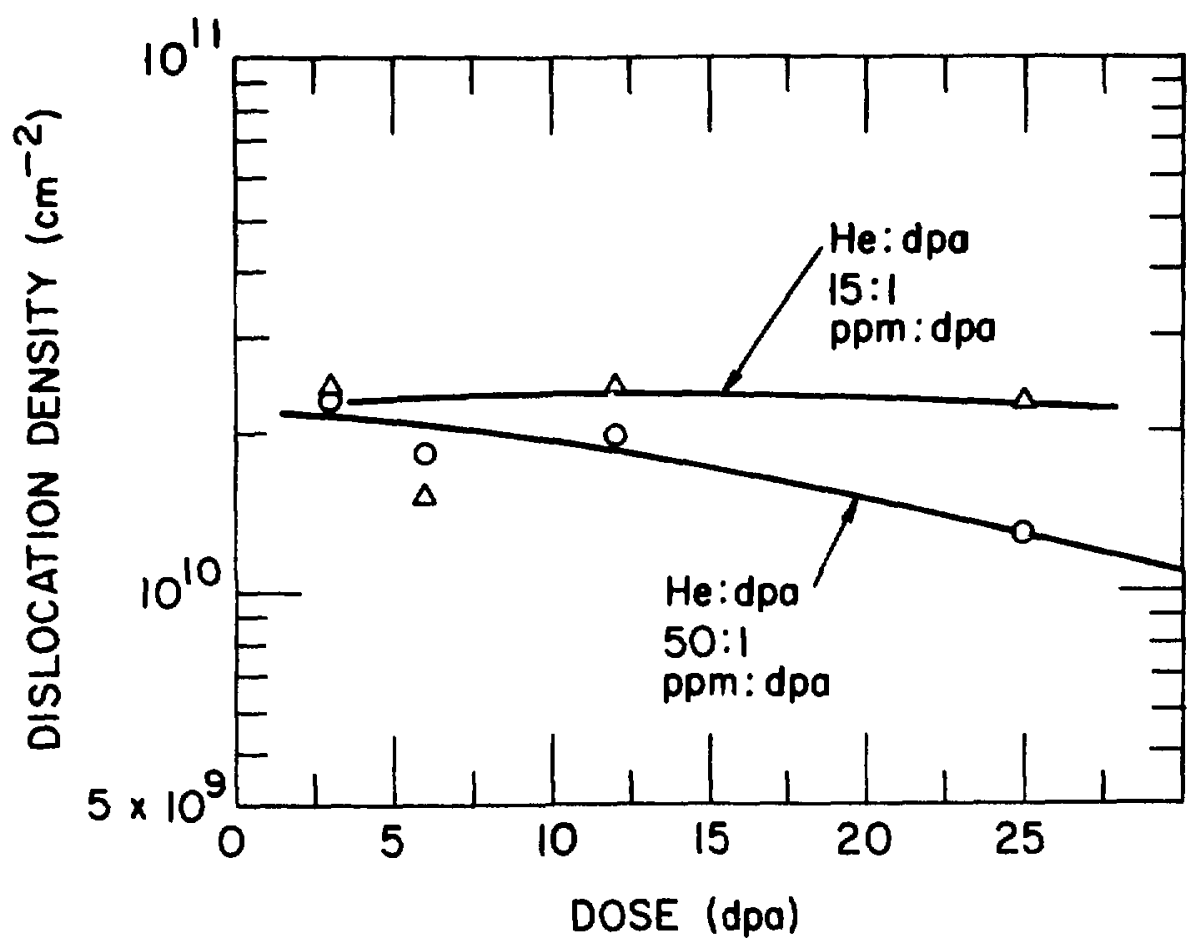

Figure I-18. Dose dependence of dislocation density in Fe-20Ni-15Cr (dose rate $=3 \times 10^{-3} \mathrm{dpa} \cdot \mathrm{s}^{-1}$, temperature $=700^{\circ} \mathrm{C}$ ).

Transmission-electron micrographs of the void population obtained under absorption contrast conditions in samples irradiated at $650^{\circ} \mathrm{C}$ to peak doses of $5,15,30$, and 60 dpa are shown in Figure I-20. A strong increase in void size occurs with an increase in dose, but no obvious change in number density is apparent. Control samples that were shielded from the ion beam were also mounted in the irradiation rig to ensure the same thermal history as the irradiated samples. Micrographs showed that the control samples were very clean and were characterized by a low dislocation density $\left(\sim 10^{8} \mathrm{~cm}^{-2}\right)$.

The effect of dose on the dislocation microstructure, imaged under twobeam conditions using a $\{110\}$ diffracted beam in an $\{001\}$ foil, is shown in Figure I-21. An interconnected cellular dislocation structure is observed at $5 \mathrm{dpa}$, which coarsens and stabilizes by $\sim 27 \mathrm{dpa}$. Regions of lower dislocation density appear to contain the majority of the voids. This correlation is more clearly demonstrated in Figure I-22. The upper micrograph shows an area in the 27-dpa specimen imaged under strong dislocation contrast conditions, and the lower micrograph shows the same area under absorption contrast conditions to enhance the visibility of the void microstructure. 


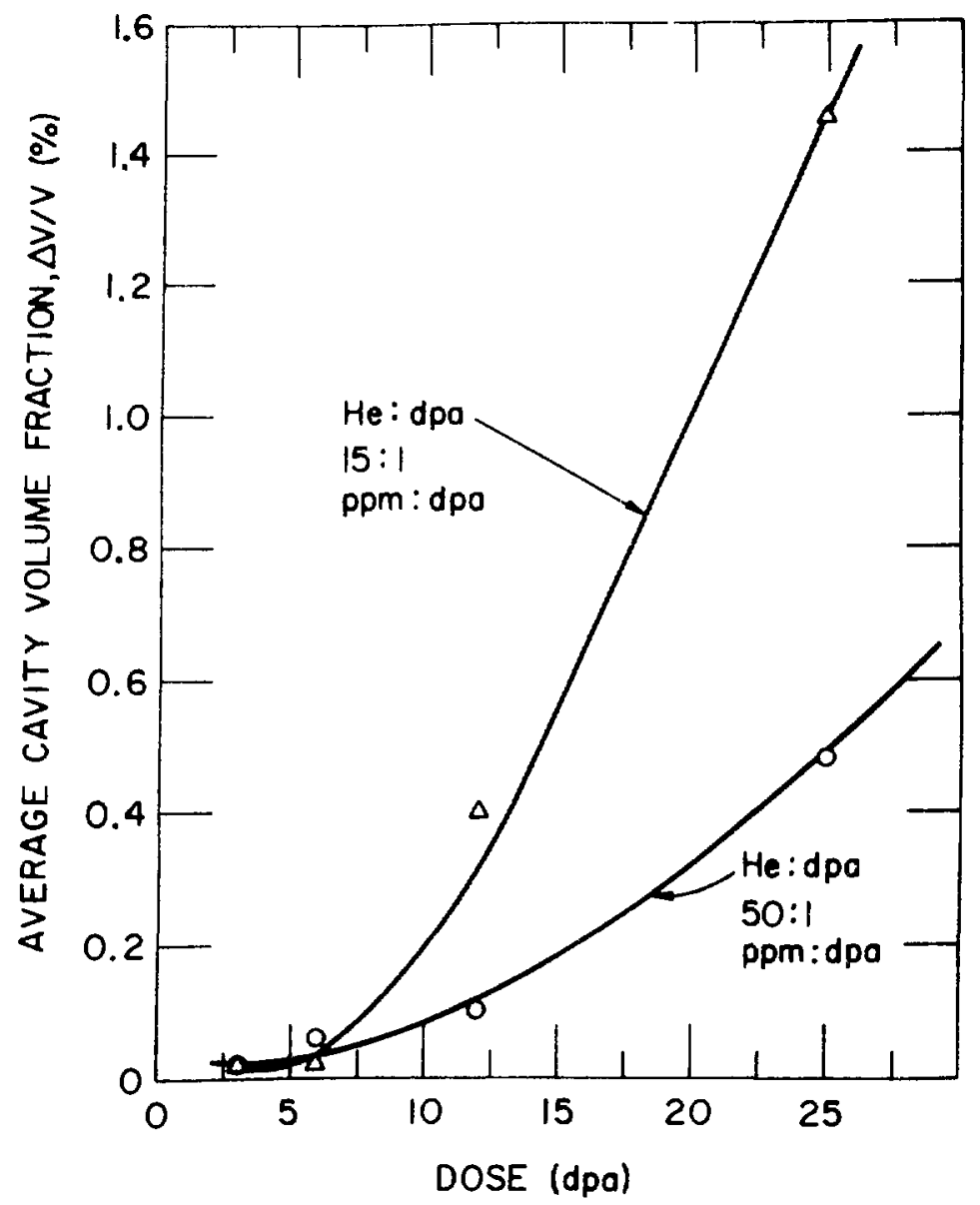

Figure I-19. Dose dependence of swelling in Fe-20Ni-15Cr (dose rate $=3 \times 10^{-3}$ $\mathrm{dpa} \cdot \mathrm{s}^{-1}$, temperature $=700^{\circ} \mathrm{C}$ ).

Quantitative verification of the general swelling behavior presented in Figures $I-21$ and $I-22$ was also obtained. Figure I-23 gives the measured average void diameter as a function of irradiation dose at $650^{\circ} \mathrm{C}$. The average void diameter increases linearly with dose, from $\sim 75 \AA$ at 5 dpa to more than $900 \AA$ at $55 \mathrm{dpa}$. The void-number density and total swelling ( $\Delta \mathrm{V} / \mathrm{V})$ are plotted as a function of dose in Figure I-24. Although only a slight increase in in number density occurs between 5 and $55 \mathrm{dpa}$, the large increase in void size over this damage regime results in a dramatic increase in total swelling. A correction is included in the calculated total swelling results to account for the voids that intersect the foil surface. Since the foil thickness varies between 1000 and $2000 \AA$, this correction is insignificant at the lower doses. However, at $55 \mathrm{dpa}$ the foil thickness (1200 $\AA$ ) and the vold size $(900 \AA)$ are comparable, and this introduces a large correction for surface voids. The computed swelling at this dose, including the correction (upper 


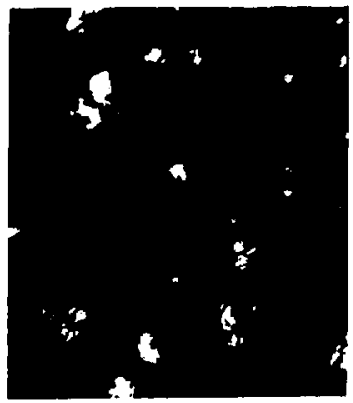

a

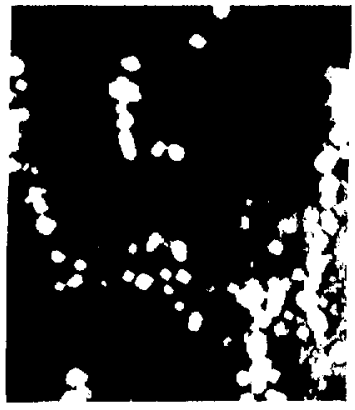

c

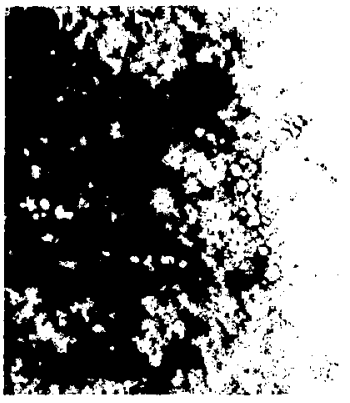

b

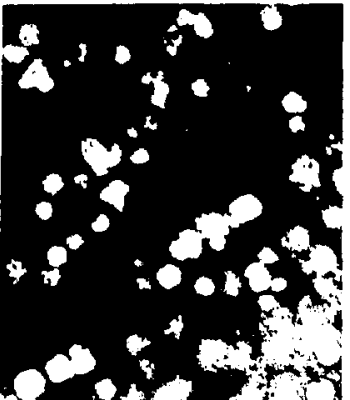

$\mathrm{d}$

Figure I-20. Absorption contrast micrographs of $\mathrm{V}-15 \mathrm{Cr}$ specimens irradiated at $650^{\circ} \mathrm{C}$ to different dose levels. (c) $27 \mathrm{dpa}$, and (d) $55 \mathrm{dpa}$.

(a) $5 \mathrm{dpa}$, (b) $11 \mathrm{dpa}$,

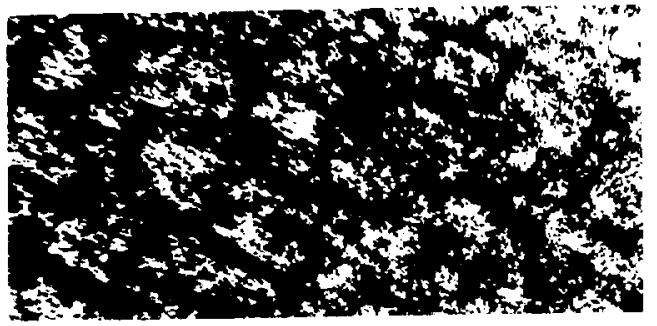

a

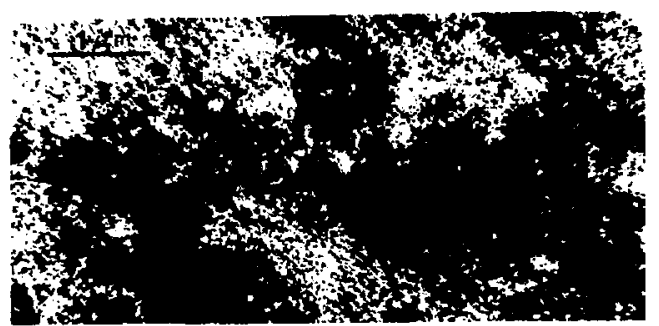

b

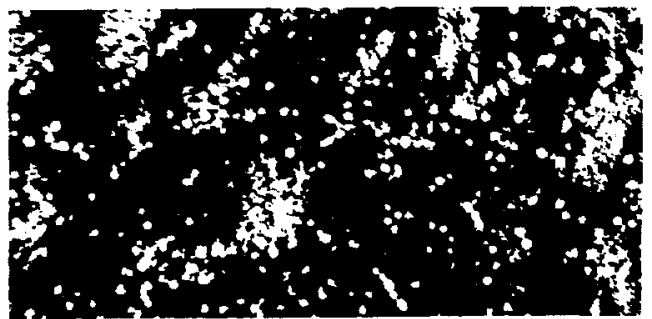

C

Figure I-21. Dislocation contrast micrographs of $\mathrm{V}-15 \mathrm{Cr}$ specimens irradiated at $650^{\circ} \mathrm{C}$ to different dose levels. (a) $5 \mathrm{dpa}$, (b) $27 \mathrm{dpa}$, and (c) $55 \mathrm{dpa}$. 

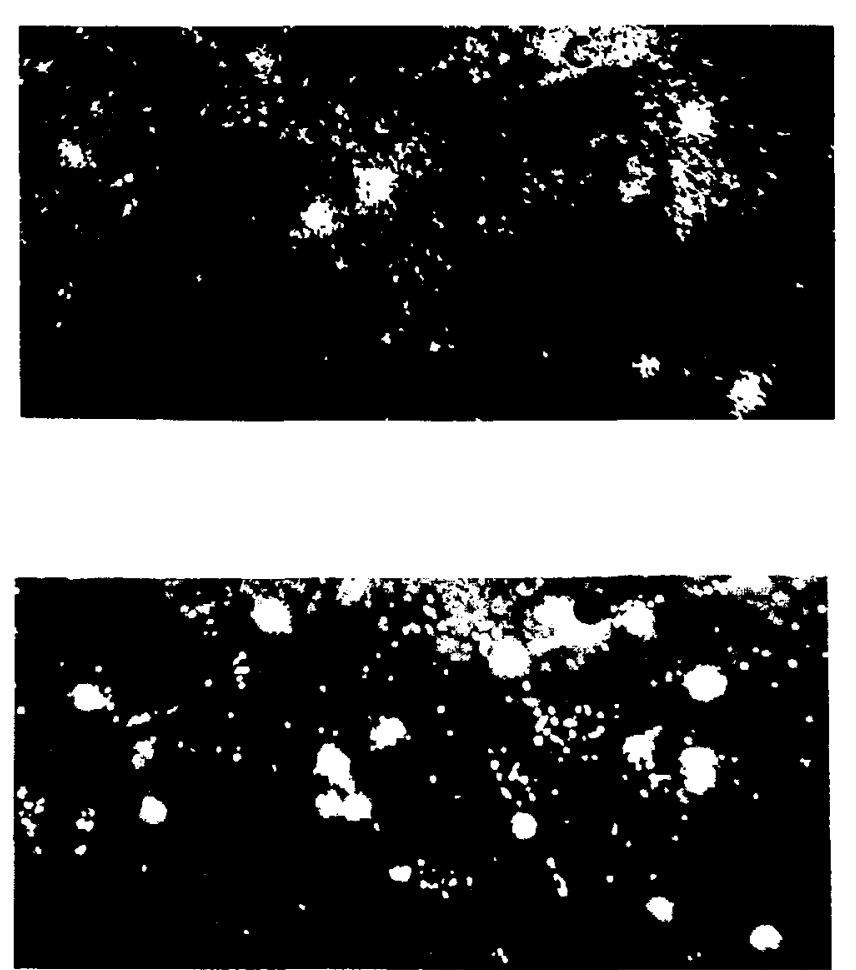

Figure I-22. The same area of the 27-dpa specimen shown in Figure I-14 imaged under strong dislocation contrast (upper micrograph) and absorption contrast (lower micrograph).

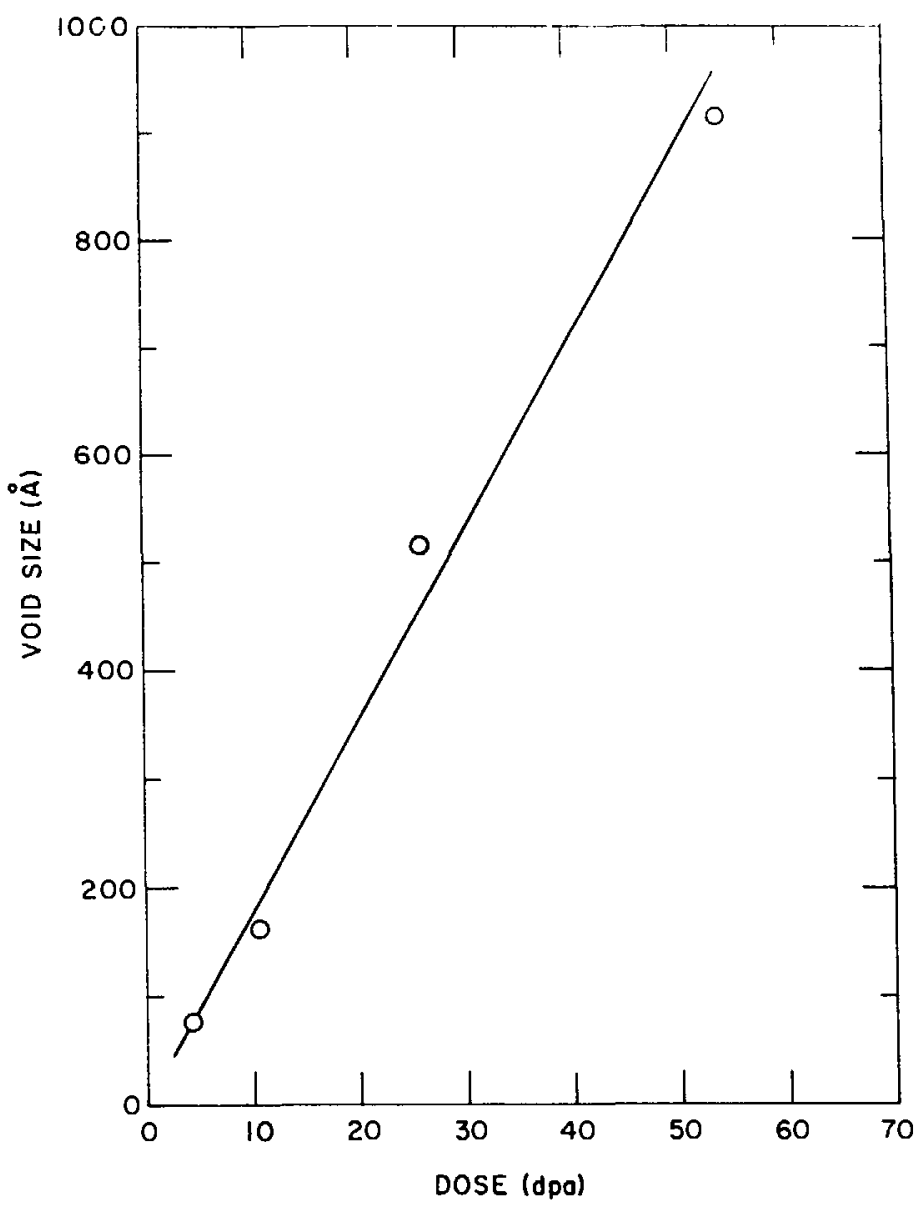

Figure I-23. Average void size observed in $\mathrm{V}-15 \mathrm{Cr}$ as a function of total dose. 


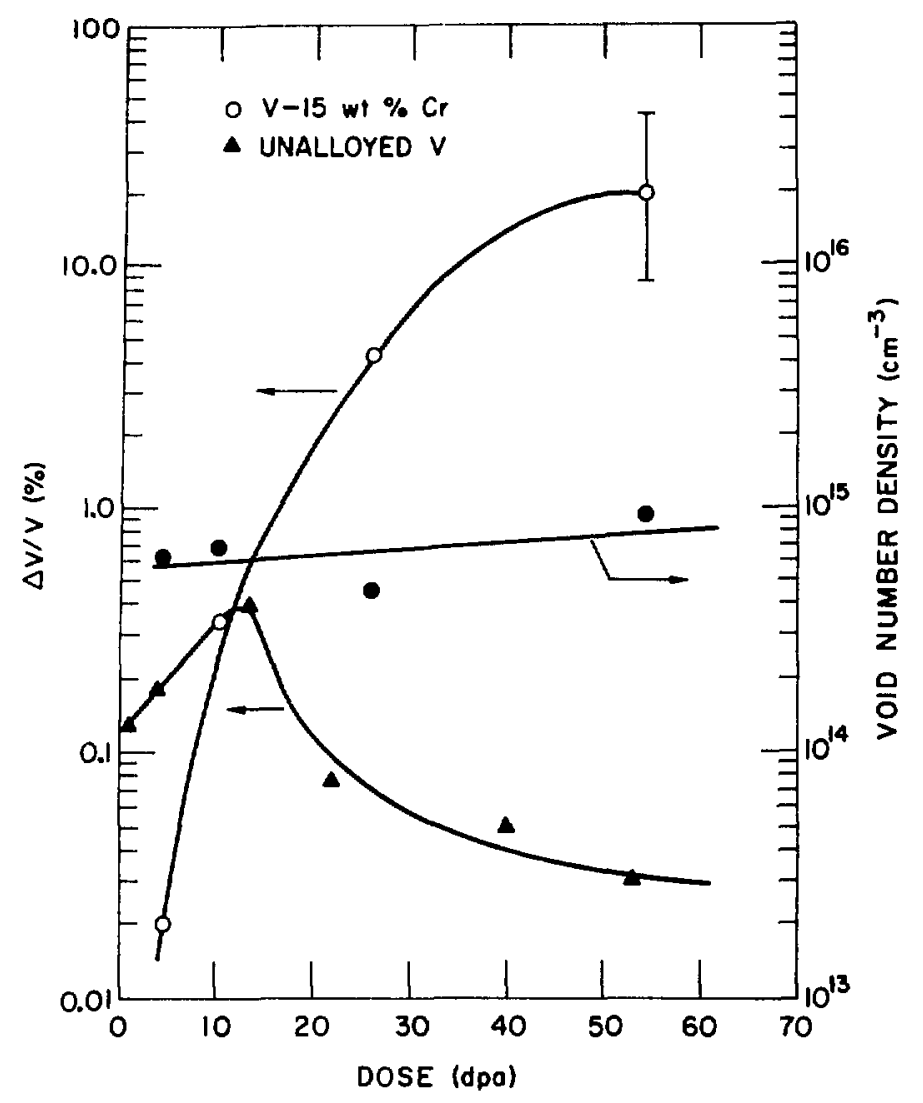

Figure I-24. Void number density and calculated total swelling for V-15Cr as a function of total dose. The total swelling of the unalloyed $\mathrm{V}$ stock is also shown.

1imit), is $42 \%$; without the correction, the value of total swelling at 55 dpa is $8.5 \%$ (lower limit) so that we estimate the actual swelling to be $\sim 20 \%$ at this dose.

Figure I-24 also shows the swelling curve for the unalloyed $V$ of the same stock irradiated under essentially identical conditions in a previous study.52 In unalloyed $\mathrm{V}$, the swelling initlally increases with dose to a peak value of $\sim 0.4 \%$ at $\sim 14 \mathrm{dpa}$, and then decreases as the dose increases. This decrease in swelling at higher doses is accompanied by an increasingly

52 S. C. Agarwal and A. Taylor, Proc. Int1. Conf. on "Radiation Effects and Tritium Technology for Fusion Reactors," Vol. I, 150, 1975. 
high density of irradlation-induced coherent $\{01$.$\} -type precipitates. These$ precipitates appear to be associated with the presence of interstitial impurities ( $C, 0$, and $N$ ). 53

Work on the temperature dependence of the single-ion and dual-ion irradiated specimers of $\mathrm{V}-15 \mathrm{Cr}$ is in progress.

Auger spectroscopy measurements on this V-15Cr alloy have been performed by L. E. Rehn under Basic Energy Sciences (BES) funding and are reported here because of their significance with respect to radiation effects in $V$ alloys. Auger studies of the surface of irradiated and unirradiated specimens showed that $\mathrm{Cr}$ segregates to the surface (and presumably to other point-defect sinks) during irradiation. The $\mathrm{Cr}$ concentration near the surface was $\sim 45 \%$ after 15 dpa, which is a factor of three larger than the average concentration in the bulk ( $\sim 15 \%$ ), Figure I-25. Proflling of the segregation by sputtering away surface layers showed a subsurface region reduced in $\mathrm{Cr}$ concentration and a return to essentially bulk value at a depth of $\sim 1000 \AA$ from the origina surface. This depth is too large for the segregation to have been Gibbsian in nature and suggests irradiation-induced segregation.

53 S. C. Agarwal, D. I. Potter and A. Taylor, ASTM STP 611, P. 298 (1976).

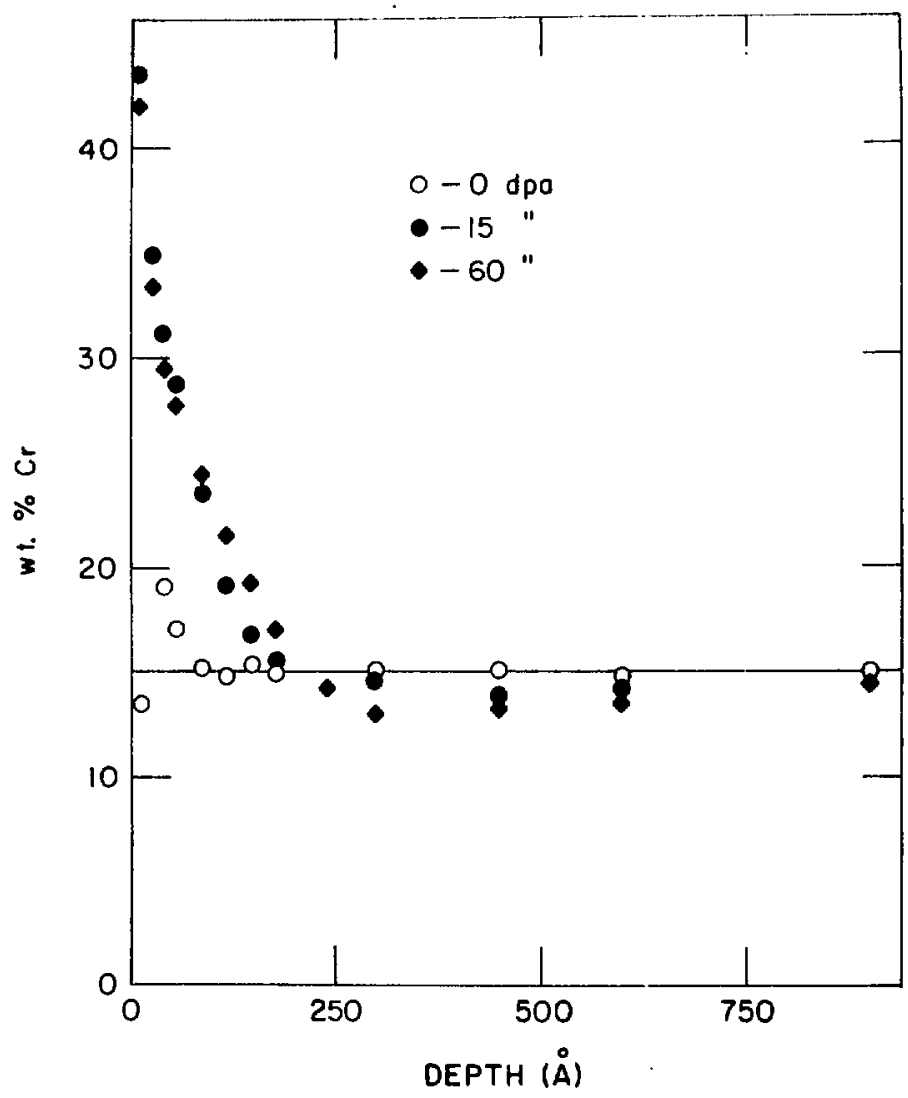

Figure I-25. Cr concentration vs. depth profiles for an unirradiated control (0 dpa) and two irradiated specimens (15 and 60 dpa peak dose). 
$\mathrm{Cr}$ is undersized in $\mathrm{V}$ and causes a fractional change in lattice parameter per atom fraction of solute equal to $-6 \% .54$ The observed enrichment of $\mathrm{Cr}$ at the surface, which serves as a sink for both interstitial- and vacancytype defects, is therefore consistent with the size-effect prediction of okamoto and Wiedersich.55 Similar measurements at our Laboratory on V-ionirradiated $\mathrm{V}-4 \mathrm{Si}$ also show enrichment of the undersized $\mathrm{Si}$ atoms at the surface. An attempt to profile the oversize solute Ti in a V-10Ti alloy was not successful because of interference between the $T i, V$, and $N$ Auger transitions. However, the surface enrichment of $\mathrm{Cr}$ and $\mathrm{Si}$ in $\mathrm{V}$ indicates that the sign of the solute misfit parameter may determine the direction of substitutional solute segregation during irradiation at elevated temperatures in binary alloys of body-centered-cubic (bcc) $\mathrm{V}$ as well as in fcc Ni.56 The results of the present work suggest the following conclusions:

(a) The swelling in $\mathrm{V}-15 \mathrm{Cr}$ increases rapidly with dose at $610^{\circ} \mathrm{C}$ and is much greater than for unalloyed $V$ at high doses; no precipitation at any dose is observed in $\mathrm{V}-15 \mathrm{Cr}$. These observations are consistent with the thesis that refractory alloys tend to be low swelling because of a general propensity toward precipitation during irradiation.

(b) The present results show that $\mathrm{Cr}$ atoms move toward defect sinks during irradiation of $\mathrm{V}-15 \mathrm{Cr}$ and provide the first direct experimental evidence for irradiation-induced segregation of substitutional solute atoms in a bcc alloy.

54 O. N. Carlson and A. L. Eustice, USAEC IS-47, (1959). 55 P. R. Okamoto and H. Wiedersich, J. Nucl. Mater., 53, P. 336 (1974). ${ }^{56}$ D. I. Potter, et al., Proc. Int1. Conf. on "Radiation Effects in Breeder Reactor Structural Materials," M. B. Bleiberg and J. W. Bennett, eds., pp. 377-386, Metallurgical Society of AIME, New York, (1977).

\section{Special Purpose Materials}

1. Ion-implantation Damage in Amorphous and Crystalling $\mathrm{Nb}_{4} 0_{\mathrm{Ni}} 60$ M. D. Rechtin, J. Vander Sande, ${ }^{*}$ and P. M. Baldo, Materials Science Division

Metallic glasses have recently evolved as an important new class of materials, not only scientifically but technologically. 57 These materials can exhibit unexpected and highly desirable physical properties conpared with their crystalline counterparts. A substantial amount of scientific research has been devoted to metallic glasses composed of transition metals,

* Massachusetts Institute of Techrology, Cambridge, Massachusetts.

57 J. J. Gilman, Physics Today 28, 46 (1975). 
such as $\mathrm{Fe}$, $\mathrm{Co}$, and $\mathrm{NL}$, in combination with the metalloid elements $\mathrm{B}, \mathrm{C}, \mathrm{P}$, and Si.58 These alloys show excellent strength, hardness, elastic stiffness, and good thermal stability.

Also great interest exists in glasses composed solely of metallic elements, 59 and some results on the refractory metal-transition metal binary alloy $\mathrm{Nb}_{40} \mathrm{Ni}_{60}$ will be discussed in the present paper. Recent work 60 has shown that amorphous $\mathrm{Nb}_{4} \mathrm{Ni}_{60}$ is resistant to radiation damage at temperatures as high as $900 \mathrm{~K}$. This phenomenon, in conjunction with thermal stability to nearly $1000 \mathrm{~K}$ and excellent mechanical hardness and strength, 61 makes this material an excellent candidate for applications in radiation environments.

Ion implantation has been used to produce amorphous layers in some metal-metalloid systems such as Ni-P.62 This modification of surface layers may be desirable for corrosion and abrasion resistance or, as will be shown, for resistance to certain radiation-damage effects. Thermal spikes produced by the ion implantation result in cooling rates of $\sim 10^{14} \mathrm{~K} / \mathrm{s}$ in the vicinity of the collision cascade. This effect may produce amorphous phases that would be virtually impossible to obtain by conventional roller or splatquenching methods.

The amorphcus $\mathrm{Nb}_{40} \mathrm{Ni}_{60}$ was prepared by levitation melting $\sim 0.5 \mathrm{~g}$ of material and splat quenching with a copper hammer and anvil. The resultant specimen was several centimeters in diameter and $\sim 50 \mu \mathrm{m}$ in thickness. Amorphous and partially crystallized 3-mm-diameter disks of $\mathrm{Nb}_{4}{ }_{0} \mathrm{Ni}_{60}$ have been irradiated to peak doses of 20 displacements per atom (dpa) at room temperature and $900 \mathrm{~K}$ (in the vicinity of the glass transition temperature). The implantations were performed in a vacuum of $7 \times 10^{-8}$ torr with $3-\mathrm{MeV} \mathrm{Ni}{ }^{+}$ ions at a dose rate of $\sim 3 \times 10^{-3} \mathrm{dpa} / \mathrm{s}$. The 20-dpa dosage corresponds to an integrated ion flux of $\sim 1.5 \times 10^{16}$ ions $/ \mathrm{cm}^{2}$. The peak in $\mathrm{Ni}^{+}$ion damage is near $0.7 \mu \mathrm{m}$, and the peak of the implanted ion range is at $0.85 \mu \mathrm{m}$, as calculated by the Brice code. 63 These calculations use a threshold displacement energy of $40 \mathrm{eV}$ and a weighted average of the elemental densities in the crystalline state. Variations in packing density of $\pm 5 \%$ alter the

\footnotetext{
58. Duwez and S. C. H. Lin, J. Appl. Phys. 38, 4096 (1967); L. E. Tanner and R. Ray, Scripta Met. 11, 783 (1977).

59 D. E. Polk and B. C. Giessen, Metallic Glasses (J. J. Gilman and H. J. Leamy eds.) ASM, Metals Park, Ohio, (1977).

${ }^{60}$ M. D. Rechtin, J. Vander Sande and P. M. Baldo, Proc. 35th Annual EMSA Conference, Boston, Massachusetts (1977), p. 42.

${ }^{61}$ B. C. Giessen, M. Madhava, D. E. Polk and J. Vander Sande, Matl. Sc 1. and Eng., 23, 145 (1976).

${ }^{62}$ A. Ali, W. A. Grant and P. J. Grundy, Rad. Effects 34, 251 (1977).

63 D. K. Brice, Sandia Laboratories Report, SLA-73-0416, (1973).
} 


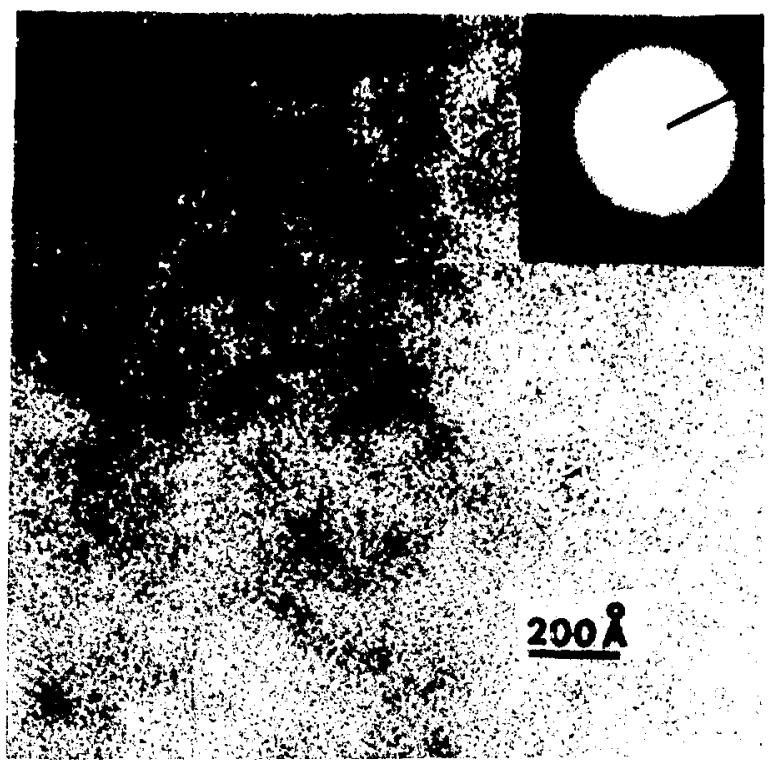

Figure I-26. Microstructure of $\mathrm{Nb}_{40} \mathrm{Ni}_{60}$ after irradiation to 20 dpa at $900 \mathrm{~K}$.

Table I-3. Lattice Spacings and Intensities from the Electron Diffraction Pattern of Partially Crystalline Specimens Annealed at Temperatures within the First Exothermic Peak.

\begin{tabular}{|c|c|c|c|}
\hline$d$-spacing (A) & Intensity ${ }^{+*}$ & $\mathrm{NiNb}^{65}$ & $\mathrm{Ni}_{3} \mathrm{Nb}^{66}$ \\
\hline $7.40 \pm 0.1$ & $\mathbf{w}$ & * & - \\
\hline $6.53 \pm 0.1$ & $\mathrm{w}$ & * & - \\
\hline $6.42 \pm 0.1$ & $w$ & * & - \\
\hline $6.36 \pm 0.1$ & w & * & - \\
\hline $6.05 \pm 0.1$ & w & * & - \\
\hline $5.77 \pm 0.08$ & $\mathbf{w}$ & $*$ & - \\
\hline $3.98 \pm 0.08$ & $w$ & * & - \\
\hline $3.72 \pm 0.06$ & $w$ & * & - \\
\hline $3.40 \pm 0.05$ & $\mathbf{w}$ & * & w \\
\hline $3.09 \pm 0.03$ & $w$ & * & $w$ \\
\hline $2.91 \pm 0.02$ & $\mathrm{w}$ & * & - \\
\hline $2.83 \pm 0.02$ & $\mathrm{w}$ & * & - \\
\hline $2.56 \pm 0.02$ & $w$ & * & $w$ \\
\hline $2.46 \pm 0.02$ & $\mathbf{s}$ & $s$ & - \\
\hline $2.23 \pm 0.02$ & $s$ & s & $\mathbf{m}$ \\
\hline $2.11 \pm 0.02$ & s & $\mathbf{s}$ & s \\
\hline $2.02 \pm 0.02$ & $m-w$ & w & $s$ \\
\hline $1.96 \pm 0.02$ & $\mathrm{~m}$ & $m$ & $s$ \\
\hline $1.86 \pm 0.02$ & $\mathrm{~m}$ & m & - \\
\hline
\end{tabular}

The symbols $w=$ weak, $m=$ medium, $s=$ strong. *

= indicate agreement with calculated lines but not observed for X-ray scans, and - indicates not possible by calculation and not observed by X-rays. 
location of peak damage only $\pm 0.03 \mu \mathrm{m}$. Specimens were prepared for electron microscopy by $6-\mathrm{keV} \mathrm{Ar}{ }^{+}$ion milling. A comparison of ion milling with conventional chemical thinning indicated no ion-milling artifacts that might interfere with interpretation of the microstructure, and ion milling yielded better quality foils. The only noticeable artifact of ion milling was the vitrification of a thin ( $<50 \AA$ ) layer of material on each surface bombarded with Ar ions.

The damage distribution was examined by a series of sectioning operations beginning with a surface section and continuing through the damage peak into the unimplanted material. The damage distribution was such that the dose at the surface was equal to approximately one-third the peak dose value. Therefore, by examining a series of sections from the surface through the damage peak, we were able to investigate displacement damage ranging from 6 to $20 \mathrm{dpa}$. The section depths were determined to $\pm 1000 \AA$ by optical interferometer measurements of the step height between a sectioned region and a masked-off region.

Irradiations were performed on both amorphous and partially crystalline samples. Some specimens underwent preirradiation annealing treatments ranging from 900 to $973 \mathrm{~K}$. The glass transition temperature is $\approx 900 \mathrm{~K}$, and the first exothermic crystallization begins near $910 \mathrm{~K}$, has a maximum at $940 \mathrm{~K}$, and ends near $970 \mathrm{~K} .61$ For those specimens that were initially amorphous, including those annealed below the crystallization range, the structures remained amorphous after irradiation to doses of 6 to $20 \mathrm{dpa}$ at both room temperature and $900 \mathrm{~K}$. Figure I-26 shows a representative microstructure from a $900 \mathrm{~K}$ irradiation with the typical low contrast "salt and pepper" structure. The image was formed using an objective aperture that included the transmitted beam and the first intense diffraction ring. Within the resolution of the microscope, no evidence of crystallinity, phase separation, nor void formation was detected. The diffraction pattern from the irradiated specimens also exhibited no discernible difference from the control samples. At the level of displacement damage used, no features attributable to accumulation of defects were observable; however, it is possible defects are present as very small clusters or atomic vacancies. Recent work on irradiation induced volume changes in a glass metal-metalloid alloy 64 may suggest these types of defects are present.

Another group of specimens was annealed prior to irradiation at temperatures within the bounds of the first crystallization peak. These samples were partially crystalline with interspersed amorphous material. Figure I-27(a) shows a TEM image of the microstructure of a specimen annealed at $973 \mathrm{~K}$ (a temperature at the end of the first crystallization peak) for 10 minutes in vacuum. The structure is representative of specimen depths beyond the ion-damage layer. The inserted selected area diffraction pattern in Figure I-27(a) was indexed using a gold foil standard pattern, The d-spacings and relative intensities for the indexed rings are listed in Table I-3. Comparison with $\mathrm{X}$-ray diffraction results on the phases $\mathrm{NiNb}^{65}$ and $\mathrm{Ni}_{3} \mathrm{Nb}^{66}$

\footnotetext{
${ }^{64}$ B. T. A. Chang and J. C. M. Li, Scripta Met. 11, 933 (1977).

65 P. I. Kripyakevich, et al, Sov. Phys. Cryst. 2,165 (1962).

${ }^{66}$ E. N. Pylseva, et al, Zh. Neorg. Khim. 3, 206 (1958).
} 


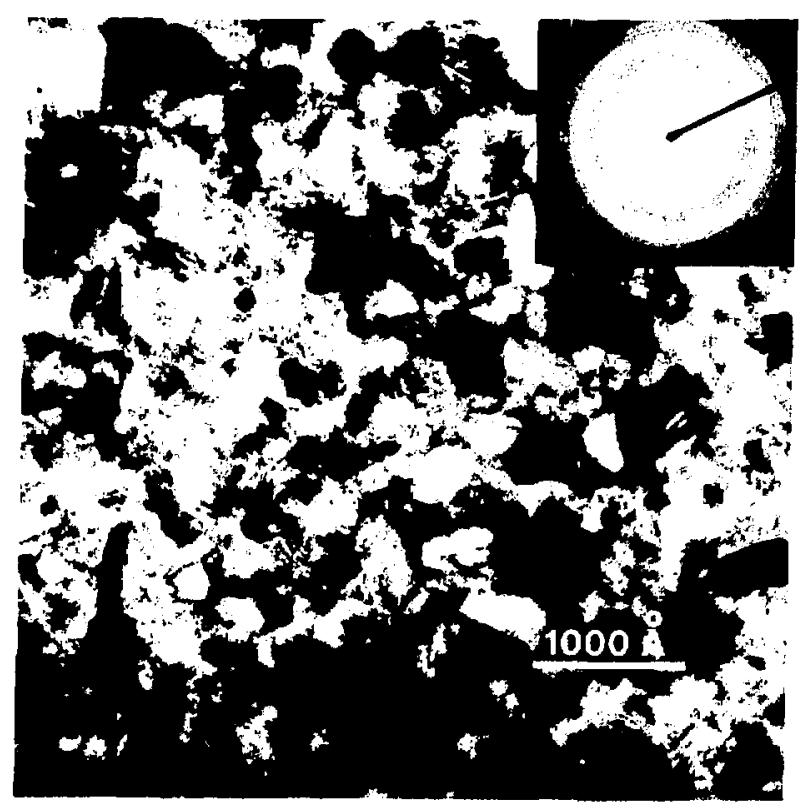

(a)

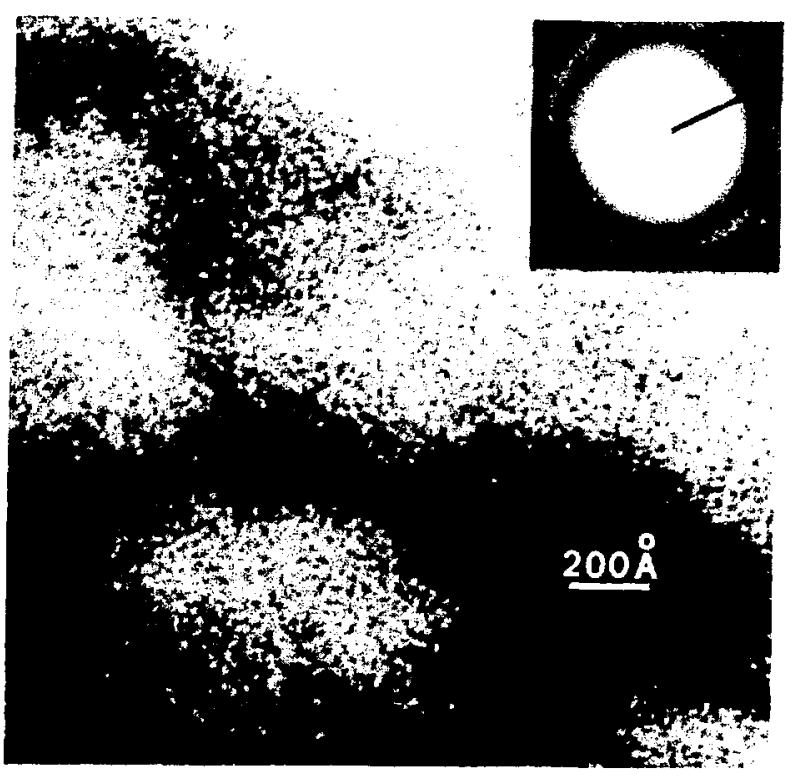

(b)

Figure I-27. Specimen preannealed to $973 \mathrm{~K}$ for 10 minutes in vacuum and (b) specimen appearance after irradiation to dose $>6 \mathrm{dpa}$ at room temperature or $900 \mathrm{~K}$. 
gave good agreement with the observed d-spacings and relative intensities of the hexagonal phase NiNb.65 It was not surprising to observe many more weak lines by electron diffraction. Electron diffraction is intrinsically a stronger scattering process. Calculations indicate that all observed lines could be ascribed to the NiNb phase. Furthermore, a number of indexed rings were present that corresponded to d-spacings greater than any possible diffraction line from the orthorhombic $\mathrm{Ni}_{3} \mathrm{Nb}$ phase. Therefore, one may infer that the first exothermic peak in the thermogram arises from crystallization of the NiNb compound. After irradiation of this partially crystalline spectmen with $\mathrm{Ni}^{+}$ions at both $900 \mathrm{~K}$ and room temperature, complete vitrification has occurred at doses from 6 to $20 \mathrm{dpa}$. The microstructure after $\mathrm{NI}^{+}$ion bombardment, as shown in Figure $\mathrm{I}-27(\mathrm{~b})$, has the uniform "salt and pepper" structure seen in the amorphous control samples and irradiated amorphous specimens (Figure I-26). Within the resolution of the microscope, we observed no crystallinity, phase separation, or void formation.

Specimens were also annealed at lower temperatures within the range of the first crystallization peak. A set of samples was annealed 10 minutes in vacuum at $950 \mathrm{~K}$ (just above the maximum of the first crystallization peak) prior to ion bombardment. The structure in Figure I-28(a) is typical of the specimen beyond the ion-damage layer and consists of a mixture of NiNb crystallites and somewhat more amorphous material than in the specimen annealed at $973 \mathrm{~K}$ [Figure I-27(a)]. In Figure I-28(b), the microstructure after irradiation at $900 \mathrm{~K}$ is shown at a depth of $\sim 1.0 \mathrm{\mu m}$, which is in the tail of the damage region. The dose level is uncertain but is probably less than a few dpa. The structure is predominantly amorphous in nature but some residual crystallites are present that have not been converted to amorphous material. This observation would suggest that conversion of the NiNb crystalline phase to amorphous material occurs at a relatively low level of irradiation. The complete reconversion to glass, produced by irradiation at both $900 \mathrm{~K}$ and room temperature, extended from the surface to a depth of $0.8-0.9 \mathrm{rm}$.

A final set of specimens was annealed 10 minutes in vacuum at $\approx 930 \mathrm{~K}$, which is at the low-temperature end of the first crystallization peak. Figure I-29(a) shows the microstructure that is typical of the structure outside the ion-damage region. The microstructure is composed of a mixture of large grains ( $\sim 1000 \AA$ ), a high density of smaller (100-300 $\AA$ diameter) grains, and amorphous material. As a result of the low temperature of annealing, this specimen has substantially fewer large grains and more amorphous material than the previous two examples. The crystalline material again appears to be the NiNb phase. Figure $I-29(b)$ is a dark-field image of the microstructure at a depth of $\sim 1.2 \mathrm{\mu m}$, which shows a number of microcrystallites or phase-se arated regions of 30-100 $\AA$ diameter. The dose level here is roughly $1 \mathrm{dpa}$ and represents an early stage in the vitrification of this partially crystalline material. A completely amorphous layer began at the surface and extended to a depth of $0.8-0.9 \mu \mathrm{m}$ in the irradiated specimen. 


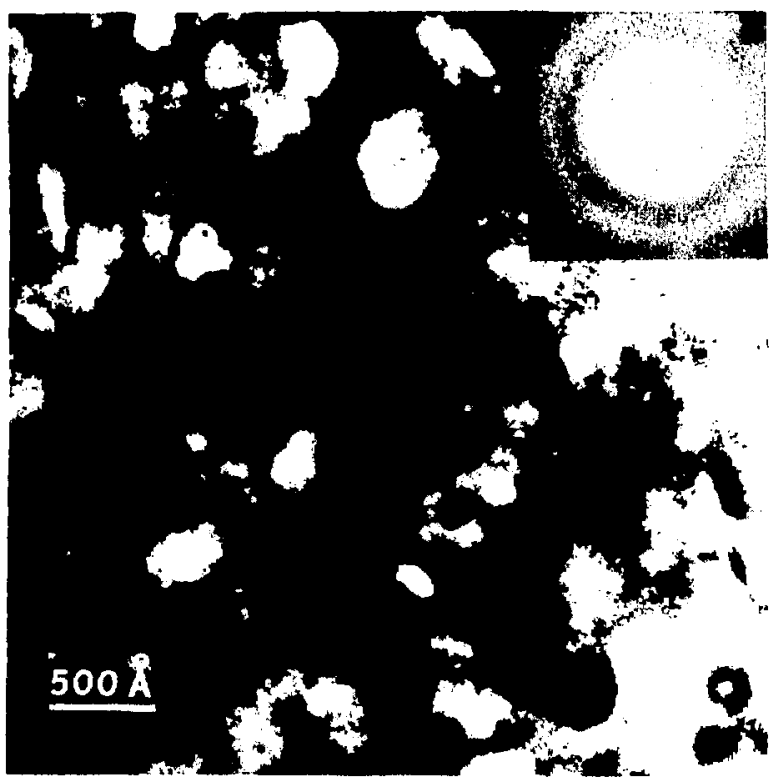

(a)

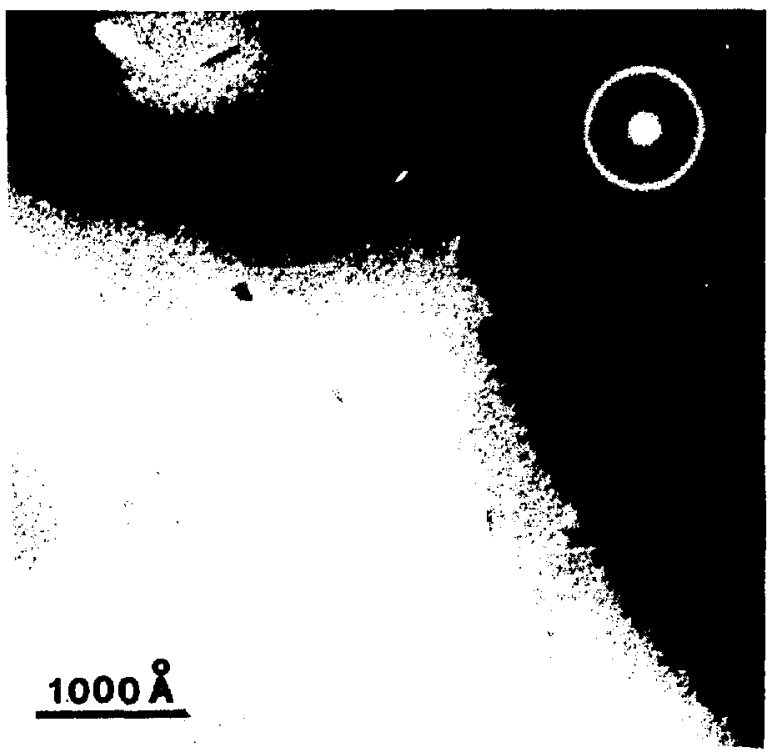

(b)

Figure I-28. (a) Specimen preannealed to $950 \mathrm{~K}$ for 10 minutes in vacuum and (b) microstructure after irradiation to $20 \mathrm{dpa}$ at $900 \mathrm{~K}$ but for a depth near the tail of the ion-damage curve at $\sim 2$ dpa. 


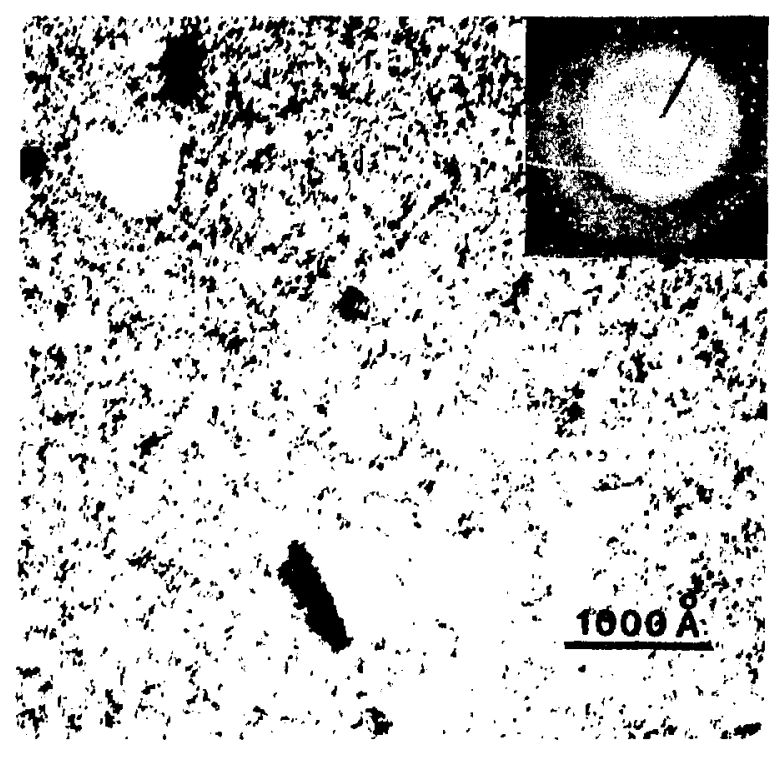

(a)

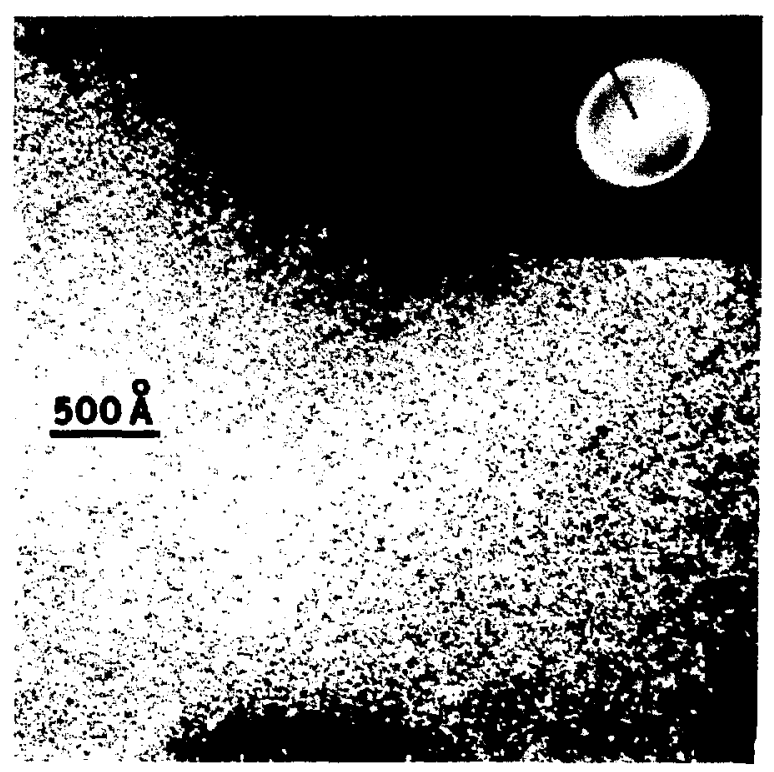

(b)

Figure I-29. (a) Specimen preannealed at $930 \mathrm{~K}$ for 10 minutes in vacuum and (b) dark-field micrograph of the structure after irradiation to $20 \mathrm{dpa}$ at $900 \mathrm{~K}$ but for section depth at the tail of the damage curve at $\sim 1 \mathrm{dpa}$. 
The refractory-transition metal glasses may show a high resistance to displacement-type radiation damage. No resolvable crystallization, phase separation, or void formation is observed at the 20 -dpa level for irradiation at room temperature and $900 \mathrm{~K}$. Furthermore, we have shown that the stable $\mathrm{NiNb}$ crystalline phase, embedded in an amorphous matrix, may be converted to the glassy state by cascade-type ion bombardment with no evidence of microstructural features attributable to accumulation of radiation-induced defects. The level of radiation damage at which the crystalline material transforms completely to amorphous material appears to be quite low, perhaps a dose as small as 1-2 dpa. These results suggest that this class of metallic glass should be investigated thoroughly as a prospective material for highflux radiation environments. 


\section{EXPERIMENTAL POWER REACTOR}

A. First-Wall/Limiter Design

D. L. Smith, J. Krazinski and H. Stevens, Fusion Power Program

The focus of the present study is the integrated design of a first-wall/ liniter system for a tokamak Experimental Power Reactor (EPR). The deposition of high heat fluxes on the plasma-side surfaces of the first-wall system produces severe cyclic thermal stresses that can affect the integrity of first-wall components. For a reactor without a divertor, this surface heat flux is equivalent to $\sim 25 \%$ of the neutron wall loading. About $40 \%$ of the surface heat flux ( $10 \%$ of the neutron wall load) is in the form of electromagnetic radiation, with the remaining $60 \%$ ( $15 \%$ of the neutron wall $10 a d$ ) attributed to ion, neutral, and electron transport.

The present first-wall design concept utilizes multiple radiativelycooled poloidal limiters. Several limiters are used in an attempt to distribute the heat load and thus reduce the energy deposition on each limiter. The maximum number considered, i.e., sixteen, corresponds to the number of toroidal field coils. The limiters are located at the joints of the flat blanket segments as shown in Figure II-1(a). Each limiter, which consists of five sections approximately $2 \mathrm{~m}$ long, conforms to the poloidal contour of the plasma [Figure II-1(b)]. From calculations by Brooks and co-workers, the average radial diffusion distance for plasma particles near the edge of the EPR is $30 \mathrm{~mm}$ per toroidal revolution. Therefore, the spatial distribution of particles striking the limiters is given by $x=30(\mathrm{~mm}) / \mathrm{N}$, where $\mathrm{N}$ is the number of poloidal limiters placed around the torus. For the case of sixteen limiters, the maximum outward diffusion between limiters is about $2 \mathrm{~mm}$. In order to further reduce the energy density on the limiters, the front face is shaped slightly convex to form a low-angle interface with the plasma surface (see Figure II-2).

The thermal responses of the limiters and first-wall in the present design have been calculated for various conditions of interest with the CINDA-3G computer code, which was used previously to calculate the thermal response of tokamak reactor first walls during cyclic plasma burns. 2 In the initial calculations, all of the transport losses from the plasma are assumed to be deposited on the limiters while the radiation losses are distributed uniformly to the liniters and first wall as a function of the exposed surface area. The 80-s power cycle given in reference 2 was used for the present analysis. The thermal energy deposited on the face of the limiter is dissipated by thermal radiation from both the front and back surfaces of the limiter. Figure II-3 shows the calculated thermal response of the plasma-side surface of $1-\mathrm{cm}-t$ hick graphite limiters that effectively cover 5,10 , and $20 \%$ of the total first wall area. The nominal neutron wall loading was $1 \mathrm{MW} / \mathrm{m}^{2}$. Increasing the 1 imiter area from 5 to $20 \%$ decreased

1 J. N. Brooks, personal communication.

2 D. I. Smith and I. Charak, "Thermal Responses of Tokamak Reactor First Walls During Cyclic Plasma Burns," Proc. Seventh IEEE Symposium on Engineering Problems of Fusion Research, Knoxville, Tennessee (October 25-28, 1977). 


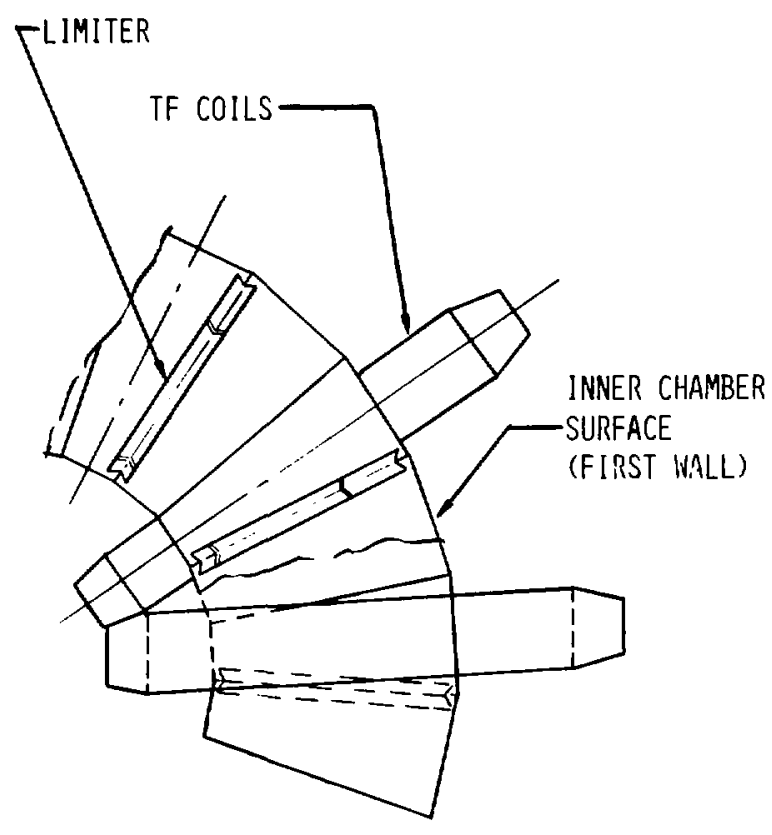

LIMITER ARRANGEMENT (PLAN VIEW)

(A)

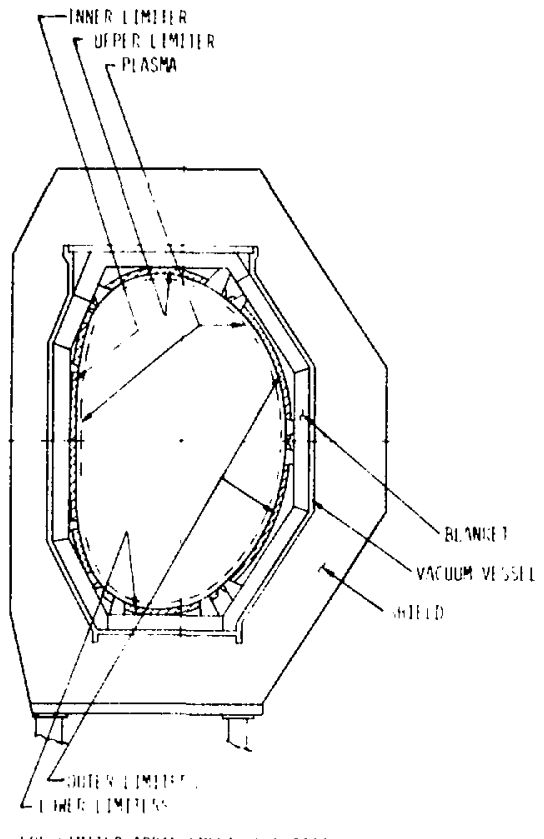

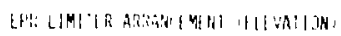

(B)

FIgure II-1. Schematic of EPR LImiters

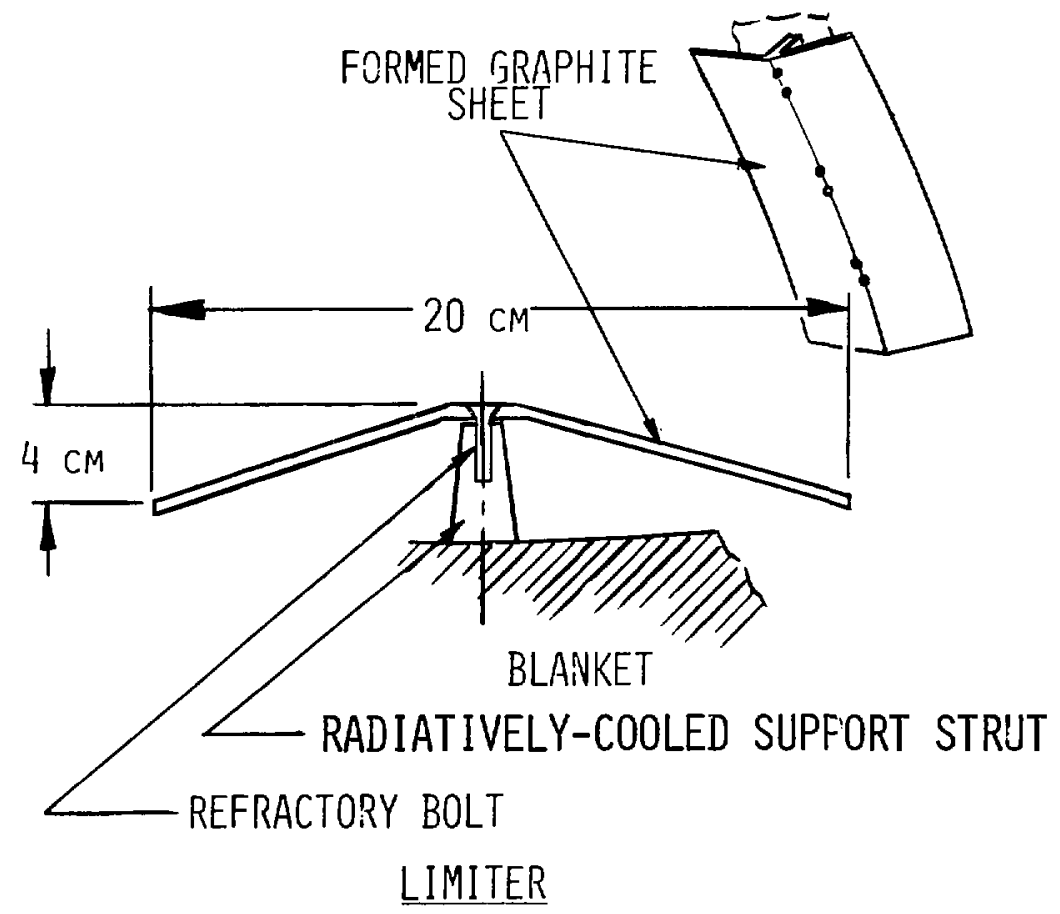

Figure II-2. Detall of IImiter Geometry 


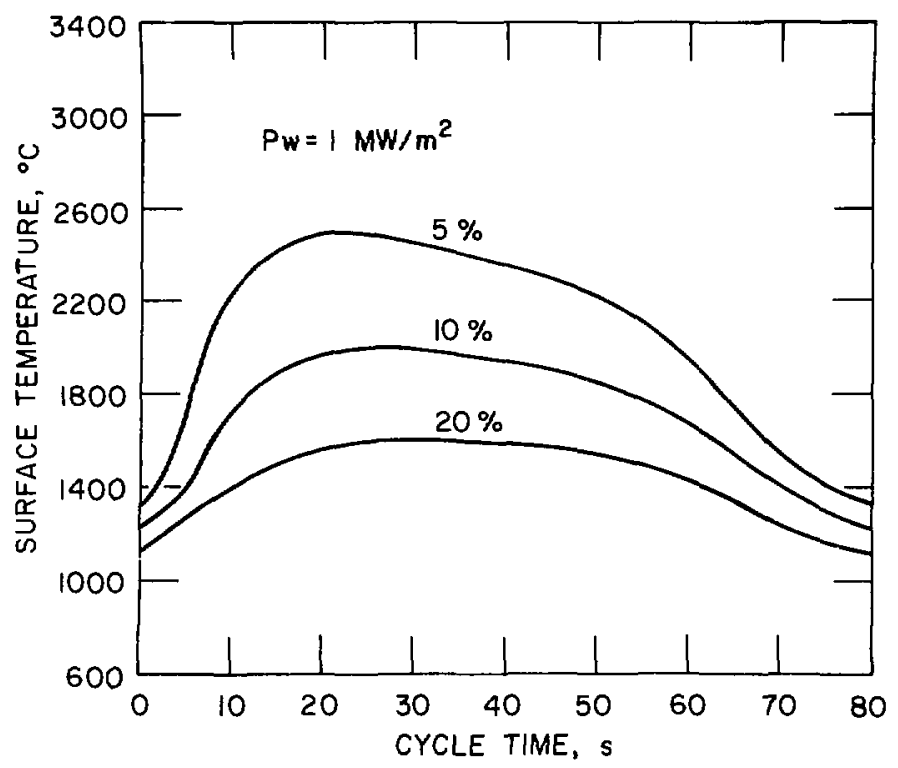

Figure II-3. Calculated Thermal Response of Surface of Graphite Limiters that Cover a Fraction of First-Wall Area.

the maximum limiter temperature from 2500 to $1600^{\circ} \mathrm{C}$ and decreased the cyclic temperature variation from $\Delta \mathrm{T}=1170^{\circ} \mathrm{C}$ to $480^{\circ} \mathrm{C}$. The thermal response of the water-cooled stainless steel first-wall was also calculated. FIgure II-4 shows the surface temperature of the stainless steel wall with and without the graphite limiters. The surface heat flux to the metal wall includes both the electromagnetic radiation from the plasma and the thermal radiation from the graphite limiter. The larger limiters ( $10 \%$ of wall area) decrease the maximum metal temperature from $400^{\circ} \mathrm{C}$ for no limiter to $384^{\circ} \mathrm{C}$ while the cyclic temperature variation of the steel wall is decreased from $\Delta \mathrm{T}=79^{\circ} \mathrm{C}$ for no limiter to $\Delta \mathrm{T}=47^{\circ} \mathrm{C}$ with the 1 -cm-thick graphite limiters that cover $10 \%$ of the wall.

When compared with the bare metal wall analyzed previously, ${ }^{2}$ the multiple limiter concept tends to reduce the magnitude of the cyclic thermal load on the stainless steel first wall. Since the 1 imiter can radiate off the front surface as well as the back, the maximum temperature of the liniter is about the same as that calculated for the graphite liner concept. 2 It should be much easier to Install, position, and replace the limiters than the larger liner slabs. 


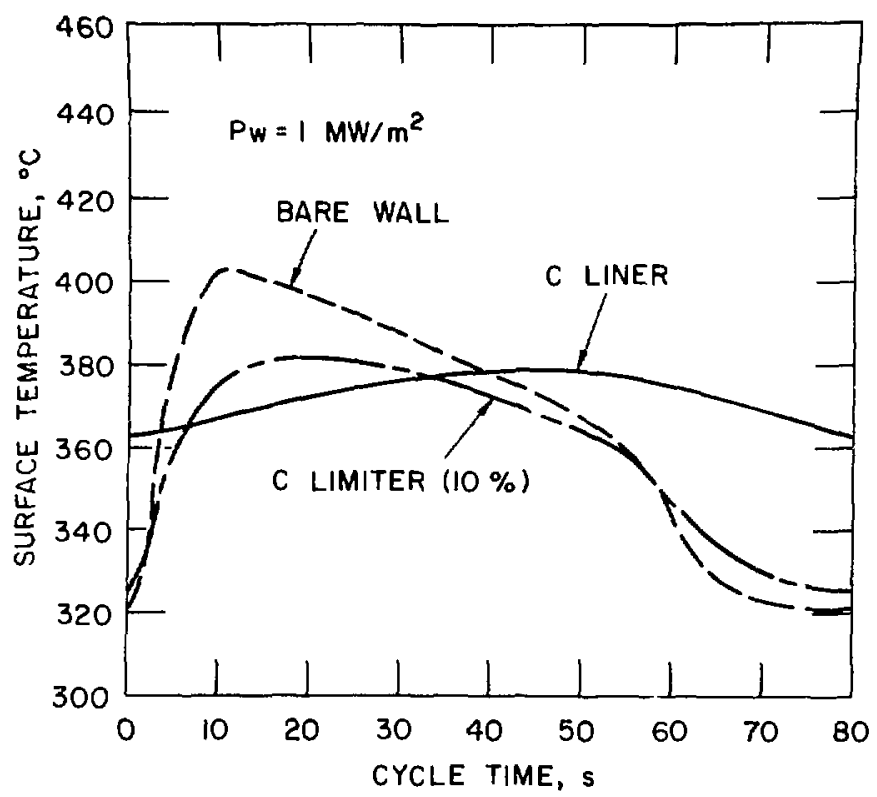

Figure II-4. Calculated Thermal Response of Stainless Steel First Wall With and Without 1-cm Thick Graphite Limiter.

\section{B. Impurity Control}

J. N. Brooks, Applied Physics Division

The plasma engineering analysis of two types of novel impurity control schemes mentioned in the last quarterly report have been completed. These are a helium retention wall, and a limiter-based system. Both types seem simple compared to divertors. In both cases, with what seems to be fairly modest requirements, the burn time of an EPR can be extended from about 1 min to a time limited only by volt-second limitations. For the helium retention wal1, a value of $R_{\alpha}=0.85$, or $15 \%$ retention, is needed to achieve the longburn condition. Such a value seems achievable, over an 30-min typical burn time, by pumping helium from the wall during the off cycle, according to preliminary estimates by Dale Smith of the Materials Science Division. Further reductions in $R_{\alpha}$ improve the power performance somewhat; this is useful but not essential.

The limiter-based system can be operated in several ways. If no pumping is used, some helium retention is probably needed along with about a $20 \%$ value for the reflected flux directed to the wall. If pumping is used, then the power performance can be made essentially equal to that obtainable with 
a divertor, or any other means. Pumping and refueling requirements would be no worse, and in some cases better, than a divertor. It remains to be seen whether a limiter system can be designed to take the high heat load from the plasma. A tradeoff between power performance, ease of cooling, pumping and refueling requirements will probably be necessary, for this or any other system.

In terms of the application of these techniques, either one could potentially be used for an EPR in order to demonstrate a burn time equal to that needed for a commercial plant. A hybrid reactor, where power production is not critical but duty factor may be, might use either one of these techniques to obtain a long burn. For a commercial, power-producing reactor, the limiter based system used with pumping seems to offer the best potential of long burn and high output power.

\section{Control of Thermal Instabilities}

Several types of control measures have been examined as candidates for the control of thermal instabilities in a tokamak reactor. These are: DT density control, (2) high-Z impurity control, particularly Ar, (3) energy confinement time control, and (4) control by ejection of $\alpha$ particles. 3 These control measures have been examined, in burn cycle simulations, for both trapped ion mode scaling (TIM) (particles and energy), and trapped electron mode (TEM) (electron energy and particles) and neoclassical (NC) (ion energy) scaling. In general, the control problem seems to be a difficult one, no one control method works perfectly under all circumstances except for $\tau_{E}$ control which has yet to be demonstrated experimentally. It has been found that DT density control works well for TIM scaling but not for TEM-NC scaiing. Argon injection looks feasible if there is little or no wall recycling of Ar, but is bad otherwise. Alpha ejection control works well only if the plasma is within about $30 \%$ of being in equilibrium, otherwise the amount of $\alpha$ 's to be ejected would be too great.

3 D. L. Jassby, "Thermal Stabilization by Controlled Ejection of Fusion Alpha Particles," Trans. Am. Nuc1. Soc. 24 (1976).

C. Model Equilibrium Field Coil System

K. Evans, Jr., Applied Physics Division

Work has recently been completed on a generalized equilibrium field coil model for tokamak reactors, and the EF coils for a large variety of reactor configurations and plasma parameters have been investigated. In particular, the sensitivity of the EF coil system to reactor size, toroidal field, aspect ratio, plasma shape, plasma $\beta$, number of coils, and distance of the coils from the plasma has been examined.

The model consists of $\mathrm{N}$ coil pairs (one up and one down) equally spaced around the TF coils and a distance, $\Delta$, from them (see Figure II-5). The TF coils are assumed to be constant tension, and their shape is calculated 


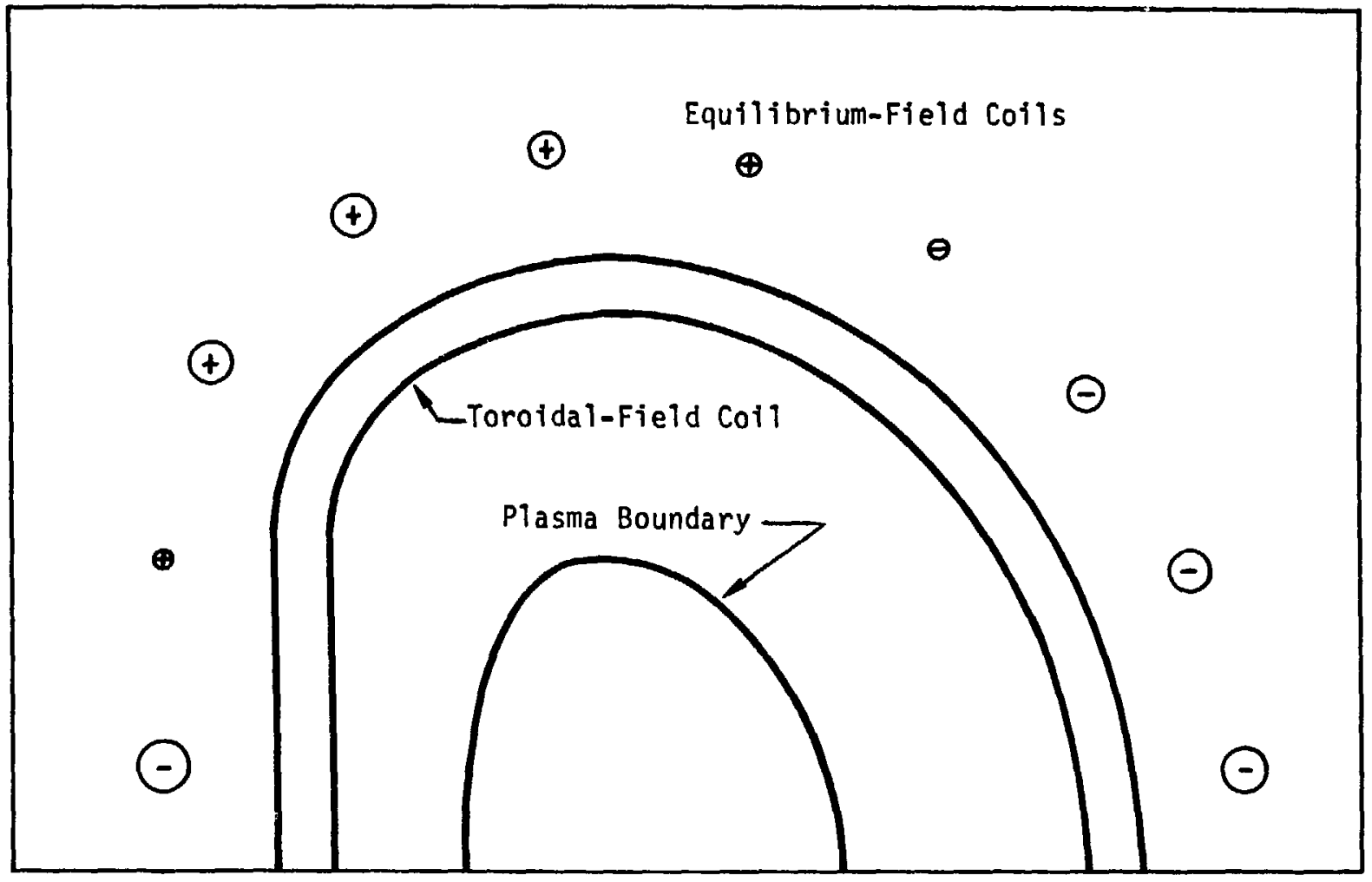

Figure II-5. Equilibrium-field coll model for a 6-m major radius reactor with $9 \mathrm{~T}$ toroldal colls for a somewhat elongated D-shaped plasma with toroidal beta of $8 \%$, plasma current of $9.8 \mathrm{MA}$ and aspect ratio of 3.5 . $(\mathrm{N}=$ 10 and $A=1 \mathrm{~m}_{.}$) 
by the approximate method of Moses and Young. ${ }^{4,5}$ The current in the coils is determined by a simultaneous least squares $f$ it to the desired external field inside the plasma and a minimization of the stored energy in the EF system.6, The desired field, which is calculated numerically by fixed boundary MHD calculations for a given plasma boundary and plasma parameters, 8 is required to be matched by the coil system with an average relative error of $0.4 \%$. The size of the EF colls is adjusted by iteration to achieve a given current density in the coils.

It has been found that there are problems in making an EF coil configura tion for highly D-shaped plasmas. (Highly D-shaped plasmas appear to have higher critical $\beta$ values and hence are desirable for reactor performance.) In addition there are difficulties with the EF system for high toroidal field $\operatorname{smal1}\left(R_{0}<6 \mathrm{~m}\right)$ reactors.

The stored energy in the EF system using this model has been found to be fit to within $20 \%$ by the following formula:

$$
u(G J)=1.3 \times 10^{-4} F(k, d) A^{-1} \exp [0.53 \Delta(m)]\left[R_{0}(m)\right]^{2.2}\left[B_{\max }^{T F C}(T)\right]^{2.8} .
$$

The form factor $F(\kappa, d)$ is highly model dependent and is unity for $k=1.65$ an $d=0.25$. (The plasma cross section is given by $R=R_{0}+a \cos (\theta+d \sin \theta)$ and $\left.Z=\kappa \cos \theta_{\bullet}\right)$ For this $E F \operatorname{coil} \operatorname{model} F(k, d)$ is well fit by

$$
\begin{aligned}
F(\kappa, d) & =1.9-2.5 \kappa+1.4 \kappa^{2}+\left(11.7-20.0 \kappa+7.0 \kappa^{2}\right) d \\
& +\left(17.1+1.4 \kappa-4.0 \kappa^{2}\right) d^{2} .
\end{aligned}
$$

Since a realistic reactor may not have $E F$ coils in the central region inboard of the TF coils, and since the more highly D-shaped plasmas need coils in this region, the form factor $F(k, d)$ should probably increase more rapidly with $d$ than the model indicates. In particular, it was found in reference 7 that an EF design for $d=0.5$ and $k=1.65$ could not be produced.

4 R. W. Moses, Jr. and W. C. Young, "Analytic Expressions for Magnetic Forces on Sectored Toroidal Coils," Proc. of the 6th Symposium on Engineering Problems of Fusion Research (1975) pp. 917-921.

5

L. R. Turner and M. A. Abdou, "Computational Model for Supercondureting Toroidal-Field Magnets for a Tokamak Reactor," Argonne National Laboratory, ANL/FPP/TM-88 (1977).

6

A. M. M. Todd, "Calculation of Coil Currents to Produce a Given Vacuum Poloidal Field," Princeton Plasma Physics Laboratory, PPPL-TM-300 (1977).

7

J. Brooks, K. Evans, Jr., H. Stevens and L. Turner, "The Equilibrium Field Coil Design for the Argonne EPR Design," Seventh Symposium on Engineering Problems of Fusion Research, Knoxville, Tennessee (1977).

8

K. Evans, Jr., "High $\beta_{t}$ Equilibria in Tokamaks," Argonne National Laboratory, ANL/FPP/TM-98 (1977); also submitted to Nuclear Fusion. 


\section{FUSION SYSTEMS ENGINEERING}

\section{A. Fusion Reactor Systems Studies}

M. A. Abdou, Applied Physics Division

The work to upgrade and document the systems code for tokamak power plants has continued. A study has been completed to compare the performance and economics of refractory alloys and stainless steel as structural materials in the first wall and blanket. The results of the study are presented in reference 1 . The following is a brief summary of the results.

A reference reactor with the parameters shown in Table III-1 and a primary lithium coolant was chosen for this study. The performance and economics of stainless steel and a vanadium alloy (representative of the refractory alloys) as structural materials were compared by examining two cases. In the first case, stainless steel is employed in the first wall, blanket structure, primary coolant piping and pumping, heat exchangers and the balance of the heat transfer and transport system. In the second case, vanadium is used in the first wall, blanket structure, primary coolant piping and pumps and the intermediate heat exchanger (IHX). In the IHX the materlals are switched so that stainless steel (or any other conventional material) is employed in the balance of the heat transfer and transport system. This scheme is found to be the most promising technique for utilizing the refractory alloys because: (1) the liquid lithium coolant is always in contact only with the refractory alloys. Problems of impurity transport that could arise if "material switching" is made somewhere in the primary coolant piping are avoided; and (2) the intermediate coolant loop, thermal energy storage, steam generator and power loop employ a conventional less expensive material and state-of-the-art technology.

Table III-2 shows the reference parameters for the heat transfer and transport system for the two cases of stainless steel and vanadium. The material plus fabrication cost is assumed to be $30 \$ / \mathrm{kg}$ for stainless steel and $440 \$ / \mathrm{kg}$ for vanadium in the first wall and blanket. The cost of the pumps, piping and IHX for the primary loop in the case of stainless steel was taken from the PLBR cost data (see reference 2). The cost of the vanadium primary loop was assumed to be three times that of the stainless steel loop.

Figure III-1 displays the cost of energy as a function of the total downtime required to replace the first wall and blanket for $L$ in the range 1-6, where $L$ is the ratio of the lifetime of vanadium to that of stainless steel. The results in this figure show that: (1) if the downtime is $\geq 150$ days, a significant saving in the cost of energy can be achieved by using the vanadium

1 M. A. Abdou, et al., "Systems Studies on Technology and Economic Aspects of Tokamak Power Plants," Presented at the Third ANS Topical Meeting on the Technology of Controlled Nuclear Fusion, May 9-11, 1978, Sante Fe, New Mexico.

2

"Prototype Large Breeder Reactor and Target Plant-Phase I: Concept Selection," General Electric Company, NEDM-14117 (1976). 
Thermal Power, MW

4950

Neutron Wall Load, MW/m

Major Radius, $\mathrm{m}^{2}$

Maximum Toroldal Field, T

$B_{t}, \%$

Inner Blanket/Shield Thickness, m

Outer Blanket/Shield Thickness, m

1.3

Table III-2. Reference Parameters for the Heat Transfer and Transport System

\begin{tabular}{lccc|}
\hline $\begin{array}{l}\text { Structural Material in the Blanket } \\
\text { and Primary Loop: }\end{array}$ & $\begin{array}{c}\text { Stainless } \\
\text { Steel }\end{array}$ & $\begin{array}{c}\text { Vanadium } \\
\text { Alloy }\end{array}$ \\
Primary Coolant & Lithium & Lithium \\
Intermediate/cycle & Na/steam & Na/steam \\
Maximum Structure Temperature, ${ }^{\circ} \mathrm{C}$ & 500 & 620 \\
Steam Temperature, ${ }^{\circ} \mathrm{C}$ & 292 & 442 \\
Thermodynamic Efficiency, $\%$ & 30.1 & 34.4 \\
Net Electric Power, MW & 1420 & 1630 \\
Blanket Structure, vol-\% & 10 & 8 \\
No. Coolant Loops & 4 & 4 \\
\hline
\end{tabular}




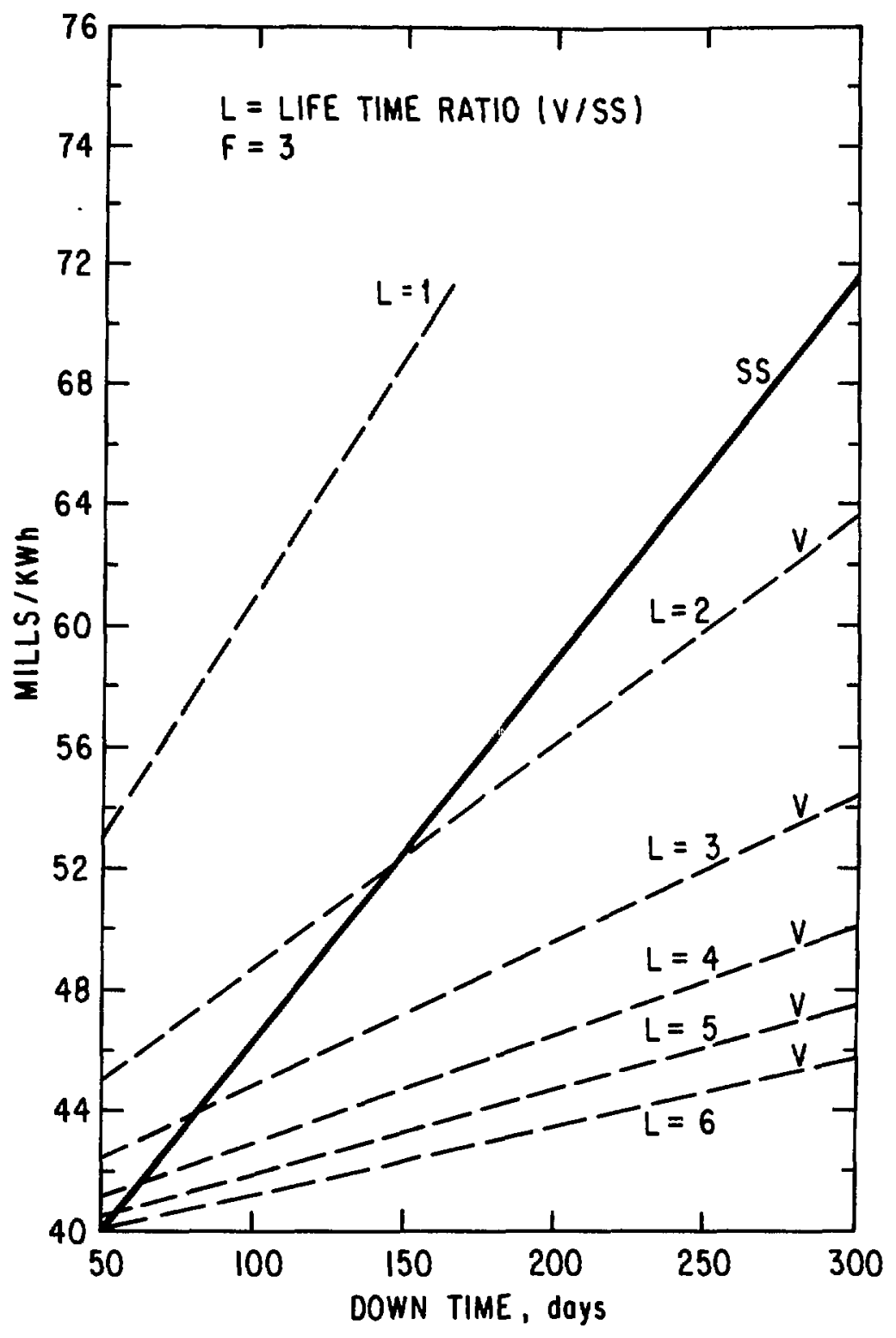

Figure III-1. Dependence of the Cost of Energy on the Downtime for (a) SS structure, and (b) Vanadium structure with lifetime ratio and the range $1-6$. Results are for $F=3$. 
alloy provided that it offers a factor of 2 or more improvement in the lifetime of the first wall and blanket structure compared to stainless steel. (2) For downtime in the range of 100 to 150 days, a factor of 3 advantage in the longevity of the first wall and blanket structure is required in order for the vanadium alloy to offer a marked economic advantage over stainless steel. (3) If the downtime is short, 50 days or less, the economic viability of the vanadium alloy (and similarly all refractory alloys) is not assured as it must offer a factor of 6 or greater better life than stainless steel.

\section{Systems Studies of Fusion Reactor Tritium Facilities}

R. G. Clemmer, Chemical Engineering Division

The computer program TCODE has now been fully integrated into the ANL fusion reactor systems package. A report ${ }^{1}$ describing TCODE is in preparation. Two papers that include descriptions of the tritium systems studies will be presented at upcoming meetings. 2,3 Work on this aspect of the systems studies is now essentially complete for FY-1978.

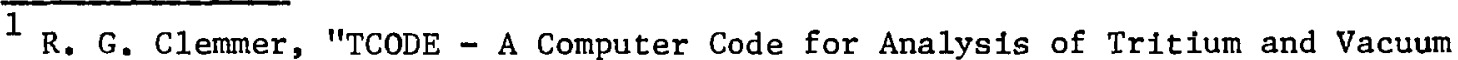
Systems for Tokamak Reactors," Argonne National Laboratory, ANL/FPP/TM-110 (1978).

2 M. A. Abdou, R. G. Clemmer, V. A. Maroni, et a1., "Systems Studies on Technology and Economic Aspects of Tokamak Power Plants," Presented at the Th1rd ANS Topical Meeting on the Technology of Controlled Nuclear Fusion, May 9-11, 1978, Santa Fe, New Mexico.

3 M. A. Abdou, C. C. Baker, R. G. Clemmer, V. A. Maroni, G. Fuller, et al., "Impact of Technology and Maintainability on Economic Aspects of Tokamak Power Plants," to be presented at the Seventh IAEA Conference on Plasma Physics and Controlled Nuclear Fusion Research, August 23-30, 1978, Innsbruck, Austria.

\section{B. Development of Blanket Processing Technology for Fusion Reactors}

The program under way in the Chemical Engineering Division to initiate the development of processing technology for liquid lithium fusion reactor blankets is continuing. Progress during the second quarter of FY-1978 is summarized below.

\section{Lithium Processing Test Loop (LPTL)}

J. R. Weston and V. A. Maron1, Chemical Englneering Division

During the second quarter of FY-1978, the LPTL was brought up to continuous operation and at the time of writing had gone through 2000 consecutive hours of service. A graphical cepresentation of the time-temperature histories for the reservoir tank, getter trap and cold trap is shown in Figure III-2. 


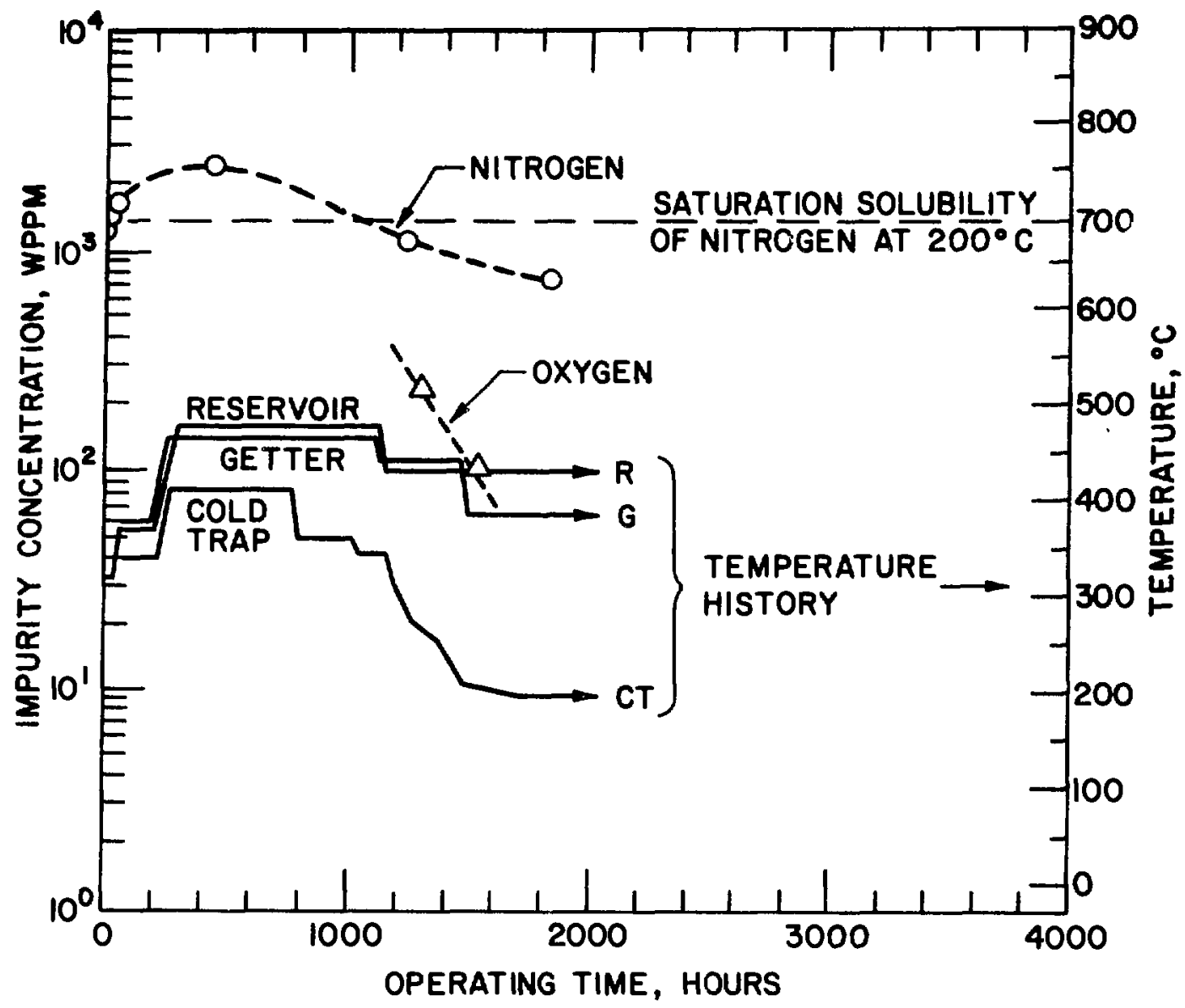

Figure III-2. Time-temperature Histories and Impurity Concentration Profiles for the First 2000 Hours of LPTL Operation.

This graph illustrates the controlled temperature ramp-up during the first 400 hours and the gradual cooldown of the cold trap crystallizer section during the inftial series of cold trap/getter trap tests.

The only problems encountered thus far have been assoclated with the burn-out of heaters on the getter trap and reservoir tank. These burn-outs appear to be occurring due to a flaw in some of the heaters and steps to correct the problem are belng taken with the help of the vendor. Because substantial excess heating capability has been built into the LPTL vessels, these initial burn-outs did not cause a shutdown of the facility. The burnedout heaters will be replaced during a scheduled maintenance perfod in early May, at which tIme we also plan to complete construction of and fill the salt tank.

The results of experimental tests on the LPTL during the second quarter of FY-1978 are summarlzed below: 
Cold Trap Heat Balance Tests: At the request of workers at HEDL who are designing a cold trap for an FMIT support facllity, a serles of tests were conducted to determine the thermal hydraulic performance of the LPTL cold trap (see Figure III-3). As the cold trap is presently instrumented, it is possible to measure lithium flow rate, inlet and outlet lithium temperature, minimum crystallizer temperature and power input to the economizer section as well as the flow rate, inlet temperature and exit temperature of the cooling air. Typical results show that without any heat input to tio economizer and with a lithium flow rate somewhere in the range from 1 to 4 $\mathrm{gPm}$, the 1 ithium temperature is reduced from $420^{\circ} \mathrm{C}$ at the cold trap inlet to $\leq 200^{\circ} \mathrm{C}$ in the crystallizer, but exits the trap at $390^{\circ} \mathrm{C}$ after recirculating through the economizer. Although the balance between the heat lost in the crystallizer and the heat carried off by the cooling air can only be made in round numbers, it does appear that the actual lithium flow rate is greater (possibly 1.7- to 2.0-X) than the empirically calculated flow rate determined For the type of flow meter used on the LPTI. (It will be possible to calibrate the LPTL flow meters more accurately after the salt tank has been brought on line.) On the whole, the LPTL cold trap appears to be adequately designed to achieve minimum cold trap temperatures $\left(\sim 195^{\circ} \mathrm{C}\right)$ at peak loop operating temperatures $\left(\sim 500^{\circ} \mathrm{C}\right)$ for reasonable lithlum flow rates ( 1 to $\left.2 \mathrm{gpm}\right)$.

Impurity Control Tests: The results of oxygen and nitrogen sampling studies carried out during the first 2000 hours of LPTL operation are shown in Figure III-2. Nitrogen rose to a level of $~ 2500$ wppm during the first 500 hours, but has since shown a steady decline to something less than 700 wppm, which is well below the saturation solubility of nitrogen ${ }^{1}$ at a cold trap temperature of $200^{\circ} \mathrm{C}$. It is not clear at this time how much of the apparent nitrogen control is due to the zirconfura-packed getter trap and how much is due to a re-equilibration of nitrogen between the lithium and the chromium in the stainless steel. A series of experiments is being formulated to help resolve this question.

Although the data for oxygen are limited to only two points, the oxygen level also appears to be declining with time. While this decline seems to be correlated with cold trap temperature, the measured oxygen levels are approxImately 10-X higher than the predicted saturation solubility ${ }^{2}$ at the corresponding cold trap temperature. A series of experiments, wherein oxygen samples are taken during controlled ramp-up of the crystallizer temperature, is planned to provide a more definitive test of oxygen level sensitivity to cold trap temperature.

1 R. M. Yonco, E. Veleckis and V. A. Maront, Journal of Nuclear Materials, 57, 317 (1975).

2 R. M. Yonco, V. A. Maroni, J. E. Strain and J. H. DeVan, "A Determination of the Solubility of Lithium Oxide in Liquid Lithlum by Fast Neutron Activation," submitted for publication in the Joumal of Nuclear Materials. 


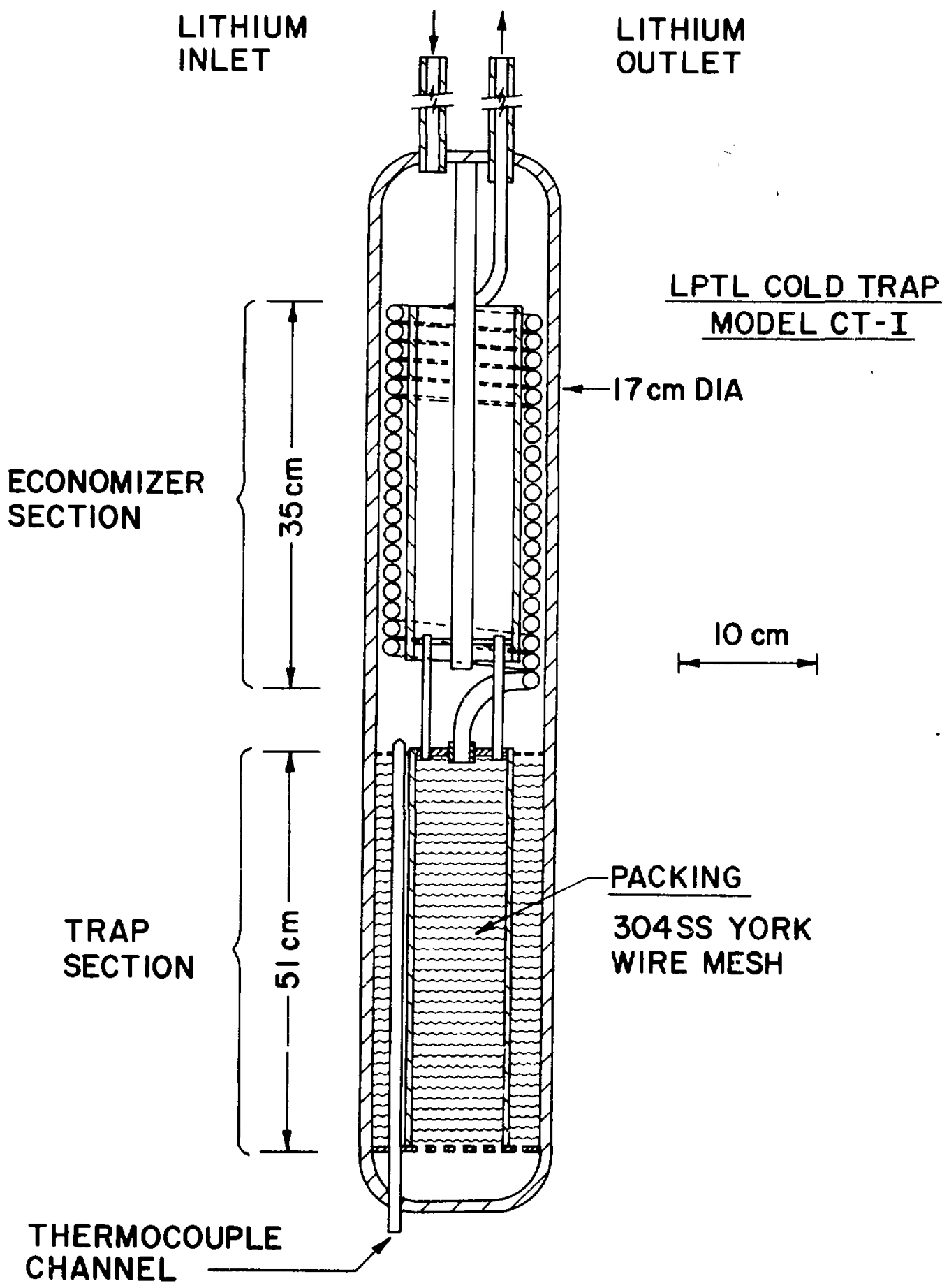

Figure III-3. Dlagram of the LPTL cold trap presently in use. 
Spectrochemical analysis of one lithlum sample from the LPTL showed that the major metallic impurities in the bulk lithium were aluminum (200 wppm), calcium ( $80 \mathrm{wppm})$ and $2 \operatorname{irconium}(200 \mathrm{wppm})$. It is worthy of mention here that all sampling of the LPTL is done from the reservolr tank, using filtertipped samplers of the type described in previous publications, 1,2 These pur. - ications also contain descriptions of the analytical methods currently being employed.

\section{Supporting Studies}

R. M. Yonco, V. A. Maroni and R. W. Peterman*, Chemical Engineering Division

During the second quarter of FY-1978 the lithium mini-test loop (LMTL) was returned to operation after refurbishing of the heating and leak sensing systems. The LMTL (see reference 1 for a description) is currently operating at $500^{\circ} \mathrm{C}$ in the main $100 \mathrm{D}$ and $600^{\circ} \mathrm{C}$ in the zirconium getter tran. Samnling studies aimed at determining nitrogen level sensitivity to getter trap temperature have been initiated. The LMTL is approaching 7000 actual operating hours since its startup in September of 1976.

Work on the development of the control circuits for the LPTL salt tank is now essentially completed. The control system has been successfully tested on the half-scale glass mock-up of the salt tank. Preparation for filming of the mock-up in operation and for tests of stirring profiles is underway. Bromobenzene containing dissolved fodine (to provide a pink color for contrast) and benzoic acid is used to simulate the salt phase. An $\sim 10^{-3}$ normal aqueous solution of $\mathrm{NaOH}$ is used to simulate the lithium phase. After introduction of the aqueous base to the bromobenzene solution the titration reaction between $\mathrm{NaOH}$ and the benzoic acid is followed using bromcresol purple as an indicator. The effects of stirring speed and stirrer shape can be studied by timing the blue to yellow color change in the aqueous phase. These tests are expected to provide insights concerning stirrer configuration, location and speed that may be useful in selecting parameters for the LPTL salt tank stirring system.

* Undergraduate Cooperative Student from Northwestern University.

1 W. M. Stacey, Jr., et al., "Fusion Power Program Quarterly Progress Report: July-September, 1976," Argonne National Laboratory, ANL/CTR-76-5 (January, 1977).

\section{Safety Studies of Fusion Concepts}

\section{Analysis of Tritium Soaking iechanisms}

R. G. Clemmer, R. H. Land and V. A. Marcini, Chemical Engineering Division

The new Overhoff tritium monitor originally scheduled for delivery in early February has just been received. Check out of this monitor is in progress and the experimental studies described in the preceding quarterly progress 
report $^{1}$ are about to get underway. Several modifications have been made to the bench-scale alr detritiation apparatus to provide greater flexibility in testing oxidizer beds and molsture traps and to accommodate the new tritium monitor.

A number of major improvements have been made in the computer code TSOAK. ${ }^{2}$ This program, which calculates the effects of tritiated water formation/adsorption/release mechanisms on air detritiation operations, now has the capability to track actual experimental data (from our test chamber and others) over the entire time span of a tritium cleanup operation. The problem of plateauing of the cleanup curve near the end of a simulated cleanup operation, described in the previous report, ${ }^{1}$ has been resolved. Figures III-4 and III-5 show the results of an attempt to fit a previously measured cleanup curve obtained for a controlled $\mathrm{T}_{2}$ release to our small test chamber. ${ }^{2}$ The dashed curve in Figure III-4 represents an exact $f_{1 t}$ to the actual data, while the solid curve in Figure III-4 delineates the ideal cleanup curve expected in the absence of HTO adsorption and release effects. The dotted curve in Figure III-4 tracks the amount of tritium soaked into the test chamber surfaces as

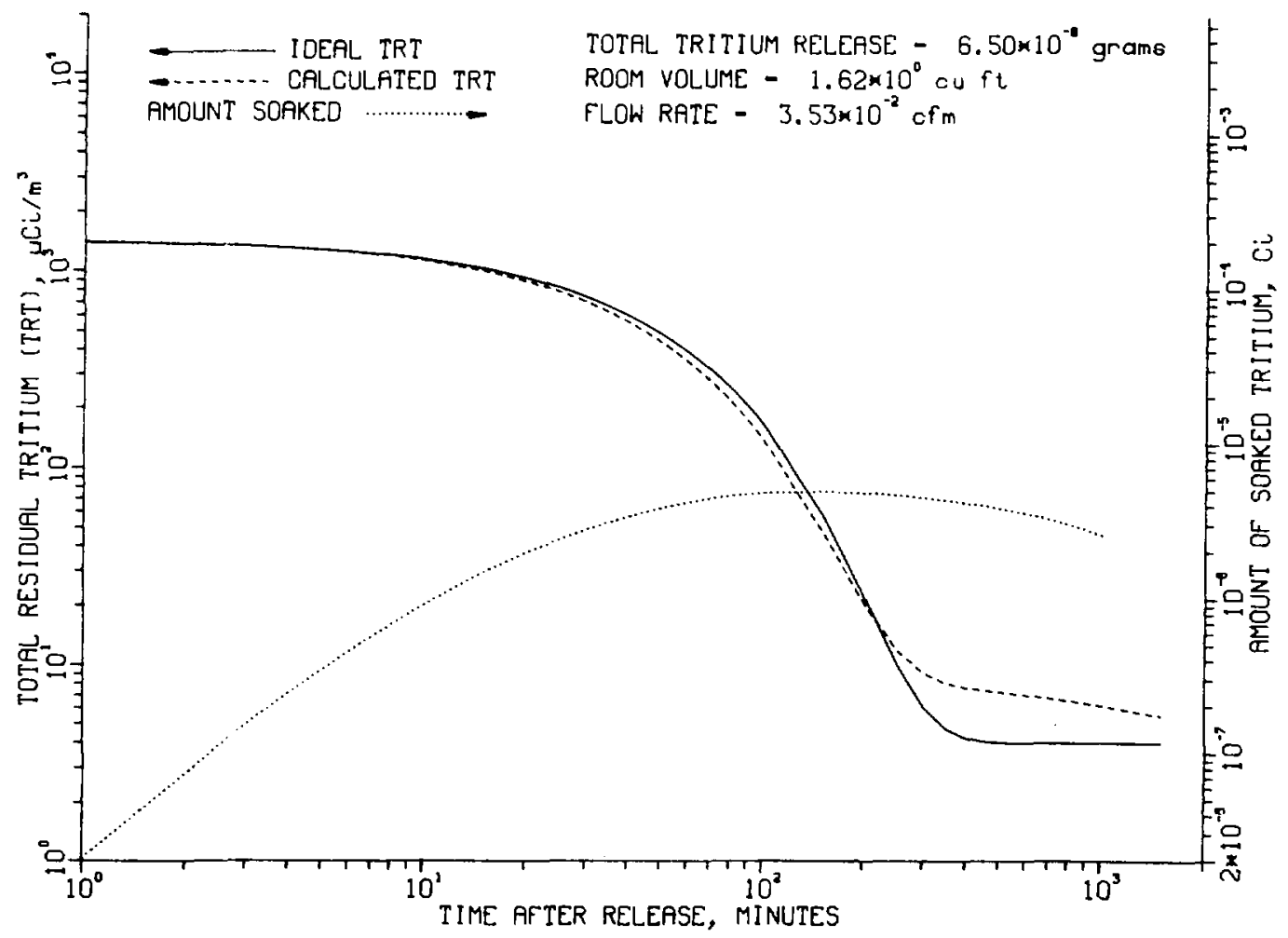

F:gure III-4. Air Detritiation Curves for a Typical Cleanup Operation Using the Bench-Scale Test Chamber. The dashed curve exactly matches the observed experimental curve. 


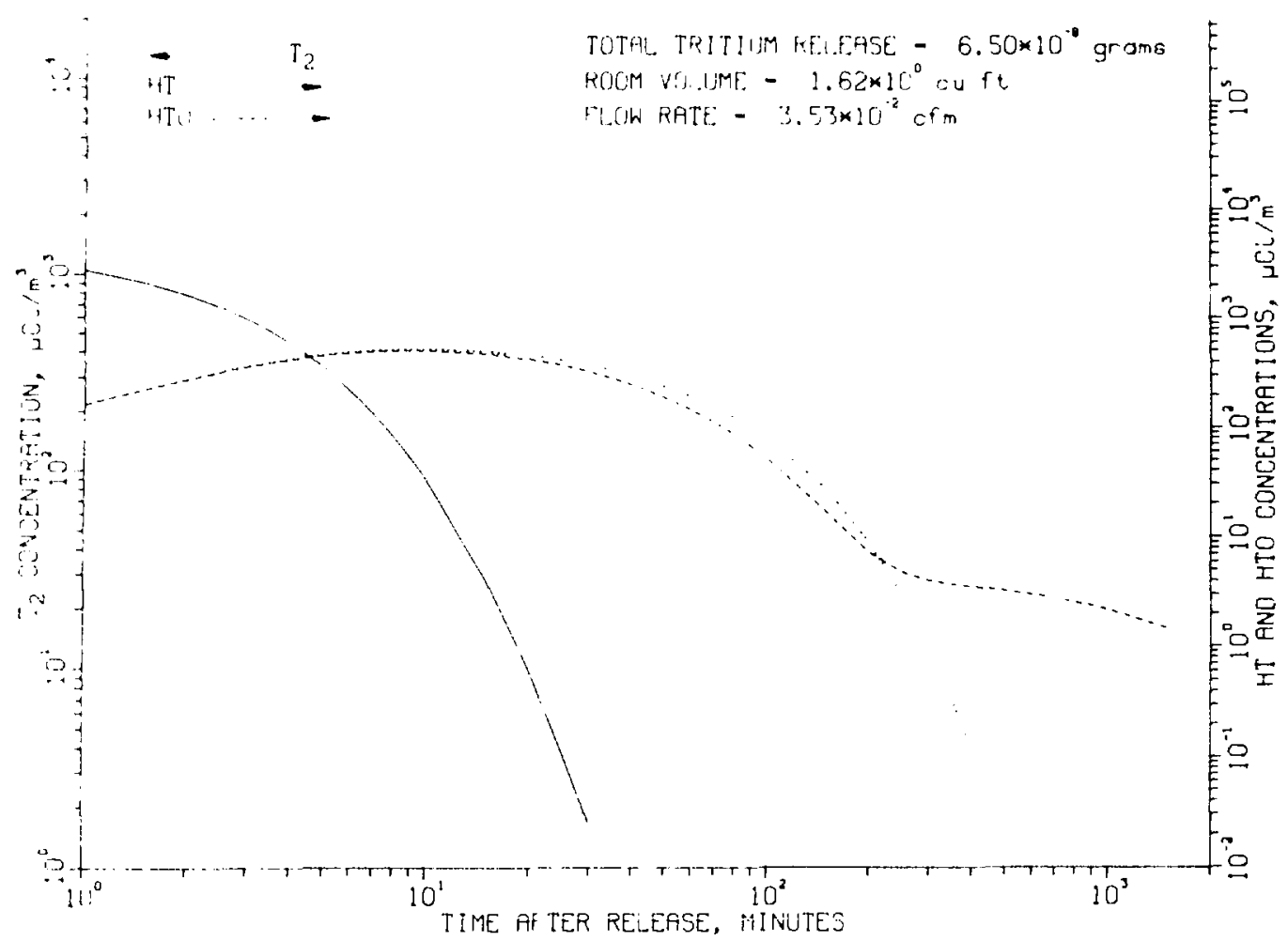

Figure III-5. Calculated Species Concentrations with Time for the Cleanup Curves in Figure III-4.

a function of time. Figure III-5 shows the calculated varlations in $T_{2}$, HT and HTO concentrations with time. Although it is not presently within our capabilities to measure (to any degree of accuracy) the $\mathrm{T}_{2}$, HT and HTO concentrations and the amount of soaked tritium (Figure III-4), the results in Figures III-4 and III-5 (particularly the relative concentrations of HTO and $\mathrm{HT}+\mathrm{T}_{2}$ near the end of the cleanup operation) are generally consistent with other experimental observations described in previous reports (see reference 2).

1 C. C. Baker, et al., "Fusion Power Program Quarterly Progress Repori, October-December, 1977," Argonne National Laboratory, ANL/FPP-77-7 (i977).

2 R. G. Clemner, R. H. Land, V. A. Maroni and J. M. Mintz, "Simulation of Large Scale Air-Detriation Operations by Computer Modeling and Bench-Scale Experimentation," Argonne National Laboratory, ANL/FPP-77-3 (November, 1977); alsc, published in abridged form in the Proceedings of the Seventh IEEE Symposium on Engineering Problems of Fusion Research, October 25-28, 1977, Knoxville, Tennessee; IEEE Publication No. 77CH1267-4-NPS (1977). 
D. MACKIIB-IV, A New Library of Nuclear Response Functions

Y. Gohar and M. A. Abdou, Applied Physics Division

A new library, MACKLIB-IV, of processed nuclear data for neutronics analysis of nuclear systems has been generated. The library was prepared using the new version of the MACK code, MACK-IV, 1 and nuclear data from ENDF/B-IV. The library includes all nuclear response functions for all materials presently of interest in fusion and fusion-fission hybrid applications. The new 1 ibrary ${ }^{2}$ is a significant upgrade from the earlier version, MACKIIB. 3

MACKLIB-IV employs the CTR energy group structure 4 of 171 neutron groups and 36 gamma groups. A retrieval computer program is included with the $1 i-$ brary to permit collapsing into any other energy group structure. The library is in the new format of the "MACK-Activity Table" that uses a fixed position for each specific response function. This permits the user, when employing the library with present transport codes, to obtain directly the nuclear responses (e.g. the total nuclear heating) summed for all isotopes and integrated over any geometrical volume. The response functions included in the library are neutron kerma factor, gamma kerma factor, gas production and tritium breeding functions, and all important reaction cross sections.

One of the significant improvements in MACK-IV is the provision for two different calculational techniques for neutron kerma factors: (a) the nuclear kinematics path that utilizes only the neutron data $f 1 l$ es in ENDF/B; and $(b)$ the gamma production path that employs the gamma production files as well as the neutron files. The ENDF/B-IV evaluations were reviewed for each material and an appropriate calculational technique was selerted to ensure the relative validity of the results.

As an example, the neutron kerma factor, $k_{n}$, for beryllium is plotted in Figure III-6 for three cases: (1) $k_{n}$ based on ENDF/B-III data using the nuclear kinematics path; (2) $k_{n}$ based on ENDF/B-IV data calculated with the nuclear kinematics path; and (3) $k_{n}$ based on ENDF/B-IV data using the gamma production path. Comparing ( 1 ) and (2), one notes that the changes in the basic data from Version III to Version IV is very small. The neutron kerma factor calculated in Case 2 is higher than that in Case 3 at high energies ( $>10 \mathrm{MeV}$ ). The reason is that no information on the individual levels

I M. A. Abdou, Y. Gohar and R. Q. Wright, "MACK-IV, A New Version of MACK: A Program to Calculate Nuclear Response Functions from Data in ENDF/B-IV Format," Argonne National Laboratory, ANL/FPP-77-5 (1978).

2 Y. Gohar and M. Abdou, "MACKLIB-IV, A Multigroup Library of Nuclear Response Functions," ANL/FPP/TM-106 (1978).

3 M. A. Abdou and R. W. Roussin, "MACKLIB: 100-Group Neutron Fluence-to-Kerma Factors and Reaction Cross Sections Generated by the MACK Computer Program from Data in ENDF FORMAT," Oak Ridge National Laboratory, ORNL-TM-3995.

4 R. W. Roussin, et al., "The CTR Processed Multigroup Cross Section Library for Neutronics Studies," Oak Ridge National Laboratory, ORNL/RSIC-37 (1977). 


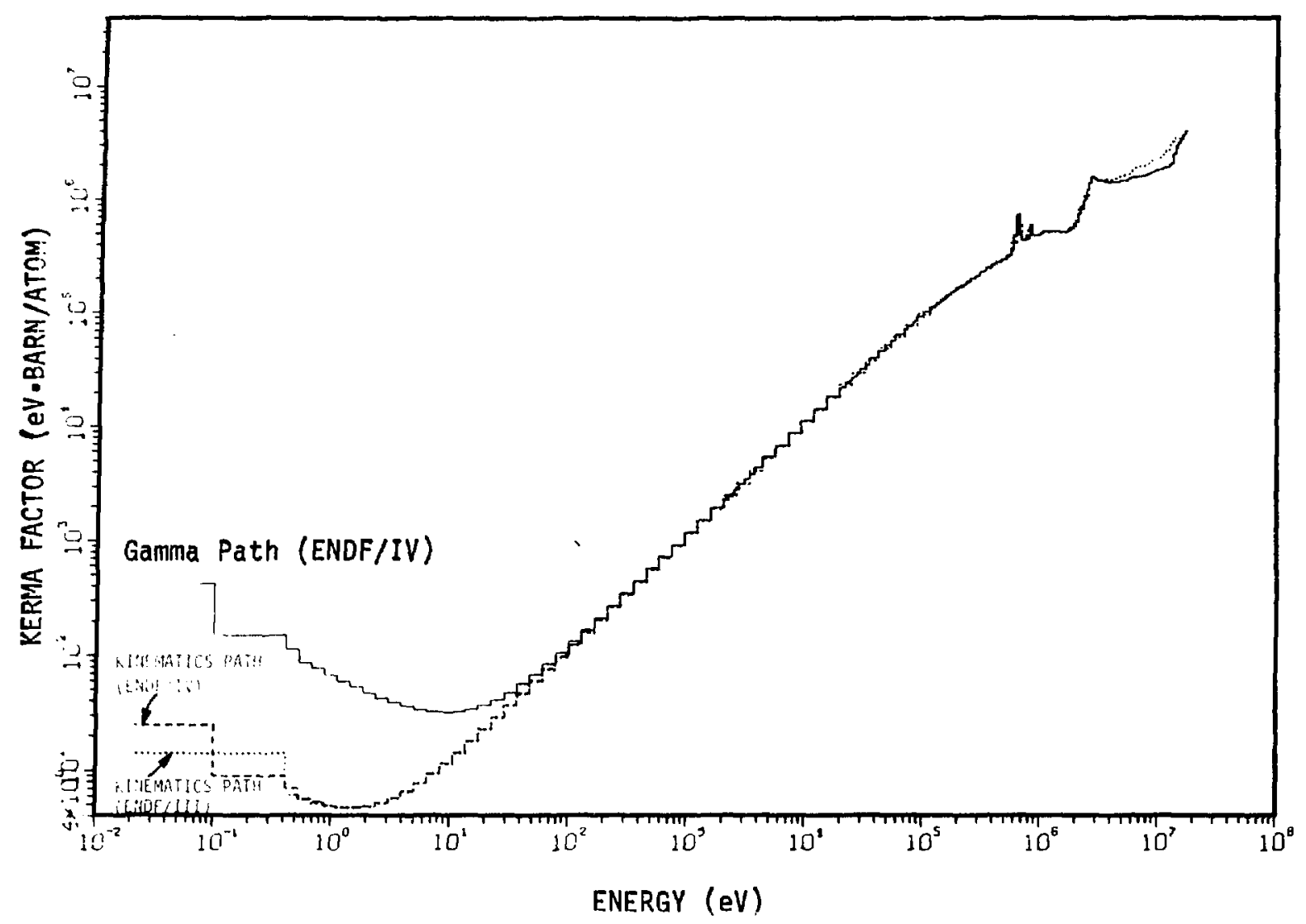

Figure III-6. Neutron Kerma Factor for Beryllium.

(partial level cross sections) are given in the neutron files for the (n, charged particles) reactions. In this case it is clear that the results from Case 3 are more accurate than those of Case 2 and, hence, the kerma factors calculated from the gamma production path are adopted for inclusion in MACKLIB-IV.

The library also includes response functions for fisstonable materials. The neutron kerma factors for $235 \mathrm{U}, 232 \mathrm{Th}$ and $23 \mathrm{~B}_{\mathrm{U}}$ are displayed in Figure III-7. Using the kerma factor methodology for calculation of nuclear heating in nuclear systems with fissionable materials should provide a significant Improvement over the approximate methods commonly used at present. Table III-3 compares the neutron kerma factors in MACK-IV ${ }^{3}$ to those in the earlier version of MACKLIB ${ }^{2}$ for several materials. The comparison is shown for selected energy ranges where large differences occur. These differences reflect a combination of effects due to changes in basic nuclear data between Versions III and IV of ENDF/B as well as differences in calculational methods.

The library is useful as a tool for neutronics and photonics analysis in many nuclear systems. 


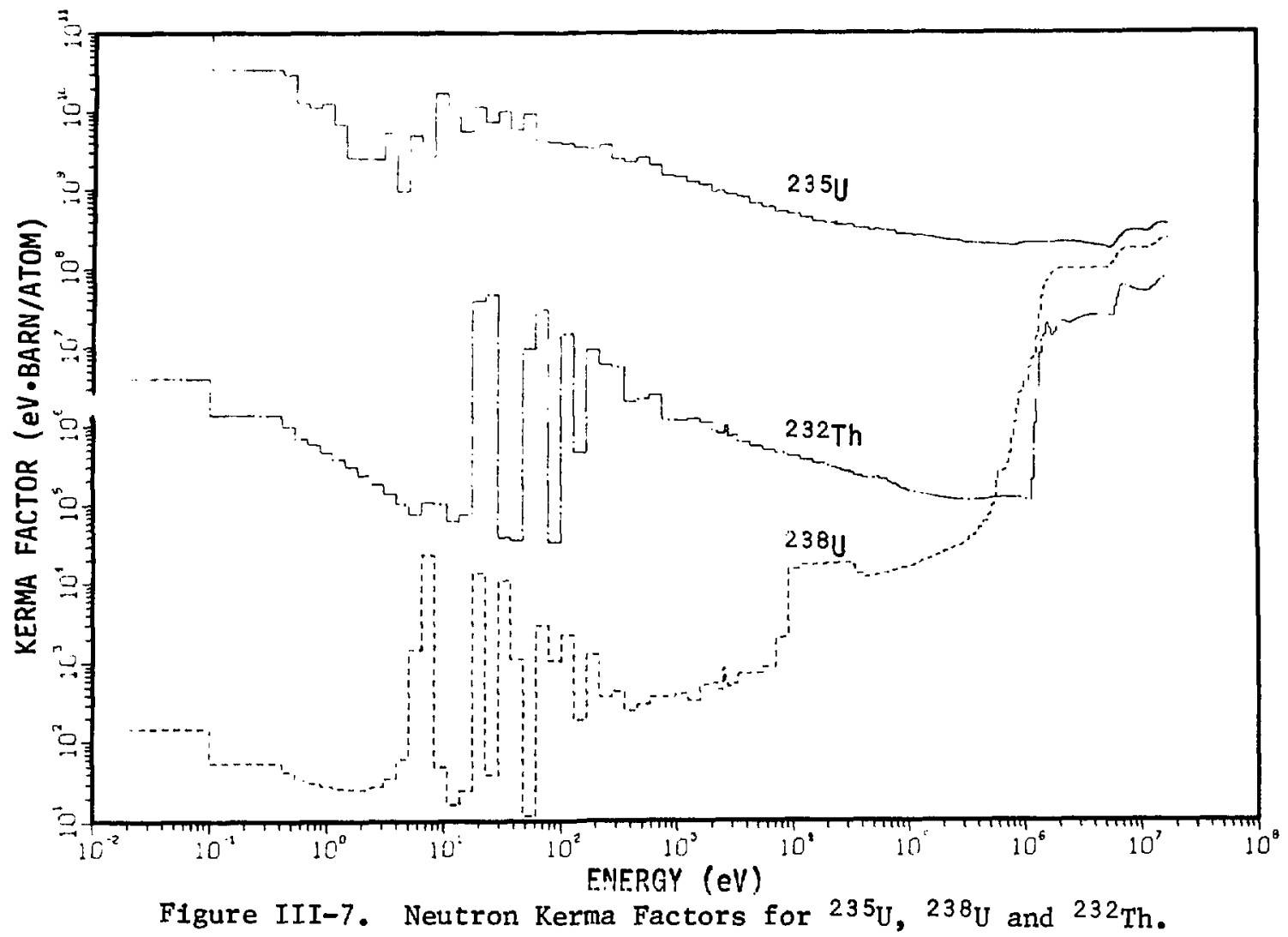

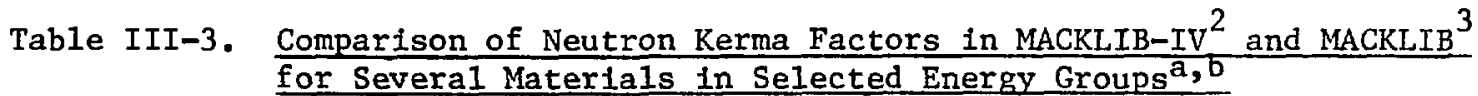

Energy Group (MeV)

\begin{tabular}{|c|c|c|c|c|c|c|}
\hline \multirow[b]{2}{*}{ Mat. } & \multicolumn{2}{|c|}{$13.499-14.918$} & \multicolumn{2}{|c|}{$10.0-11.052$} & \multicolumn{2}{|c|}{$1.0026-1.102$} \\
\hline & MACKLIB/IV & MACKLIB & MACKLIB/IV & MACKLIB & MACKLIB/IV & MACKLIB \\
\hline $\mathrm{Be}$ & 3.018 & 3.473 & 1.848 & 2.738 & 0.516 & 0.521 \\
\hline${ }^{6} \mathrm{Li}$ & 4.901 & 4.400 & 4.760 & 4.154 & 1.684 & 1.782 \\
\hline${ }^{7} \mathrm{LI}$ & 4.185 & 3.313 & 3.785 & 2.952 & 0.408 & 0.416 \\
\hline $10_{B}$ & 6.260 & 3.686 & 5.002 & 3.433 & 1.118 & 1.518 \\
\hline${ }^{12} \mathrm{C}$ & 4.618 & 3.244 & 1.980 & 2.407 & 0.350 & 0.364 \\
\hline $\mathrm{A} 1$ & 6.252 & 4.010 & 2.852 & 2.893 & 0.148 & 0.206 \\
\hline $\mathrm{Nb}$ & 1.207 & 1.045 & 0.764 & 0.792 & 0.082 & 0.093 \\
\hline $\mathrm{Cu}$ & 3.517 & 2.712 & 1.898 & 1.994 & 0.096 & 0.101 \\
\hline $\mathrm{Pb}$ & 0.282 & 0.266 & 0.232 & 0.252 & 0.041 & 0.047 \\
\hline
\end{tabular}

a. All MACKLIB kerma factors are based on ENDF/B-III data but those of MACKLIB-IV are based on ENDF/B-IV.

b. All neutron kerma factors in units of MeV-barn/atom. 
E. Energy Storage and Power Supply Requirements for Comerclal Fusion Reactors

J. N. Brooks, Applied Physics Diviston

Detalled burn cycle studies of the startup and shutdown phases of the reference $7-m$ reactor have been performed in order to define the driving system requirements. For the present, SCR-type voltage sources have been assumed to drive both the $\mathrm{OH}$ and $\mathrm{EF}$ colls. The role of oxygen contamination, startup density level and neutral beam heating power on startup requirements has been examined. In general, it has been found that all of the power supply requirements have been decreased over previous estimates. The role of resistive volt-second losses in the plasma, which formerly dominated the choice of operating point, has been reduced substantially because of the new experimental data and the simulated use of varlous cost-savings techniques. An example of the power supply requirements, for one particular mode of operation (not the optimum), are resistive volt-seconds for startup - $17 \mathrm{v}-\mathrm{s}$ (down from $125 \mathrm{v}-\mathrm{s}$ ); EF maximum power - $1369 \mathrm{MVA}$ (down from $3651 \mathrm{MVA}$ ); and EF stored energy - $20 \mathrm{GJ}$ (down from $4.6 \mathrm{GJ}$ ). The total power supply system cost, exclusive of the neutral beam power supply cost, for this particular case is $\$ 90 \mathrm{M}$, down from about $\$ 167 \mathrm{M}$.

\section{F. Blanket/Shield Design Evaluation for Commercial Fusion Reactors}

\section{Blanket/Shield Design Study}

D. L. Smlth, R. Clemmer, S. D. Harkness, J. Jung, J. Krazinski, H. C. Stevens and C. K. Youngdahl, Fusion Power Program

A study of tokamak reactor first wall/blanket/shield technology has been initiated in cooperation with McDonnell Douglas Astronautics Company (MDAC). The objectives of this program are the identification of key technological limitations for various tritium-breeding-blanket design concepts, establishment of a basis for assessment and comparison of the design features of each concept, and development of optimized blanket designs. The approach being used involves a review of previously proposed blanket designs, analysis of critical technological problems and design features assoclated with each of the blanket concepts, and a detailed evaluation of the most tractable design concepts.

Initial phases of the program involve the evaluation of tritium-breeding blanket concepts according to the proposed coolant. The ANL effort is presently evaluating liquid-lithium-cooled blanket designs while MDAC is evaluating helium-cooled designs. A joint effort has been undertaken to provide a consistent set of materials property data that will be used for analysis of all blanket concepts. The neutronics and tritium processing analyses are being conducted at ANL and the overall systems analyses are being coordinated by MDAC.

A generic 2400 MWt tokamak power reactor with a major radius of $7.0 \mathrm{~m}$, a minor radius of $2.3 \mathrm{~m}$, and a slightly elongated plasma is used for the blanket analyses. Other reactor design parameters are summarized in Table III-4. The 


\section{Table III-4. Basic Machine DesIgn}

\begin{tabular}{|c|c|c|}
\hline $\mathrm{R}$ & Major radius & $7.0 \mathrm{~m}$ \\
\hline $\mathbf{a}$ & Minor radius & $2.33 \mathrm{~m}$ \\
\hline A & Aspect ratio & 3.0 \\
\hline K & Elongation factor & $1.3 \mathrm{~m}$ \\
\hline$\Delta v_{v}$ & Vacuum scrape-off region & $0.2 \mathrm{~m}$ \\
\hline$B_{\max }$ & $\begin{array}{l}\text { Maximum toroidal-field } \\
\text { region }\end{array}$ & $9 \mathrm{~T}$ \\
\hline$v_{p}$ & Plasma volume & $950 \mathrm{~m}^{3}$ \\
\hline$A_{p}$ & Wall area & $729 \mathrm{~m}^{2}$ \\
\hline$\beta_{t}$ & Toroldal beta & 0.07 \\
\hline${ }_{p}^{B}(a)=3$ & $\begin{array}{l}\text { Pololdal beta } \\
q(0)=1\end{array}$ & 1.75 \\
\hline$I_{D}$ & Plasma current & $11.6 \mathrm{MA}$ \\
\hline & Average electron temperature & $8 \mathrm{keV}$ \\
\hline & Average Ion temperature & $7.95 \mathrm{keV}$ \\
\hline & Average Ion density & $1.5 \times 10^{20} \mathrm{~m}^{-3}$ \\
\hline nt & & $3.2 \times 10^{20} \mathrm{~s}-\mathrm{m}^{-3}$ \\
\hline $\bar{n}_{\alpha}$ & $\begin{array}{l}\text { Average alpha particle } \\
\text { density }\end{array}$ & $1.87 \times 10^{18} \mathrm{~m}^{-3}$ \\
\hline $\bar{n}_{e}$ & Average electron density & $1.93 \times 10^{20} \mathrm{~m}^{-3}$ \\
\hline $\mathrm{P}_{\mathrm{T}}$ & Peak thermal power & $2380 \mathrm{MW}$ \\
\hline $\mathrm{PW}_{\mathrm{n}}$ & $\begin{array}{l}\text { Peak average neutron wall } \\
\text { loading }\end{array}$ & $2.41 \mathrm{MW} / \mathrm{m}^{2}$ \\
\hline $\mathrm{PW}_{\mathrm{t}}$ & $\begin{array}{l}\text { Peak average total wall } \\
\text { loading (no divertor) }\end{array}$ & $3.26 \mathrm{MW} / \mathrm{m}^{2}$ \\
\hline$Z_{\text {eff }}$ & & 1.71 \\
\hline Burn time & & 30 minutes \\
\hline Down time & & 1 minute \\
\hline
\end{tabular}


Impact on blanket destgn produced by a nonbreeding tnner blanket and displacement of breeding volume by a divertor are being evaluated parametrically.

The two main aspects of the materlals considerations are the spectfication of the design crfterla and a compllation of materlals property data. The stress criteria are based on elevated temperature design criterla specified by the ASME Botler and Pressure Vessel Code. The structural materials, tritfum breeding materfals, and coolants being constdered are summarized in Table III-5. Each of the five structural alloys 1 isted are constdered as representative of a class of alloys and are not necessarily assumed to be optimum. Results from the complete blanket analysis will indicate which properties of each alloy class are limfting the operating conditions and blanket lifetime.

A nuclear analysis of the tritium-breeding performance has been made for the three breeding systems, viz., liquid 1 ithium, $L 1_{2} \mathrm{O}$, and $\mathrm{L}_{7} \mathrm{~Pb}_{2}$. The analysis focused on three mafor categortes: (1) trend of variation of breeding ratio with breeding zone thickness, (2) effects of a graphite reflector and beryllium neutron multiplier on the breeding ratio, and (3) impact of tritium breeding on the minimum blanket/shield thickness requirements for protection of the toroldal-field colls. Preliminary results for a reference blanket with no reflector or neutron multiplier indicate that the minimum blanket thicknesses required to attain a breeding ratio of unfty are $0.33,0.22$, and $0.10 \mathrm{~m}$ for $L 1, L_{1} O$, and $L 1_{7} \mathrm{~Pb}_{2}$, respectively. Figure III-8 shows the breeding ratios attainable ${ }^{2}$ as a function of blanket thickness for the three breeding materials. Results are shown for three cases, viz., the reference blanket, an $0.20-m$ thick graphite reflector (outside the blanket) and an $0.05-\mathrm{m}$ thick beryllium neutron multiplier behind the first wall. Breeding ratios in excess of 1.4 are attainable with all three breeding materials. These relatively high breeding ratios will be necessary for blanket designs that incorporate a divertor and do not breed in the inner blanket.

The effects of fractional fuel burnup and doubling time on the required breeding ratio have been analyzed. Figure III-9 is a plot of the required breeding ratio as a function of fractional burnup for selected doubling times. For a low fractional burnup of $1 \%$, which is typical of a reactor with a divertor,

Table III-5. Reference Materlals Considered in Blanket Design Study

\begin{tabular}{|c|c|c|c|}
\hline Structura1 & Materials & Breeding Materials & Coolants \\
\hline Fe-Alloy: & $316 \mathrm{SS}$ & Liquid Ifthium & Liquid Lithium \\
\hline Ni-A11oy: & IN 625 & Solid $\mathrm{Li}_{2} \mathrm{O}$ & Helium \\
\hline Ti-Alloy: & $\mathrm{T} 16242$ & Solid $\mathrm{Li}_{7} \mathrm{~Pb}_{2}$ & Water (Steam) \\
\hline V-Alloy: & $\mathrm{V}-15 \mathrm{Cr}-5 \mathrm{~T} i$ & & Liquid Sodium \\
\hline Nb-A11oy: & Fs -85 & & Molten Salt \\
\hline
\end{tabular}




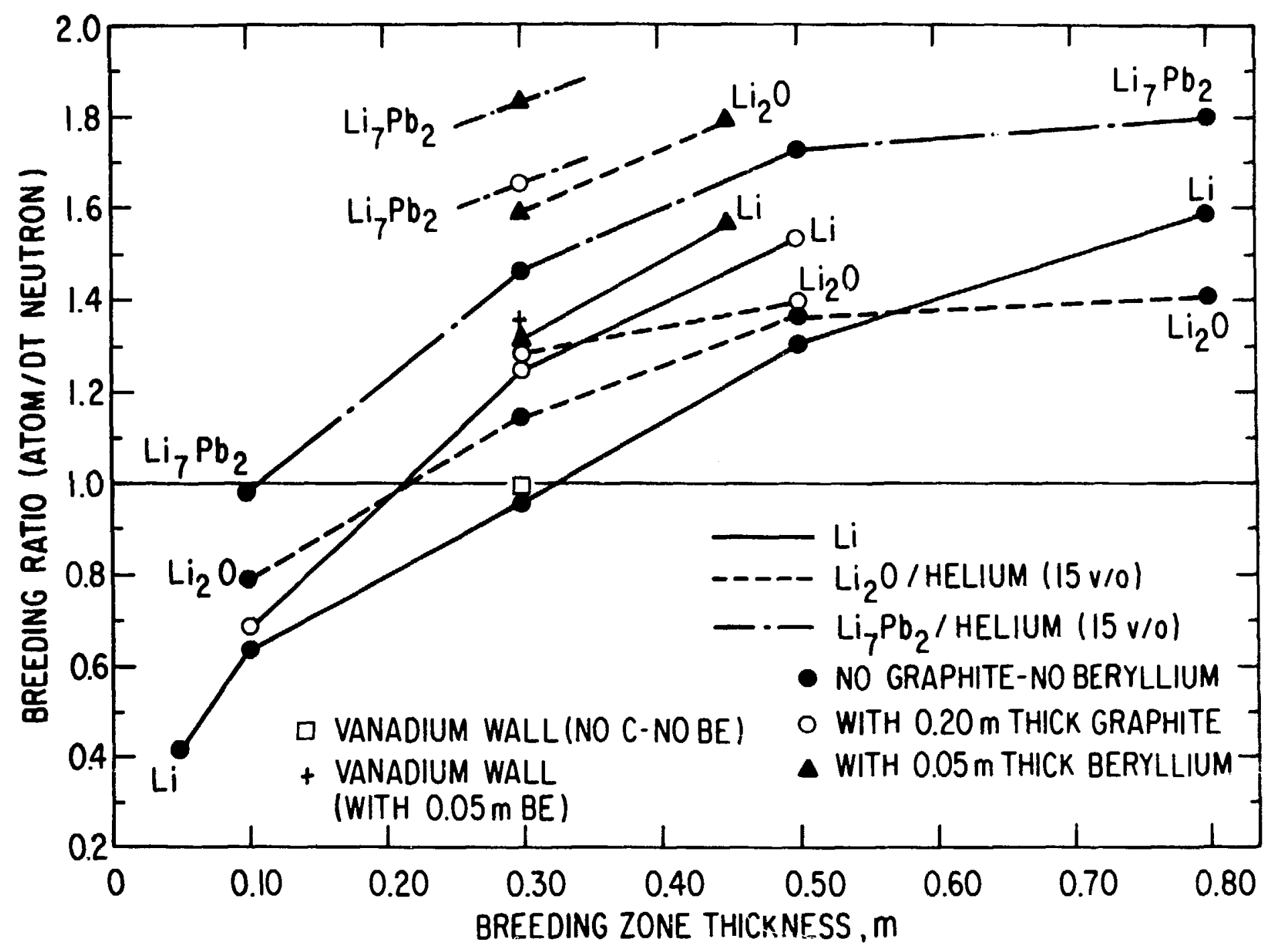

Figure III-8. Plot of breeding ratio versus breeding zone thickness for three breeding materials. 


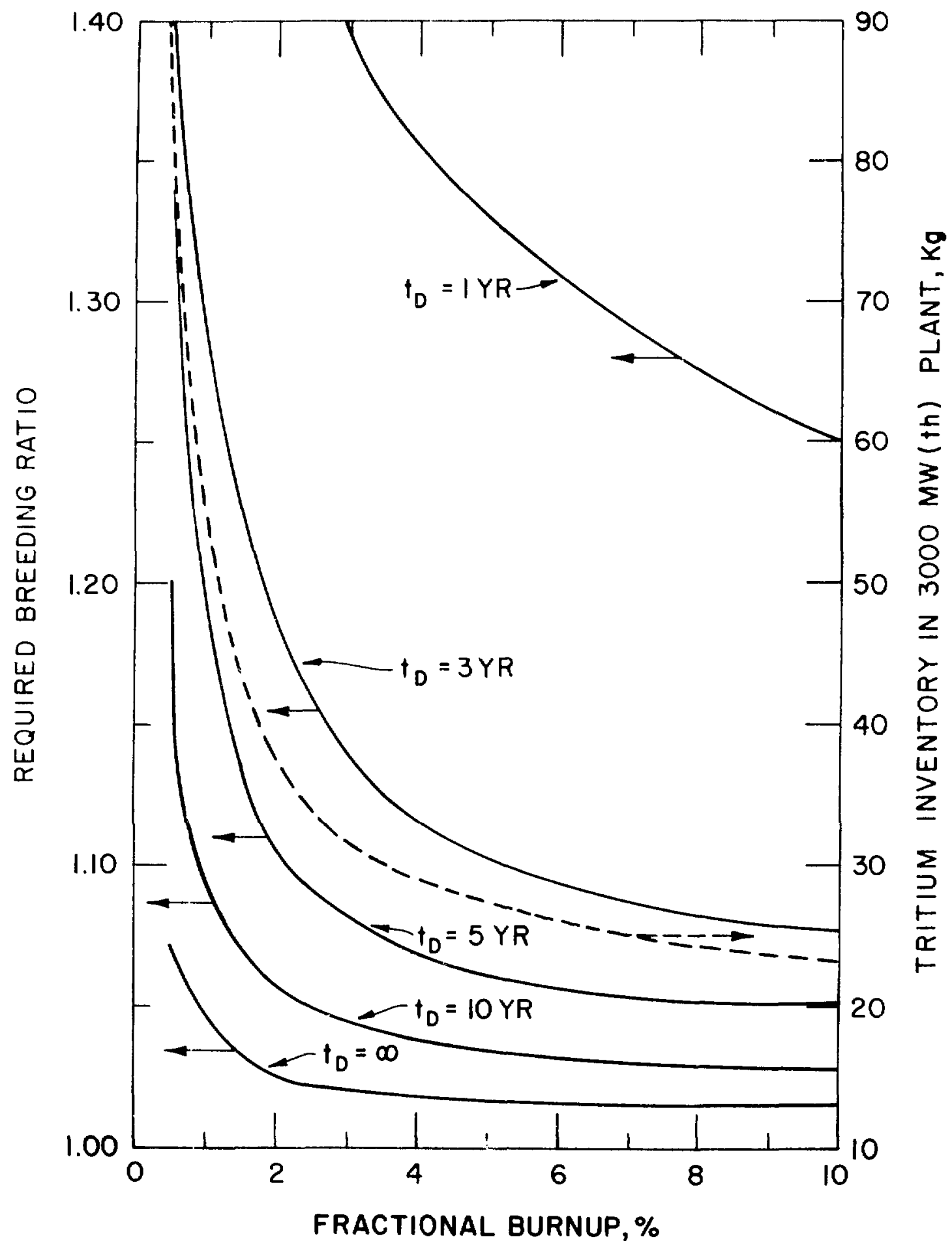

Figure III-9. Effect of Fractional Burnup and Doubling Time Upon Required Breeding Ratio 
an effective breeding ratio of 1.2 is required for a doubling time of $5 \mathrm{y}$. For a higher fractional burnup of $6-8 \%$, which is typical of a reactor without a divertor, an effective breeling ratio of only 1.05 is required for a doubling time of $5 \mathrm{y}$. As a consequence, the tritium inventory required for a reactor with a divertor is substantially larger than for a similar reactor without a divertor.

The analyses of critical aspects of mechanical design, thermal-hydraulic considerations, and stress conslderations in lithfum-cooled blanket concepts have been inftlated. Three types of blanket configurations; viz., complete wedges of the torus, large blanket slabs and small blanket modules; are belng evaluated in the mechanical design. The complete wedge conflguration consists of twelve blanket segments corresponding to the number of toroidal-field coils. The large slab configuration consists of the minimum number of blanket segments, 1.e., 96-144, that can be removed from the reactor without disassembling the toroldal-field colls. The small module configuration consists of a relatively large number, possibly 1800, of blanket segments that can be easily handled. The impact of these three blanket conflgurations on the mechanical design are being evaluated in terms of fabrication, manffolding, maintenance, repair, etc. The impact of vacuum wall position on blanket design is also being evaluated. The three vacuum wall concepts considered are the first wall, the outer edge of the blanket in the high temperature region, and outside the blanket in the low temperature regton.

Emphasis of the thermal-hydraulic and stress analyses is being placed on the first-wall region of the blanket. This effort includes evaluation of firstwall deslgn on the thermal response of the structural wall, effects of coolant flow pattern on the thermal response of the structural wall, and effects of materials variations on the acceptable stress and operating levels. Timedependent first-wall surface heat fluxes for designs with radiatively-cooled liners and multiple limiters have been compared with those for bare walls. A radiatively-cooled Ifner substantially reduced the thermal cycling and, hence, the thermal stresses, Induced in the structural wall compared to a bare wall. However, the thermal cycling and maximum temperatures of the liner become critical. Multiple limiters that cover a fraction, e.g., 5-20\%, of the first wall possess some advantages. The limiters can withstand higher surface heat fluxes than a full iner, since the limiters can thermally radiate heat from their front surface to exposed bare first walls. Also, thermal inertia provided by the limiters tends to reduce the magnitude of thermal cycling of the bare structural wall. The present calculations are devoted to optimization of the number and size of limiters. A second major advantage of the multiple limiter concept is the smaller size or number compared to that of a full liner.

2. An Analysis of the Relationship Between Ava1lable Materials Properties and Allowable Fusion Reactor Design Cond1tions

S. D. Harkness, B. Cramer*, J. Davis*, D. Kummer*, S. Majumdar and B. Misra, Fusion Power Program

A study was conducted to define the limitations in system performance that resulted from the selection of either type 316 stainless steei or an Idealized

\footnotetext{
* McDonne11 Douglas Astronautics Company, St. Louis, Missour1.
} 
vanadium alloy for a lithium-cooled tokamak fusion reactor system. These studies resulted in a definition of the physical properties for fatigue, creep-fatigue, crack growth and creep rupture that were required to achieve a goal life of $10 \mathrm{MW}-\mathrm{yr} / \mathrm{m}^{2}$. The fatigue and creep-fatigue properties of annealed stainless steel appear marginal while the expected vanadium properties appear quite adequate. The potential benefits of both cold work and irradiation on the fatigue properties of type 316 stainless steel were identifled. The crack growth analysts again showed that the type 316 stainless steel properties may be in need of improvement. The creep rupture requirements were found to be in line with the limited avallable data on irradiated stainless steel.

\section{a. Introduction}

Available material properties often limit the designers ability to construct an economical, efficient system. The current work is an attempt to begin to quantify the limits imposed on a tokamak fusion reactor design by the selection of type 31.6 stainless steel as the structural material. Specifically the cyclic loading inherent to tokamak operation was analyzed for 1 ts effect on the lifetime of the first wall structure. System studyl, 2 analysis has shown that there is strong economic incentive to achieve a minimum of a $\sim 10 \mathrm{MN}-\mathrm{yr} / \mathrm{m}^{2}$ lifetime at a wall loadi.1g of at least $2 \mathrm{MW} / \mathrm{m}^{2}$. The results of the present assessment of creep-fatigue and crack growth properties indicate that as presently understood, the use of annealed type 316 stainless steel may limit the development of an economic commercial tokamak reactor design.

The conclusions reached by this study were based on a thermal-hydraulic analysis of both cylindrical and U-bend, lithium-cooled first wall modules. The stress analysis based on the thermal histories calculated for different burn cycles was then used as input to the estimates of the creep-fatigue and crack propagation belavior.

The following highlights emerged from the creep-fatigue analysis:

1. Based on the use of unirradiated properties, annealed type 316 stainless steel must be limited to wall loadings of less than $2.5 \mathrm{MW} / \mathrm{m}^{2}$ for a 1-minute burn cycle if a $10 \mathrm{MW}-\mathrm{yr} / \mathrm{m}^{2}$ 11fe is to be achieved. The avallability of a 6-minute burn cycle would allow wall loadings of $3.6 \mathrm{MW} / \mathrm{m}^{2}$ while a $60-$ minute burn cycle would enable $7 \mathrm{MW} / \mathrm{m}^{2}$ wall loadings, based on a fatigue criteria.

2. Coldworking type 316 stainless steel is expected to allow higher wall loadings (up to $\sim 4 \mathrm{MW} / \mathrm{m}^{2}$ for the l-minute burn cycle case).

3. The irradiation strengthening of annealed type 316 stainless steel may result in higher allowable wall loadings (up to $\sim 4.6 \mathrm{MW} / \mathrm{m}^{2}$ for the 1-minute burn cycle case).

1 M. Abdou, "Parametric Systems Analyses for Tokamak Power Plants," Argonne National Laboratory, ANL/FPP/TM-97 (1977).

2 G. M. Fuller, "Fusion Reactor First Wall Systems Analysis," ER-582 (November, 1977). 
4. Vanadium alloys are not expected to be limited by their fatigue properties due to the relatively low thermal stresses that are generated.

5. Radiation enhanced stress relaxation is expected to cause the first wall to be only stressed by the primary coolant pressure during the burn. The large stresses resulting from the radial temperature gradient are only present during the down time. This phenomenon serves to minimize the amount of expected creep damage.

The Untversal Slopes equation approach was taken as a means of assessing the relative effects of irradiation hardening and metallurgical state on the fatigue properties of type 316 stainless steel, as recently outlined by Michel and Korth. ${ }^{3}$ The equation developed for estimating both the effects of intial coldwork and Irradiation hardening is as follows:

$$
\Delta E_{t}=3.5 \frac{\sigma}{E} N_{f}^{-0.12}+\frac{1}{2} D^{0.6} \mathrm{~N}_{f}^{-0.6}
$$

where

$$
\begin{aligned}
& \sigma_{u}=\text { ultimate tensile strength, MPa } \\
& E=\text { Young's Modulus, MPa } \\
& N_{f}=\text { cycles to failure } \\
& D=\text { ductility parameter, } \ln \varepsilon_{u} \\
& E_{u}=\text { uniform strain (\%) }
\end{aligned}
$$

The ductility parameter was chosen as the uniform elongation to reflect the possible importance of dislocation channeling processes to both fatigue crack inftiation and propagation.

Both coldworking and Irradiation have the effect of increasing the ultimate tensile strength while reducting the ductility (uniform elongation) compared to the unirradiated properties of annealed type 316 stainless steel. In order to study these effects on the fatigue life of stainless steel, Eq. 1 was used to generate the curves presented in Figure III-10. The source of tensile data was the Nuclear Systems Materials Handbook. ${ }^{4}$ The predicted effect, in both cases, is a reduction in low cycle performance and an enhancement in the high cycle regime. This enhancement could have a beneficlal effect on the expected fatigue life of the material. As shown in Figure III-10, wall loadings below the level at which the $10 \mathrm{MW}-\mathrm{yr} / \mathrm{m}^{2}$ curves intersect the fatigue curve appropriate for the material condition will allow a $10 \mathrm{MW}-\mathrm{yr} / \mathrm{m}^{2}$ or greater lifetime. Thus, for a one-minute burn cycle, wall loadings up to $\sim 4.6 \mathrm{MW} / \mathrm{m}^{2}$ would be

3 D. J. Michel and G. E. Korth, "Effects of Irradiation on Fatigue and Crack Propagation In Austenttic Stainless Steels," In Radiation Effects In Breeder. Reactor Structural Materials, p. 129 (1976).

4

Nuclear Systems Materlals Handbook, Vol. I, Design Data (October, 1975). 


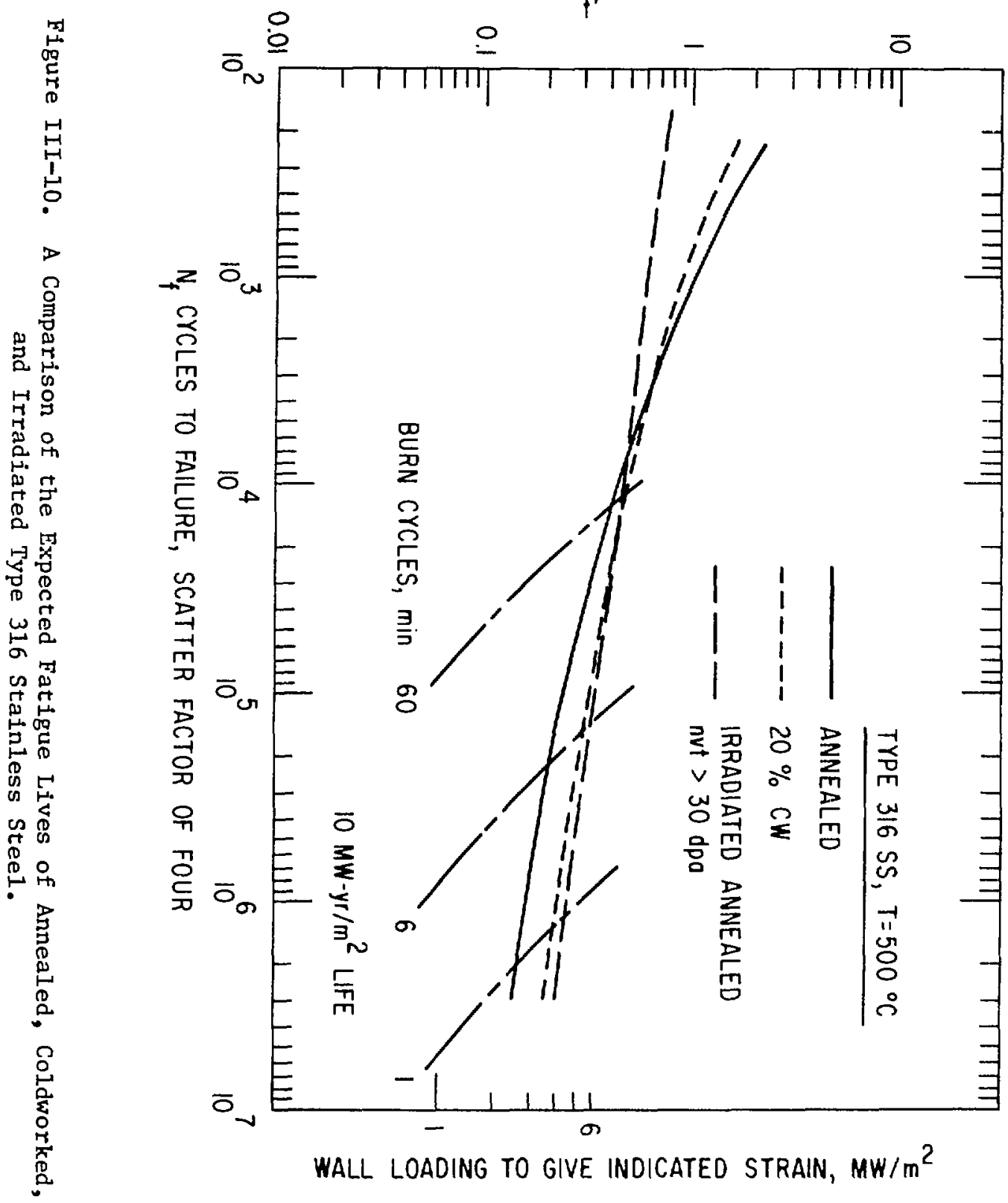


allowable based on the irradiated tensile properties of annealed 316 stainless steel and $\sim 4 \mathrm{MN} / \mathrm{m}^{2}$ based on the unirradiated properties of $20 \% \mathrm{cold}-$ worked 316 as compared to a $11 \mathrm{mlt}$ of $\sim 2.5 \mathrm{MN} / \mathrm{m}^{2}$ ior unirradiated annealed type 316. Similarly for the 6-minute burn cycle allowable wall loadings, based on the fatigue criterion are $5.7,5.5$ and $3.6 \mathrm{MN} / \mathrm{m}^{2}$ for the three cases, respectively.

Major points emerging from the crack propagation analysis included:

1. For a wall loading of $2 \mathrm{MW} / \mathrm{m}^{2}$ a reduction in expected crack propagation rates of a factor of 40 may be necessary if a $10 \mathrm{MW}-\mathrm{yr} / \mathrm{m}^{2} 11$ fetime is to be achieved for a system with a 6-minute burn cycle. Crack propagation therefore appears to be the life-limiting property for a stainless steel first wall structure.

2. Crack propagation is not expected to be governed by fracture toughness considerations.

3. Crack growth rates in lithium may be significantly slower than the available data that were obtained in air. Experimental data on irradiated materlal taken in the expected reactor chemical environment are badly needed.

Fracture mechanics analyses were used to determine first wall life as a function of the crack grcwth variables. In this analysis the growth of initial flaws is calculated in a stepwise manner until efther (1) the crack size exceeds the structural thickness, at which time a coolant leak is assumed to occur or (2) the calculated stress intensity exceeds the material fracture toughness at which time fracture occurs. Fracture toughnesses will probably be high relative to required values. This property should, however, recelve attention in material testing programs due to possible effects of irradiation embrittlement.

The required crack growth properties are compared with properties for irradiated 304 stainless steel provided in the Nuclear Systems Materials HandBook $^{4}$ and adjusted for cyclic frequency effects. The approach was to calculate time to coolant leakage based on each of several crack growth rate versus stress intensity range curves and then select the curve, through interpolation, which yielded the desired life. A ratio of minimum to maximum stress in the cycle ( $R$ ratio) of 0 was used in the calculatiuns.

The resulting effect of stress level on required crack growth properties is shown in Figure III-11(a). The three crack growth lines shown are those required at operating stresses of 70,210 and $350 \mathrm{MPa}$ using a scatter factor of 4.0 on life. Varlables assumed in establishing these curves are a wall life of 5 years or $10 \mathrm{MW}-\mathrm{yr} / \mathrm{m}^{2}$ (20 years for a scatter factor of 4), a structural thickness of $0.25 \mathrm{~cm}$, an initial flaw depth $\left(a_{0}\right)$ of $0.125 \mathrm{~cm}$, and a flaw aspect ratio of 0.5 . Also shown in the figure is a shaded area corresponding to the available crack growth properties for steel tested in air. Shown in Figure III-11(b) is a cross-plot of the crack growth rates taken at a stress intensity range of $11 \mathrm{MN} /(\mathrm{m}) 3 / 2\left(10^{4} \mathrm{PSI} \sqrt{\mathrm{in}}\right)$. Horizontal 1ines corresponding approximately to temperatures for the steel data are also shown. These results show combinations of stress and temperature at which the presently 

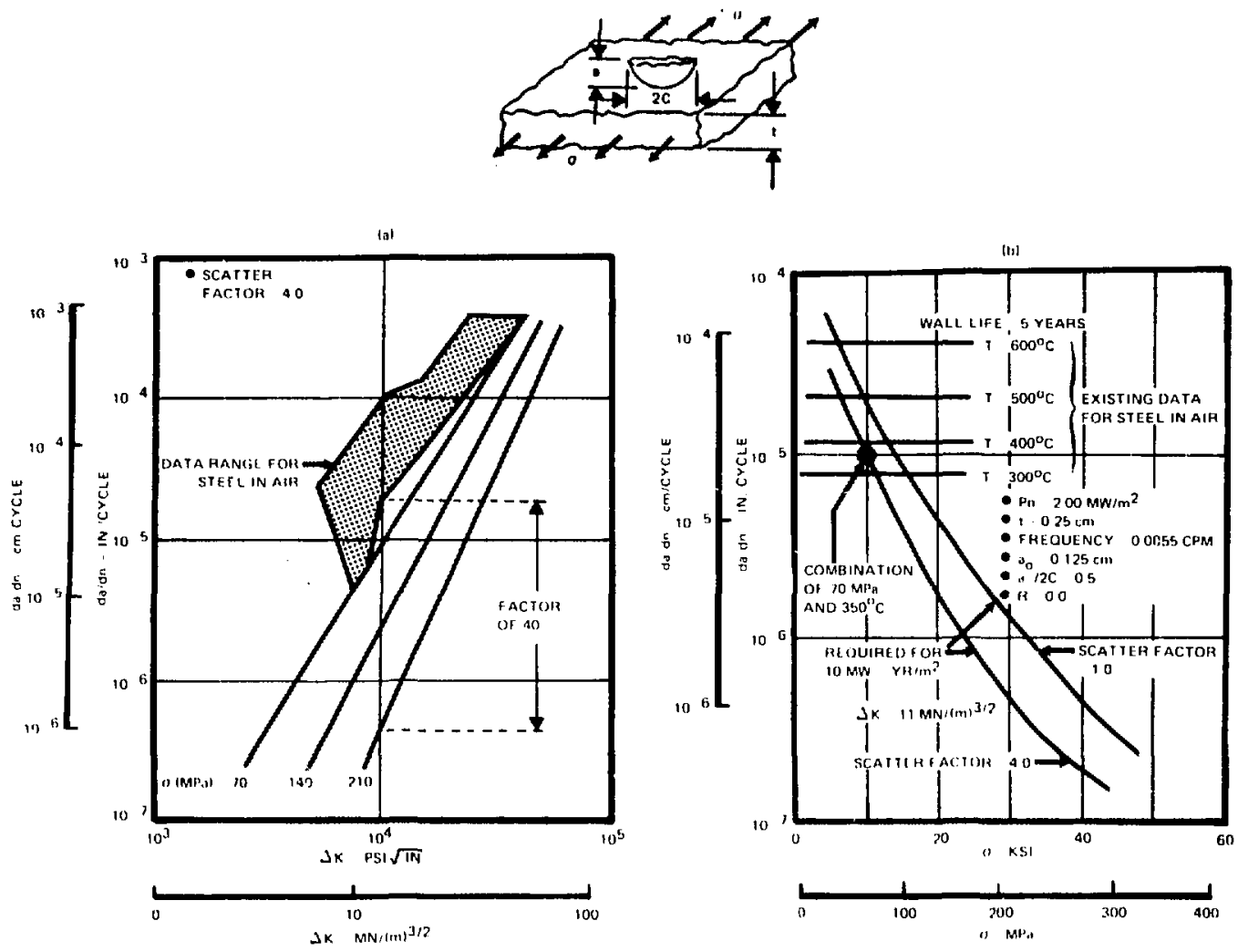

Figure III-11. Comparison of Expected Crack Growth Properties with Those Needed to Achieve a $10 \mathrm{MW}-\mathrm{yr} / \mathrm{m}^{2}$ Wall Life.

avallable properties would meet the life goal. One combination, for example, would be $70 \mathrm{MPa}$ at a temperature of approximately $350^{\circ} \mathrm{C}$ (Figure III-II(b)). Acceptable stress levels range from about 40 to $100 \mathrm{MPa}$, however, these stresses are below those which will exist in first wall components. At a stress level of $210 \mathrm{MPa}$, which might be typical at wall loadings of $2 \mathrm{MW} / \mathrm{m}^{2}$ and wall thickness of $0.25 \mathrm{~cm}$, a property improvement of approximately a factor of 40 is required. The results shown in Figure III-11 are based on constant elastic stresses in the first wall during the plasma burn.

\section{b. Creep-Fat1gue Property Requirements}

The cyclic stresses imposed by representative tokamak burn cycles were analyzed in terms of both known and estimated creep-fatigue properties for type 316 stainless steel as well as for a generic vanadium alloy. The Initial thermal stress imposed on a clamped hemispherlcal module as a function of wall loading is presented in Figure III-12. These stresses w111 be rapidly reduced by radiation enhanced creep processes such that after only a few hundred hours

S. Majumdar, B. Misra and S. D. Harkness, "Thermal Stress and Creep Fatigue Limitations in First Wall Design," IAEA Conference on Fusion Reactor Design (1977). 


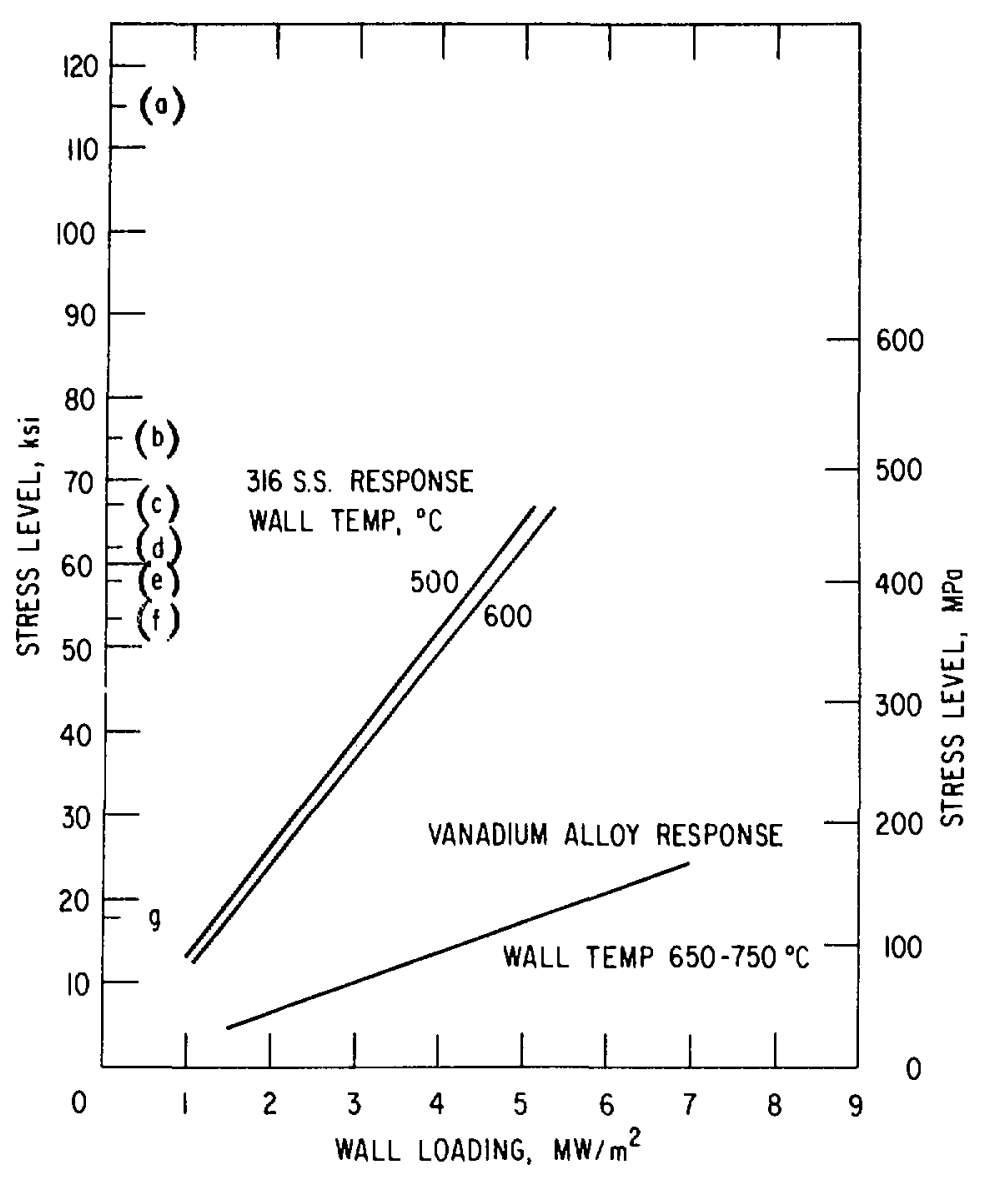

Figure III-12. Average Effective Stresses Expected in a LithiumCooled Module as a Function of Wall Loading.

(a) Ultimate strength, annealed type 316 stainless steel at fluences $\geq 30 \mathrm{dpa}$ at $500^{\circ} \mathrm{C}$.

(b) Ultimate strength, annealed type 316 stainless steel at fluences $\geq 30 \mathrm{dpa}$ at $600^{\circ} \mathrm{C}$.

(c) Minimum yield strength at $500^{\circ} \mathrm{C}, 20 \%$ coldworked type 316 stainless steel.

(d) U1timate strength, annealed type 316 stainless steel at $500^{\circ} \mathrm{C}$.

(e) Minimum yield strength, 20\% coldwork type 316 stainless steel at $600^{\circ} \mathrm{C}$.

(f) Ultimate strength, annealed type 316 stainless steel at $600^{\circ} \mathrm{C}$.

(g) Yleld strength, annealed type 316 stalnless steel at $500-600^{\circ} \mathrm{C}$. 
the stresses imposed during the burn are reduced to near zero. This results, however, in the module being under stress during the down part of each cycle. The stresses are equal in magnitude but of opposite sign to the original thermal stresses so that the plasma side of the first wall is in tension and the lithium side in compression at the stress levels shown in Figure III-12. Though this situation may change after the on-set of swelling ${ }^{6}$ depending on the detalled interaction of swelling and creep processes, it was assumed for the purposes of the present study that the module is unstressed (except for the relatively low primary coolant pressure stresses) throughout its life during the burn pulse. The restriction of loading to the of f-burn period of the cycle reduces the amount of projected creep damage because only thermal creep will occur, that the wall will be at lower temperatures than are present during the burn and the off-burn times are relatively short. Thus, the expected effect of the cyclic thermal stresses on a tokamak first wall becomes a fatigue rather than a creep-fatigue problem.

It should be noted that significant strengthening of annealed type 316 stainless steel by irradiation does not occur in the $400-600^{\circ} \mathrm{C}$ temperature range until an exposure of $\sim 6 \mathrm{dpa}$ or a half of $\mathrm{MW} / \mathrm{m}^{2}$ has been achieved. Thus, it may be that during the initial stages of operation a tokamak might be linited to wall logadings of $\sim 2 \mathrm{MW} / \mathrm{m}^{2}$ followed by the higher limits dictated by the irradiated properties. This point must await experimental fatigue property determination as well as more information on other potentially life limiting properties.

A similar creep-fatigue analysis has been conducted for a generic vanadium alloy 5,6 using a compilation of avallable fatigue and creep-rupture properties. It was found that very long fatigue life is expected for vanadium alloys, due principally to the fact that the thermal stresses are $\sim 50 \%$ lower than those found in austentic stainless steels at the same wall loading.

\section{c. Grack Growth Property Requirements}

Surface flaws must be expected in any engineering structure. Therefore, It is important that crack growth properties of the first wall are adequate so that coolant leakage into the plasma chamber will not occur during the life of the structure. Effort was directed at identifying the crack growth properties required to attain a $10 \mathrm{MW}-\mathrm{yr} / \mathrm{m}^{2}$ first wall life. Emphasis was placed on addressing the impact of stress, structural thickness, initial flaw size and flaw aspect ratio on crack growth property requirements.

Required crack growth properties were generally treated as design independent although the range of values assigned to the variables were those typical of first wall components. Burn and nonburn times of 90 minutes and 6 minutes, respectively, were used for the purposes of calculating cyclic frequencles in comparing present 316 stainless steel crack growth data with the required properties. Actual stresses and operating parameters will have

6 S. D. Harkness, D. Kummer, et al., "The Establishment of Alloy Development Goals Important to the Commercialization of Tokamak-based Fusion Reactors," Argonne National Laboratory, ANL/FPP/TM-99 (1977). 
to be determined for each candidate first will design for purposes of comparing with required crack growth rates.

Due to the combined effects of thermal creep, irradiation creep, and swelling which occur in the first wall structure during the plasma burn, tensile stresses will exist in :he first wall during the nonburn part of the cycle. The required crack growth rate was determined as a function of stress intensity range for a tansile stress history in a U-bend cell at a neutron wall loading of $2.5 \mathrm{MW} / \mathrm{m}^{2}$. The time dependent stress history upon which these required properties are based was determined using inelastic analysis. Th1s curve is compared with the stainless steel data in Figure III-13. The data range for steel shown in the figure is based on a lower hold time corresponding to the nonburn period. In this case the cyclic frequency used was $0.083 \mathrm{cpm}$ based on a 6 -minute hold time and assumed equal time unloaded $(1 / 12=0.083 \mathrm{cpm})$. The resulting comparison in Figure III-13 indicates that considerable improvement in properties is also required even when creep is considered. With respect to this fallure mode, however, irradiation and or thermal creep increase wall life.

Better properties (lower crack growth rates) will be required at higher wall loadings. As wall loading is increased the allowable stress at a given temperature, is also increased. The reason for this is that shorter lives (in years) are required at the higher neutron wall loadings (e.g., 2.5 years at $P_{n}=4$ versus 5 years at $P_{n}=2$ ) to meet the $19 \mathrm{MW}-y r / \mathrm{m}^{2}$ life requirement. However, relations between the wall loading and first wall conditions must also be considered. That is, higher thermal stresses will be associated with higher wall loadings.

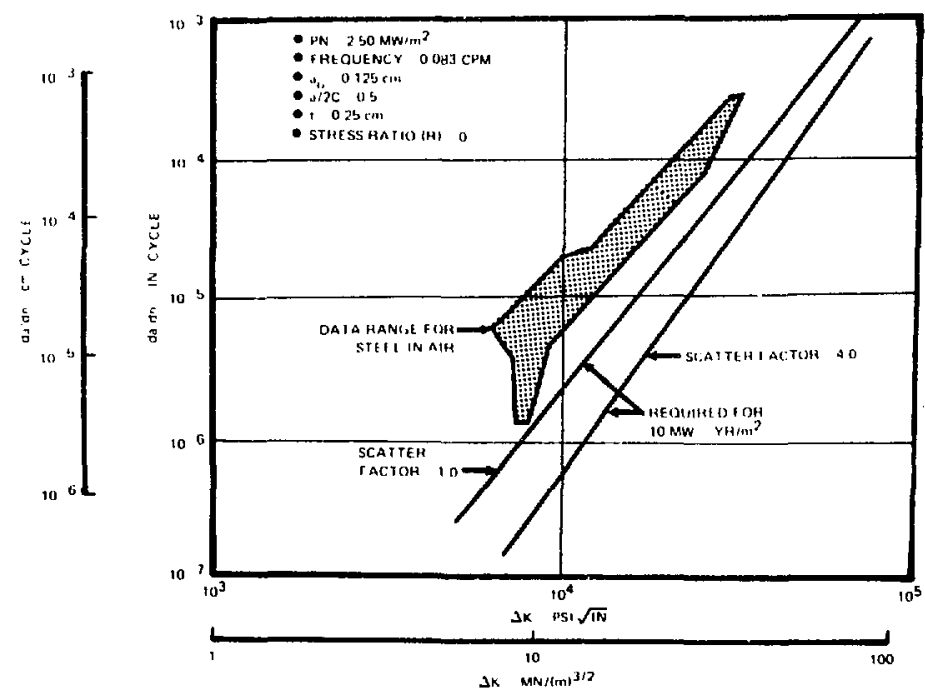

Figure III-13. Evaluation of Expected Crack Growth Properties in Terms of a Time Dependent First Wall Stress History. 
The effect of structural thickness on required crack growth properties at a stress of $210 \mathrm{MPa}$ is shown in Figure III-14. Required propertles for three thicknesses, are compared with the data for stainless steel. The crossplot of thickness versus required crack growth rates at $\Delta \mathrm{K}=1 \mathrm{MN}(\mathrm{m}) 3 / 2\left(10^{4}\right.$ PSI $\sqrt{I n}$ ) in FIgure III-14b shows that even at greater thicknesses the avallable crack growth properties do not approach those required.

Similar effects were also noted for the variables $a_{0}$ (Initial flaw depth) and $a / 2 c$ (flaw aspect ratio). That is, even for relatively small initial flaws, a considerable improvement in crack growth properties is required. As initial flaws approach zero the improvement required is reduced and generally tends to agree with findings discussed with respect to fatigue property requirements.

Data applied in the comparisons are based on tests in air. Effects of environment, therefore, need to be considered since the first wall in a fusion reactor will contact a low partial pressure of energetic hydrogen on one side of the wall and coolant such as liquid 1ithium on the other side. The degree to which environment can affect crack growth rates is shown in Figure III-15.7 Contact with sodium improves resistance to crack growth by about a factor of

7 D. S. Priddle and M. V. Wiltshire, Intemational Joumal of Fracture (697) (1975).
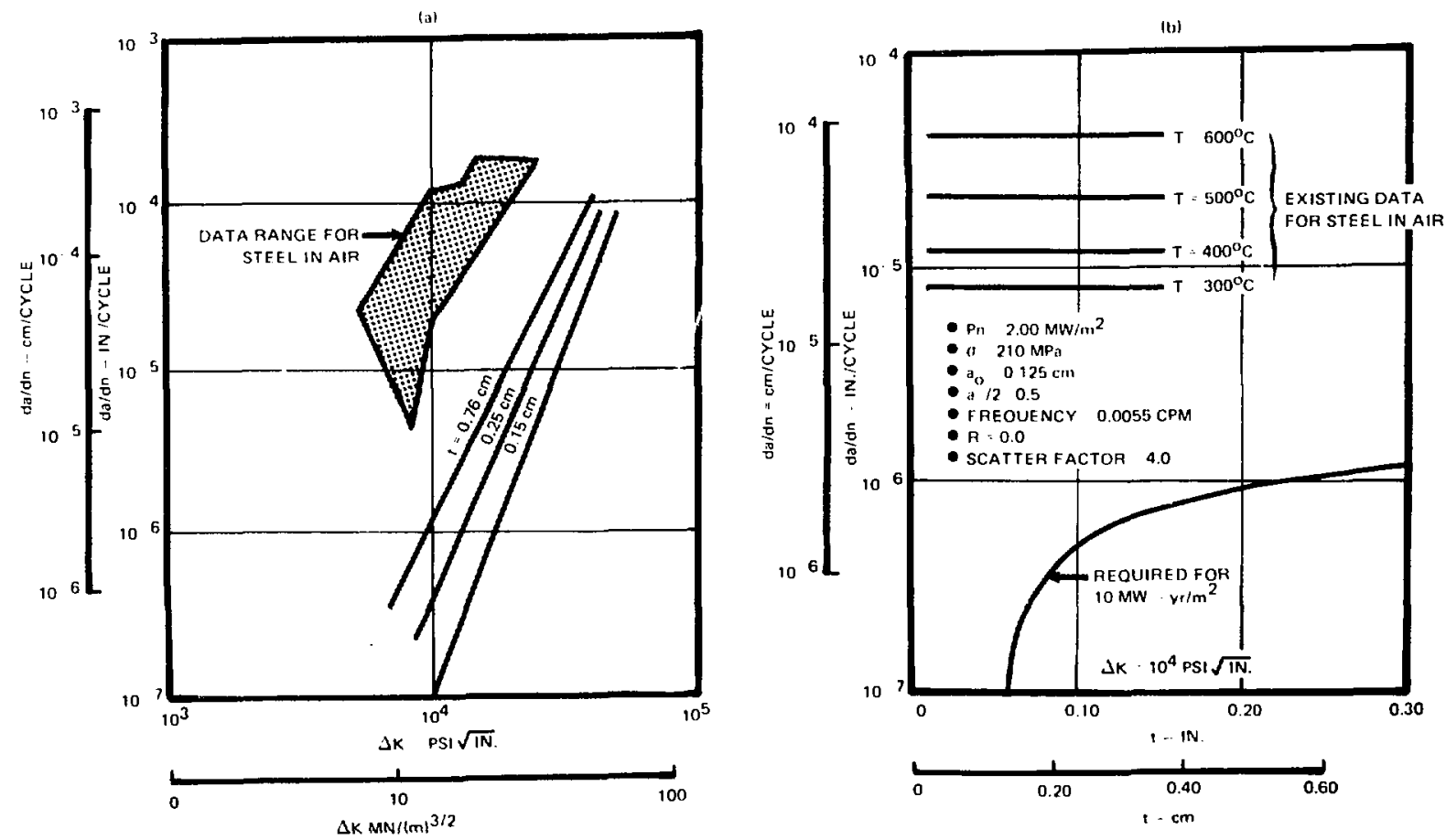

Figure III-14. The Effect of Wall Thickness on the Crack Growth Rates Required to Achieve a $10 \mathrm{MW}-\mathrm{yr} / \mathrm{m}^{2}$ Life. 


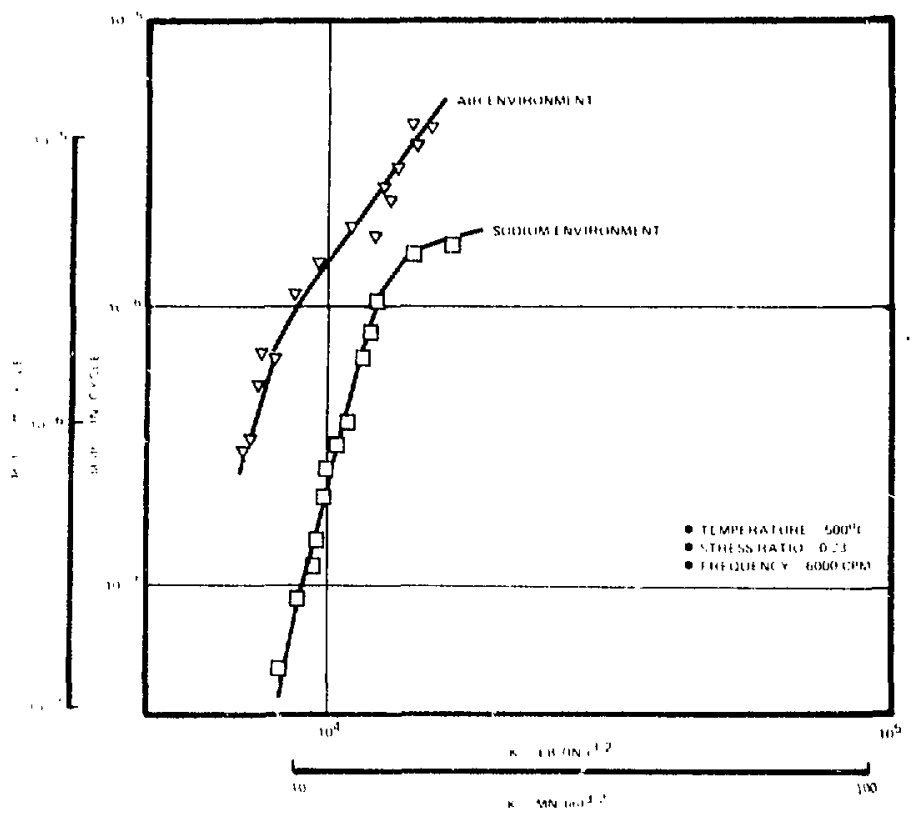

Figure III-15. A Comparison of Crack Growth Rates in Air and in Sodium.

7 at the stress intensity range of $11 \mathrm{MN} /(\mathrm{m}) 3 / 2\left(10^{4} \mathrm{PSI} \sqrt{\mathrm{in}}\right)$. This improvement, if is applies to the actual reactor environment, would reduce the gap between existing and required properties as discussed in this section. However, much more needs to be known about environmental effects, including the effects of energetic hydrogen isotopes.

\section{Fusion Reactor Blanket Design Study}

R. G. Clemmer, Chemical Engineering Division

This part of the ANL/MDAC blanket studies program has involved analyses of commercial reactor tritium inventories and development of guidelines for required tritium breeding ratios. Also, a "fuel-pin" type of breeding blanket was analyzed with respect to tritfum inventories and tritium production requirements. Currently the sultability of $\mathrm{LI}-\mathrm{Pb}$ alloys as breeding materlals is being assessed.

Tritium Breeding Requirements: TCODE was used to calculate tritium inventories as a function of fractional burnup for a hypothetical commercial reactor. The blanket inventory was assumed to be $10 \mathrm{~kg}$. The required ratio was then calculated (including decay losses) for varlous tritium inventory doubling times. As is shown in Figure III-16, at very low fractional burnup, the inventory becomes quite large and, as a result, relatively high breeding ratios appear to be necessary. In reactors having no active impurity control, the fractional burnup (FB) could be as high as $10 \%$, and a breeding ratio (BR) of 1.05 would be suffictent to provide inventory doubling in five years. 


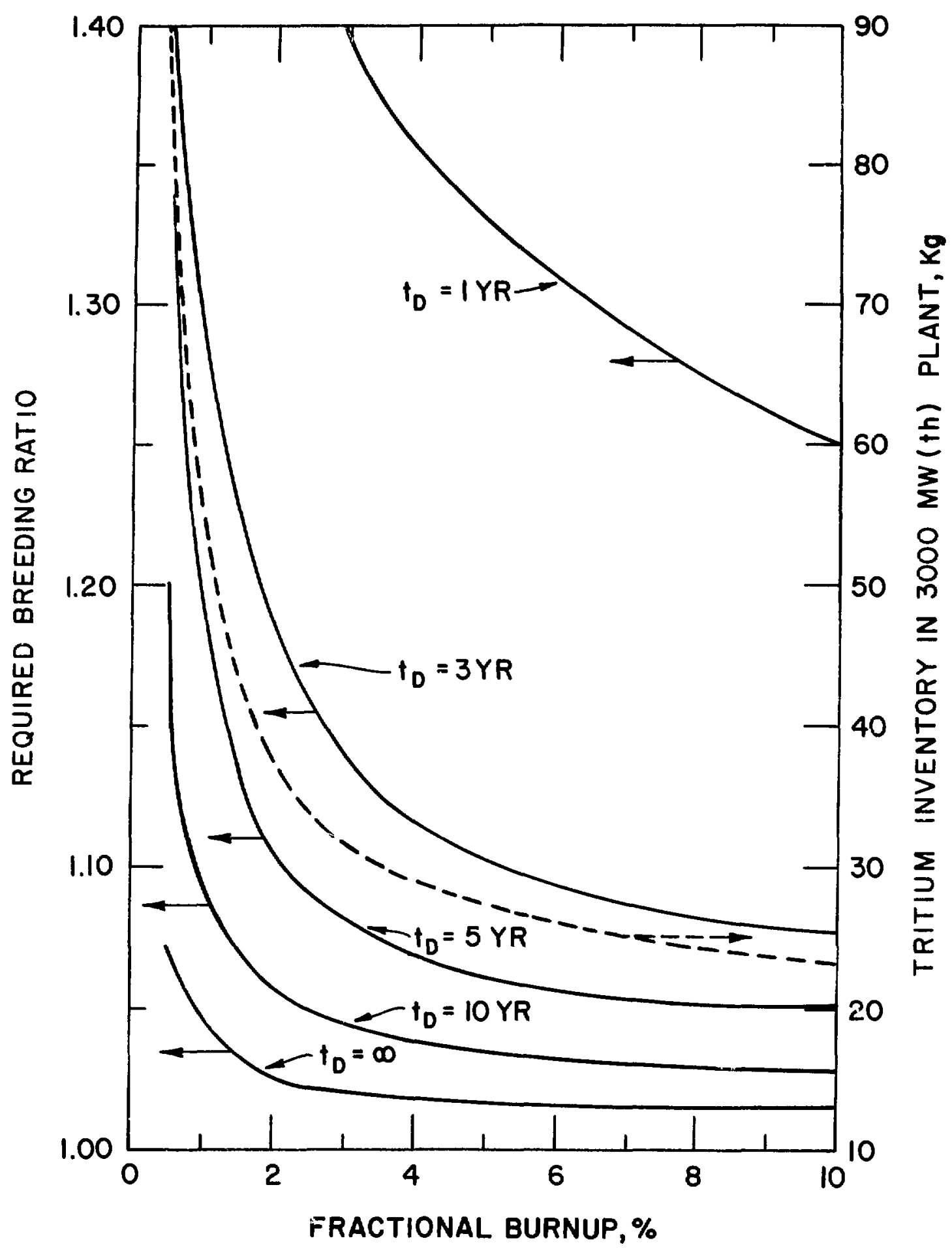

Figure III-16. Effect of Fractional Burnup and Doub1ing Time Upon Required Breeding Ratio for a $3000 \mathrm{MW}(\mathrm{th})$ Tokamak Reactor. 
However, with a divertor or gas blanket impurity removal scheme, FB could conceivably be less than $1.0 \%$. If $F B=1.0 \%$, a $B R$ of 1.20 is required to double the tritium inventory in five years. If we assume $\mathrm{FB} \geq 2 \%$, then a breeding ratio of 1.10 will double the tritium in five years or less.

Fuel Pin Breeding Scenarios: It has been suggested ${ }^{1}$ that the breeding material in a fusion reactor could be encased in a "fuel-pin" type assembly that would be removed from the blanket periodically to recover the bred tritium. This approach might be useful in easing some of the difficulties associated with in-situ recovery of tritium from solid breeder materials. A computer program, TPIN, has been written for the purpose of analyzing the implications of this concept. The time between pin processing operations, the months of fuel reserve on hand, the number of identical reactors operating together, the breeding ratio, and the fuel cycle tritium inventories were all used as input variables. The only tritium depletion mechanism built into TPIN was the tritium $\beta$-decay loss (processing losses were assumed to be zero). Selected results are shown in Table III-6. It is clear that the inventories are a strong function of the time that the pins remain in the blanket. In order to take advantage of the fuel pin approach, it would be desirable to leave the pins in the blanket at least six months. This implies a total tritium inventory of about $90 \mathrm{~kg}$ for the base case plant in Table III-6. Under these conditions, one reactor will require a breeding ratio (BR) of 1.20 to double its tritium inventory in 5 years, and $B R \geq 1.10$ to double at all. Further, the figures at the bottom of Table III-6 show that a breeding ratio of 1.10 will not be sufficlent if the fuel cycle inventory is allowed to $r$ ise as high as $50 \mathrm{~kg}$.

The results in Table III-6 can be combined to calculate the annual growth rate in the number of new reactors that can be brought on-line with the bred tritium. If a growth rate of $10 \%$ is required, then the breeding ratio must be $\geq 1.20$ for semiannual pin replacement. It appears that the "fuel-pin" concept requires increased tritium inventories, makes tritium production difficult, and uses tritium less efficiently than continuously processed blanket concepts. For these reasons, the concept may only be applicable to $\mathrm{Li}-\mathrm{Pb}$ or $\mathrm{Li}_{2} \mathrm{O}$ blanketed reactors where breeding ratios in excess of 1.2 appear to be readily achievable. 1,2

1 S. D. Harkness, Argonne National Laboratory, personal communication.

2 J. C. Jung, Argonne National Laboratory, personal communication.

4. Evaluation of Steam as a Potential Coolant for Non-breeding Blanket Designs

H. C. Stevens, B. Misra and C. K. YC ngdah1, Fusion Power Program

A number of alternate blanket designs and cooling concepts are under investigation at the Argonne National Laboratory for the tokamak-type fusion power 


\section{Table III-6. "Fuel Pin" Fusion Reactor Breeding Scenarios for 3000 MW(th) Plant}

\begin{tabular}{|c|c|c|c|c|c|c|c|c|c|c|}
\hline \multirow{2}{*}{$\begin{array}{l}\text { Months of Pin } \\
\text { Operat ion } \\
\end{array}$} & \multirow{2}{*}{$\begin{array}{c}\text { Months Fuel } \\
\text { Reserve }\end{array}$} & \multirow{2}{*}{$\begin{array}{l}\text { No. of } \\
\text { Reactors }\end{array}$} & \multirow{2}{*}{$\begin{array}{l}\text { Tritium needed } \\
\text { to start plant, } \\
\mathrm{kg} \\
\end{array}$} & \multirow{2}{*}{$\begin{array}{l}\text { Tricium in } \\
\text { Fuel cycle. } \\
\quad \mathrm{kg} \\
\end{array}$} & \multicolumn{3}{|c|}{$\frac{\text { Time to add a Plant, } y r}{\text { Breedting Ratio }}$} & \multicolumn{3}{|c|}{$\frac{\text { Maximum Tritium Inventories, } \mathrm{hg}}{\text { Breeding Ratio }}$} \\
\hline & & & & & & $\underline{1.10}$ & $\underline{1.20}$ & 1.05 & 1.10 & \\
\hline 1 & 1 & 1 & 28.5 & 17.5 & 7.0 & 2.75 & 1.25 & 28.9 & 29.4 & 30.5 \\
\hline 3 & 3 & 1 & 50.7 & 27.5 & 27.0 & 6.0 & 2.5 & 51.6 & 53.2 & 56.4 \\
\hline 6 & 1 & 6 & 28.5 & 17.5 & 11.5 & 3.5 & 1.5 & 84.7 & 87.9 & 94.2 \\
\hline 6 & 3 & 2 & 50.7 & 17.5 & $x$ & $7.1)$ & 2.5 & 84.9 & 88.1 & 94.5 \\
\hline 6 & 6 & 1 & 84.8 & 17.5 & $x$ & 15.5 & 5.0 & 85.7 & 88.8 & 95.2 \\
\hline 12 & I & 12 & 28.5 & 17.5 & $\infty$ & 4.0 & 2.0 & 150.0 & 156.2 & 168.9 \\
\hline 12 & 3 & 4 & 50.7 & 17.5 & $\infty$ & 9.0 & 3.0 & 150.2 & 156.5 & 169.1 \\
\hline 12 & 6 & 2 & 84.8 & 17.5 & * & 25.5 & 6.0 & 150.9 & 157.2 & 169.8 \\
\hline 12 & 12 & 1 & 155.8 & 17.5 & * & $\infty$ & 13.0 & 153.7 & 160.0 & 172.6 \\
\hline 6 & 6 & 1 & 68.3 & $\therefore 0$ & & 10.0 & & & 72.8 & \\
\hline 6 & 6 & 1 & 77.3 & $=0.0$ & & 12.5 & & & 81.6 & \\
\hline 6 & 6 & 1 & 87.3 & 20.0 & & 16.5 & & & 91.3 & \\
\hline 6 & 6 & 1 & 117.3 & 50.0 & & $\infty$ & & & 120.5 & \\
\hline
\end{tabular}

*Negative tritium production (i.e., consumes more tritium than is bred). 
reactors. 1,2 Most of these studies addressed the relative merits of a wide range of coolants (e.g., liquid lithium, helium and pressurized water) and structural materials (e.g., austenitic stainless steel and vanadium-based alloys). As the first generation of fusion power plants are likely to be non-breeding types, we have extended our studies to evaluation of steam ${ }^{3}$ as a potential coolant with stalnless steel and more recently with nickel-based alloys such as Inconel 625 as the blanket material.

The principal functions of the proposed blanket systems for these reactors are to provide a relatively thin zone $(30$ to $50 \mathrm{~cm}$ ) of high density shielding material that can function at elevated temperatures (up to $650^{\circ} \mathrm{C}$ ) in a wav that permits the retrieval of most of the thermalized neutron and gamma energy as sensible heat. Conceptual design and analysis of potentially useful blanket configurations complete with appropriate maintenance scenario that could perform these functions has been a major undertaking within the EPR stcdies conducted to date. The blanket design considered (see Figure III-17) in the analysis is composed of monolithic Inconel 625 blocks, $0.25-m$ in the radial direction, $1-\mathrm{m}$ in the toroldal direction and $1.2-\mathrm{m}$ in the poloidal direction. Coolant flows in the poloidal direction through an array of bored channels. Since the heat generation rate decreases exponentially with radial location, the flow area of the coolant channels and their spacing are varied radially to make the temperature distribution in the blanket block as uniform as possible.

A set of six coolant channels with iteratively adjusted cross-sectional areas and interchannel distances was evaluated during the first round of analyses.

$A$ computer code capable of solving a set of three-dimensional thermal hydraulic equations was used to establish the transient and quasi-steady state temperature distribution within the blanket block. Because of the large thermal inertia of the blanket blocks, the overall thermodynamic efficlency of the power conversion system and the size of the thermal storage system depends significantly on the D-T burn cycle. Hence, to Investigate the effort of the burn cycle on the performance of ANL/EFR, the following three burn cycles, each with 15-s dwell time, were considered: (1) $65 \mathrm{~s}$, (2) $120 \mathrm{~s}$, and (3) $600 \mathrm{~s}$. The neutron power profile was provided by neutronic calculations for the ANL/EPR. ${ }^{2}$ The thermal hydraulic and power cycle analyses are based on the assumption that the vacuum wall, and the vertical inner and outer blanket is cooled by pressurized water while the horizontal upper and lower blanket

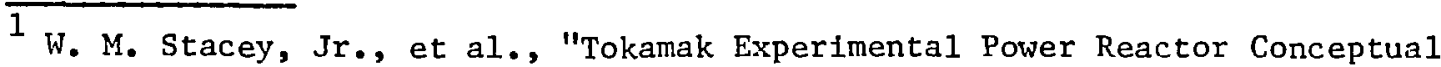
Design," Argonne National Laboratory, ANL/CTR-76-3 (August, 1976).

2

W. M. Stacey, Jr., et al., "EPR-77, A Revised Design for the Tokamak Experimental Power Reactor," Argonne National Laboratory, ANL/FPP/TM-77 (March, 1977).

3 B. Misra, C. K. Youngdahl, H. C. Stevens and V. A. Maront, "Thermal Hydraulic and Mechanical Analysis for Near-Term Fusion Reactor Blanket Designs," Trans. Am. Nuc. Soc., 27, p. 72 (1977). 


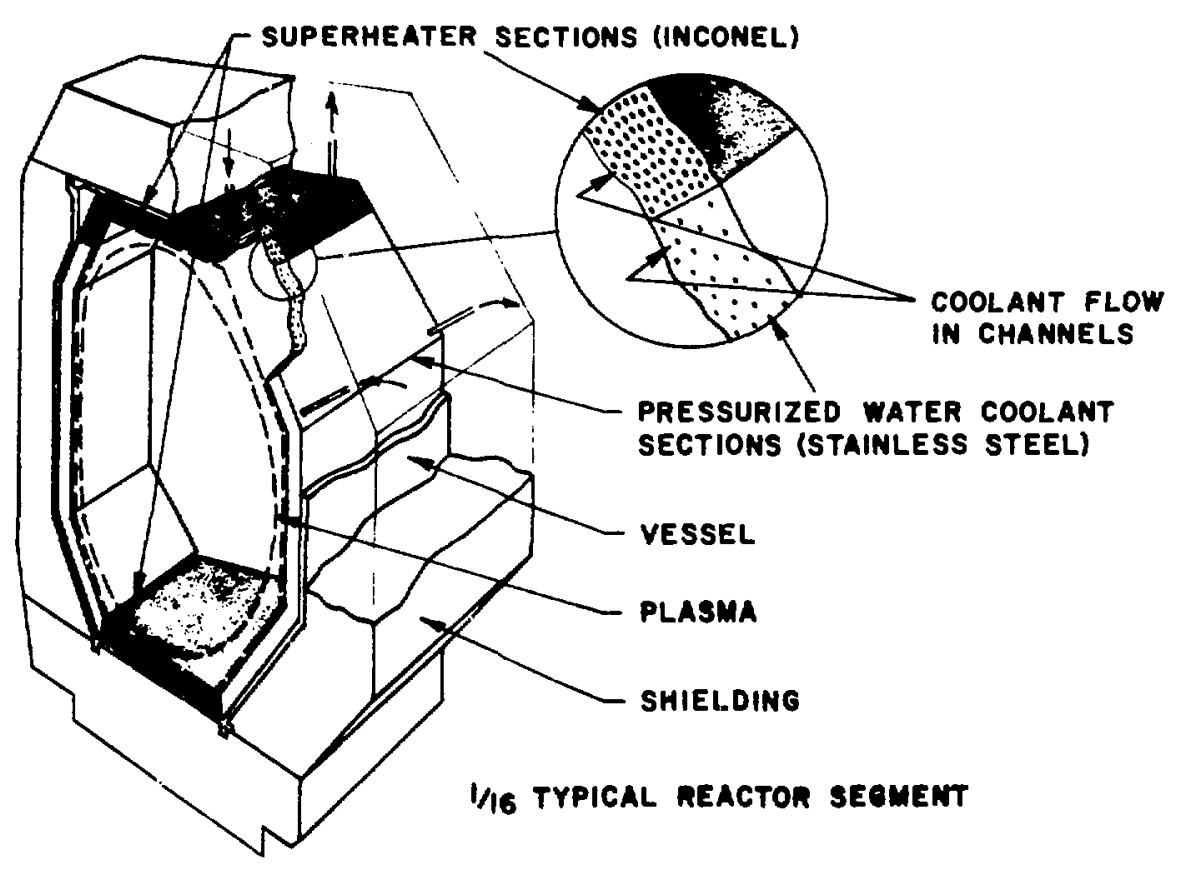

Figure III-17. Schematic of EPR Blanket/Superheater.

serves as the energy source to superheat steam from $300^{\circ} \mathrm{C}$ to approximately $500^{\circ} \mathrm{C}$ without exceeding the maximum allowable temperature of $650^{\circ} \mathrm{C}$ for Inconel 625.4

A significant drawback of many of the previous conceptual design and scoping studies of tokamak-type fusion power reactors $1,2,5,6$ is that they have not taken into consideration the effect of thermal-hydraulic design on the thermal stress distribution within the blanket block. It is known from mechanical response analysis that severe thermal stresses can be present within the blanket blocks when the coolant channel distribution is selected to meet only the thermal hydraulic criteria and stress concentrations are highly sensitive to coolant channel arrangement. Hence, thermo-mechanical analyses were carried out in conjunction with thermal hydraulic analyses in selecting the coolant channel arraisgements.

4 R. F. Mattas, Personal Communication, Argonne National Laboratory (1977).

5 C. A. Flanagan, et a1., "Oak Ridge Tokamak Experimental Power Reactor Study - 1976," Oak Ridge National Laboratory, ORNL/TM-5575 (December, 1976).

6 c. C. Baker, at al., "Experimental Power Reactor Conceptual Design Study," General Atomic Company, GA-A13534 (July, 1975). 
The results of the thermal hydraulic and power cycle analyses show that the thermodynamic efficlency approaching $41.5 \%$ can be achieved based on steam as the coolant. The results of mechanical analysis show that preliminary thermal mechanical optimization of blanket block design can be accomplished at the conceptual design level using relatively simple computational methods and improvements in strain levels can be accomplished without any significant change in thermal hydraulic performance. Of course, numerous questions pertaining to tritium containment must be fully addressed before this approach to power cycle operation could truly be considered acceptable. It appears from a cursory analysis that a Rankine cycle using steam directly from the blanket system presents no more serious tritium containment problems than a closed loop helium driven Brayton cycle, which has, in the past, been employed in numerous designs of advanced power conversion systems for commercial fusion power reactors.

\section{G. Cross Section Measurements, Evaluations and Techniques}

\section{Fast-Neutron Total and Scattering Cross Sections of Elementa1 Titanium}

P. Guenther, P. Moldauer, A. B. Smith and J, Whalen, Applied Physics Division

Energy-averaged total-neutron cross sections of elemental titanium are measured from $=1.0$ to $4.5 \mathrm{MeV}$ with statistical accuracies of $\approx 1$ percent. Differential-elastic-neutron-scattering angular distributions are measured from 1.5 to $4.0 \mathrm{MeV}$ at incident energy intervals of $\approx 0.2 \mathrm{MeV}$. Differential cross sections for the inelastic-neutron excitation of "states" in titanium at: $158 \pm 26,891 \pm 8,984 \pm 3,1428 \pm 3 y, 1541 \pm 30,1670 \pm 80,2007 \pm 8$, $2304 \pm 22,2424 \pm 16$ and $2615 \pm 10 \mathrm{keV}$ are measured in the incident-neutron energy range 1.5 to $4.0 \mathrm{MeV}$. Neutrons corresponding to additional states at approximately 2845 and $3010 \mathrm{keV}$ were qualitatively observed. The experimental results are interpreted in terms of an energy-averaged optical-statistical and coupled-channels models including consideration of collective vibrations. The implications of these models and their use in the context of strong fluctuating structure are discussed.

\section{Nuclear Data for High-Energy Neutron-Damage Sources*}

A. B. Smith and D. L. Smith, Applied Physics Division, and L. R. Greenwood and R. R. Helnrich, Chemical Engineering Division

The conceptual design of a proposed U.S. facility for high-energy neutron damage studies is described briefly. This facility would utilize the ( $+\mathrm{Li}$ ) process as the neutron source and thereby provide a continuous output of $\sim 2 \times$ $10^{16}$ high-energy neutrons per second. Nuclear data needs in the areas of neutron production, shielding and dosimetry for high-energy neutron damage sources such as the proposed U.S. facility are considered. The existing differential data base for several fast-neutron dosimeter reactions is reviewed briefly. Guidelines for future accuracy requirements in this area are also provided.

* This is the abstract from an invited paper presented at the NEANDC Meeting, Oak Ridge National Laboratory, April 3-7, 1978. 


\section{MAGNETIC SYSTEMS}

\section{A. Energy Storage and Transfer Program}

R. E. Fufa, R. Wehrle, R. P. Smith and R. L. Kustom, Accelerator Research Facilities Division

\section{Homopolar Generator}

Modifications to the Homopolar generator (HOPE 1) reported in the last quarterly report have been completed and testing of the generator system is underway. Energles ranging from 600 Joules to 6800 Joules have been switched from the storage coll to the Hope 1 system with no adverse effects on the generator. Data are being collected on the drum, voltage, current, maximum speed and coasting time, as well as the effects on the radial magnetic field due to acceleration and deacceleration of the drum are being monitored. These tests are being performed at varlous brush and air bearing pressures.

The data have yet to be completely analyzed, however, inftial analysis reveals some interesting trends. A maximum voltage appears across the rotating drum and the brushes at a point in time when the current through the drum is not zero (see Figure IV-1). The maximum speed of the drum ccurs when the voltage across the drum is at a maximum and, as the voltage decreases, the speed remains constant until the current goes to zero, at which time the speed begins to decrease. The amount of energy being transferred from the storage coil to the generator is reduced by about a factor of two. Figure IV-1 shows the voltage across the drum, the current through the drum and the speed of the drum as a function of time. The questions to be resolved are, where does the energy go, what is the reason for our low transfer efficlency, and why does a voltage maximum and a current minimum appear at different points in time? Since the speed of the rotating drum does not decrease until the current goes to zero, it may be possible that the radial magnetic field is changing or that the brush contact pressure is varying.

\section{Inductor-Converter Bridge}

The computer programs required for the dynamic control of the Inductor Converter (IC) bridge with an Intel System $80 / 20$ microcomputer have been completed and debugged and the output interface clrcults from the microcomputer to the IC bridge driver are assembled and working. All that remains to be done is the assembly of the three input interface circuits; work has started on their construction and testing of the circuits will begin as soon as they are finished. The Inductor-Converter bridge switching SCR's, along with their driver circuits, are being checked out. As soon as the assembly of circuits is complete, testing of the system will resume. 


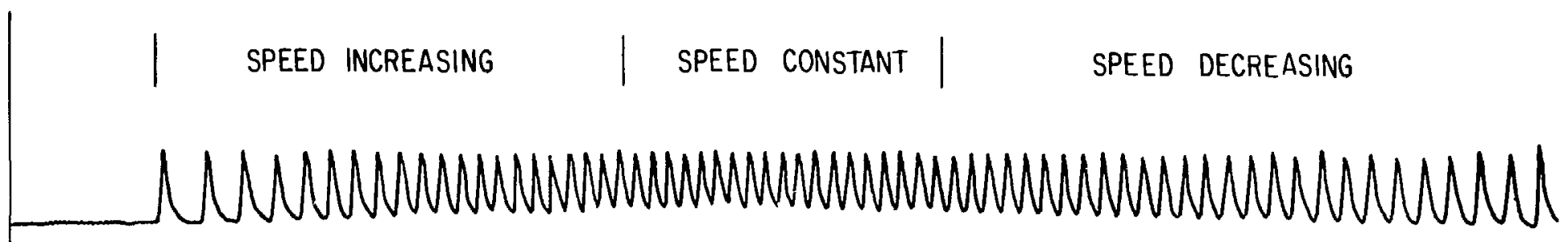

SPEED OF DRUM

$\stackrel{\infty}{\circ}$
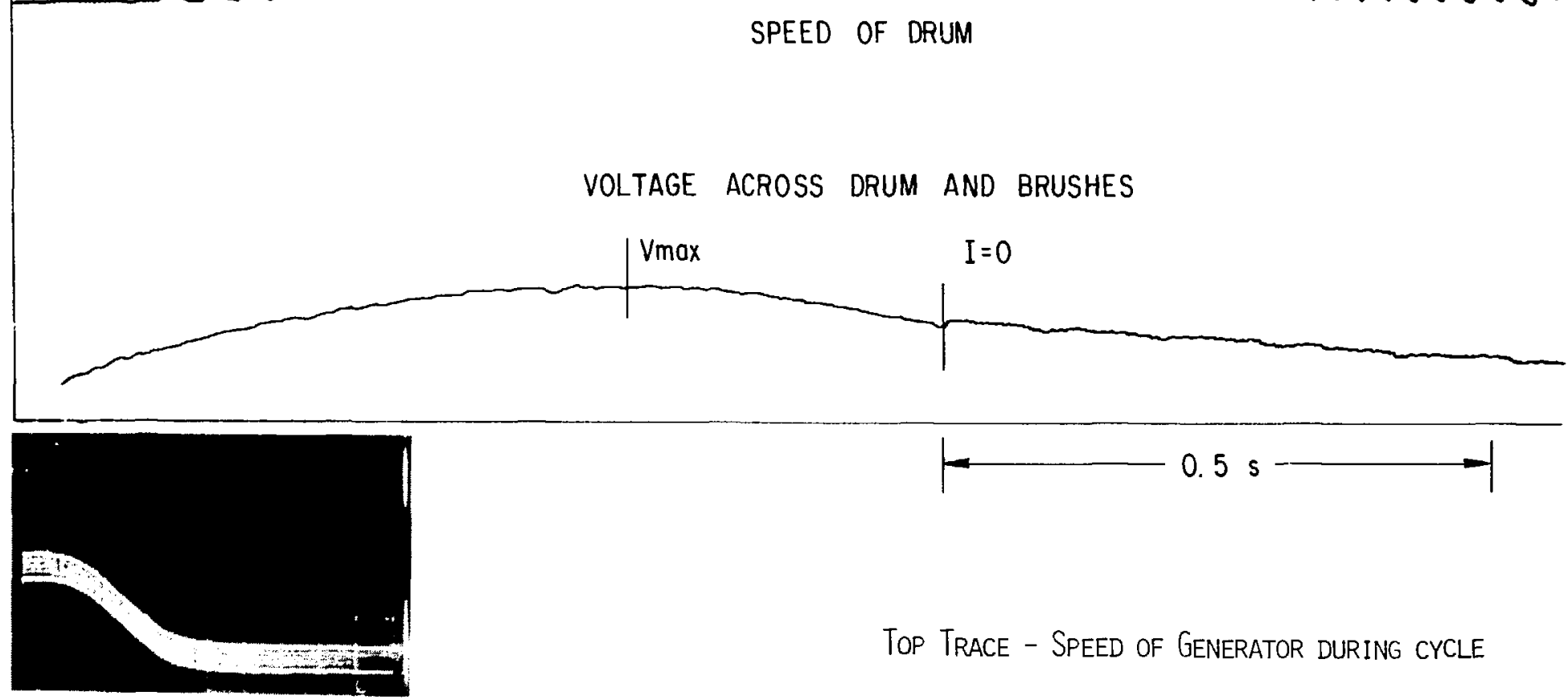

Top Trace - Speed of Generator during cyCle

$300 \mathrm{~A} \quad 0.5 \mathrm{SEC} / \mathrm{DIV}$

CURRENT THROUGH HOPE 1

Bottom Trace - Voltage Across Drum and Brushes

Figure IV-1. HOPE-1 - Voltage Across the Drum, Current Through the Drum and Speed of the Drum as a Function of Time. 


\section{B. Negative Ion Source Development}

J. A. Fasolo, Accelerator Research Fac1lities Division

\section{Direct Extraction $\mathrm{H}^{-}$Source}

The initial modifications of the Penning-type cesium-activated surface plasma source have been completed. The source housing and the $n=1$ bending magnet have been built. Vacuum system and beam line modifications have been completed. The source has been mounted, pumped down and connected to the power supplies and monitoring devices; it is ready to produce a beam.

Cesium has been admitted into the source from the external boiler and hydrogen has been admltted through the pulsed gas valve to check the operation of the valve and the vacuum system.

Power supplies, controls, interlocks and monttoring and diagnostic equipment have been installed and are ready for use after testing and debugging. Testing and debugging of the SCR-switched arc modulator and its control logic has begun, with the modulator working into a l-ohm dummy load. 


\section{APPLIED PLASMA PHYSICS}

\section{A. Disparate Clump Approximation in Neoclassical Transport Theory}

C. D. Boley and E. M. Gelbard, Applied Physics Division

In tokamak plasma transport calculations, it is sometimes necessary to treat the different charge states of impurity atoms separately, without invoking the coronal approximation. General expressions for the neoclassical transport coefficients are now avallable for multispectes plasmas in a variety of collisionality regimes, but the computation of these coefficients of ten involves the inversion of large matrices. Since, in addition, the temperatures and densities of all species are coupled, the running time for one-dimensional diffusion calculations increases rapidly with the total number of species and charge states. In the previous report, 1 we described a "disparate clump" approximation in which neoclassical transport coefficients simplify substantially. Within this approximation the plasma may contain many charge states of each atomic specles, so long as the different atomic species are disparate in mass. The calculations have now been extended in two respects:

1. We have compared our disparate-clump expression for the Spitzer function with the work of Moore, 2 in which the Spitzer function is calculated, via a variational principle, for a plasma consisting of electrons and to simple ion species of masses $\mathrm{m}_{1}$ and $\mathrm{m}_{2}$. For purposes of comparisc two cases are relevant: (a) $m_{1}=m_{2}$, In which the two lons form a cli, (b) $m_{1} \ll m_{2}$, in which each ion defines a clump. Very good agreement is obtained in each case.

2. With the aid of general neoclassical relations, ${ }^{3}$ we have evaluated the Ware pinch and bootstrap current transport coefficients in the disparate clump approximation. The results are given by one-dimensional integrals that, though complicated, are completely explicit and amenable to numerical computation. They are functions of the collisionality index of the particular charge state and the effective charge of the clump.

1 C. D. Boley and E. M. Gelbard, "Fusion Power Program Quarterly Progress Report, October-December, 1977," Argonne National Laboratory, ANL/FPP-77-7, p. 49.

2 T. B. Moore, "Transport Properties of a Tokamak Plasma with Impurities," Fusion Research Center, University of Texas, FRCR \#122 (1976).

3 S. P. Hirshman and A. H. Boozer, "The Neoclassical Current in a ToroidallyConfined Multispecies Plasma," Princeton Plasma Physics Laboratory, PPPL-1409 (1977). 


\section{B. Theoretical Spectroscopic Data for Silver-Like Ions}

Y. K. Kim and K. T. Cheng, Radiological and Environmental Research Divisi

To provide spectroscopic data for impurity ions relevant to fusion reactc studies, we have calculated transition wavelengths and probabilities for selec ions in the silver isoelectronic sequence using relativistic Hartree-Fock (RHF wavefunctions. Throughout the sequence, the $4 \mathrm{~d}^{10} 5 \mathrm{~s} \rightarrow 4 \mathrm{~d}^{10} 5 \mathrm{p}$ transition provides a strong resonance line so that it can easily be identified in hot plasi

For $Z>60,4 \mathrm{f}$ replaces $5 s$ as the ground state, and we expect that $4 \mathrm{~d}^{10} 0_{4 \mathrm{f}}$ $4 \mathrm{~d}^{10} 5 \mathrm{~g}$ should be a strong resonance line also. In Table V-1, we give waveleng $(\lambda)$ and absorption oscillator strengths ( $f$ ) for some dipole-allowed transitior between $4 \mathrm{~d}^{10} \mathrm{nl}(\mathrm{n}=4,5 ; \ell=0-4)$ states of $\mathrm{W}^{27+}$ and $\mathrm{Au}^{32+}$ ions.

Our experience on $\mathrm{Na}$ and $\mathrm{Cu}$ sequences ${ }^{1,2}$ shows that single configuration RHF calculations glve reliable spectroscopic data for highly stripped alkalilike Ions (i.e., lons with one valence electron).

In the silver sequence we also found good agreements between theory and experiment on the $\mathrm{Pr}^{12+}$ ion. 3 However, complications arise at high $\mathrm{Z}$ when the energies of the inner-shell excited states $4 \mathrm{~d}^{9} 4 \mathrm{f}^{2}$ become comparable to those of the $4 \mathrm{~d}^{10} 5 \mathrm{l}$ states. Since $4 \mathrm{~d}^{9} 4 \mathrm{f}^{2}$ and $4 \mathrm{~d}^{10} 5 \mathrm{l}$ configurations can mix with eac other when they have the same parity and total angular momentum, the single configuration RHF results may be affected by the configuration mixing. Fortunately, the mixing between these states arises from inter-shell $(n=4$ and correlations which are known to be unimportant at high 7.4 We have carried out exploratory calculations on the configuration mixing between the $4 \mathrm{~d}^{9} 4 \mathrm{f}^{2}$ an $4 \mathrm{~d}^{10} 5 \mathrm{l}$ states, and have found the effects of the mixing to be minor. In view of this, we conclude that the single-configuration RHF results in Table V-1 are reliable; $\lambda$ within $2 \%$ and $f$ and $A$ within $20 \%$.

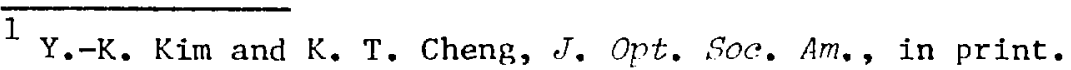

2 K. T. Cheng and Y. K. Kim, "Spectroscopic Data for Cu-Like Ions," Argonne National Laboratory, ANL/FPP/TMi-109 (April, 1978).

3 K. T. Cheng and Y. $-K$. KIm, "Fuston Power Program Quarterly Progress Report, April-June, 1977," Argonne National Laboratory, ANL/FPP-77-2, p. 85; see also J. Sugar, J. Opt. Soc. Am., 67 (1977) p. 1518.

4 D. Layzer, Ann. Phys. (N.Y.), 8 (1959) p. 271. 
Table V-1. Theoretical Data on Wavelength $\lambda$, Absorption Oscillator Strength $f$, and Iransition Rate $A$ for $\mathrm{W}^{27+}$ and $\mathrm{Au}^{32+}$.

\begin{tabular}{|c|c|c|c|c|c|c|c|}
\hline \multirow[b]{2}{*}{ Transition } & \multirow[b]{2}{*}{$j-j^{\prime}$} & \multicolumn{3}{|c|}{$W^{27+}$} & \multicolumn{3}{|c|}{$\mathrm{Au}^{32+}$} \\
\hline & & $\lambda(\dot{A})$ & $\mathrm{f}$ & $A\left(10^{10} \mathrm{~s}^{-1}\right)$ & $\lambda(\AA)$ & $\mathbf{f}$ & $A\left(10^{10} \mathrm{~s}^{-1}\right)$ \\
\hline \multirow[t]{2}{*}{$5 s-5 p$} & $1 / 2-1 / 2$ & 280.6 & 0.228 & 1.93 & 236.8 & 0.212 & 2.52 \\
\hline & $1 / 2-3 / 2$ & 172.7 & 0.754 & 8.44 & 131.4 & 0.779 & 15.1 \\
\hline \multirow[t]{2}{*}{$5 p-5 d$} & $1 / 2-3 / 2$ & 126.3 & 1.080 & 22.6 & 99.41 & 1.067 & 36.0 \\
\hline & $3 / 2-5 / 2$ & 162.9 & 0.813 & 13.6 & 135.8 & 0.764 & 18.4 \\
\hline \multirow[t]{2}{*}{$4 f-5 d$} & $5 / 2-3 / 2$ & 43.95 & 0.062 & 32.1 & 31.72 & 0.055 & 54.8 \\
\hline & $7 / 2-5 / 2$ & 43.64 & 0.063 & 29.4 & 31.49 & 0.055 & 49.5 \\
\hline \multirow[t]{2}{*}{$4 f-5 g$} & $5 / 2-7 / 2$ & 28.36 & 0.804 & 500 & 21.45 & 0.875 & 951 \\
\hline & $7 / 2-9 / 2$ & 28.59 & 0.792 & 517 & 21.65 & 0.863 & 982 \\
\hline
\end{tabular}


FPP AND FPP-RELATED DOCUMENTS AUTHORED BY ARGONNE PERSONNEL

M. A. $A B D O U$

Important Aspects of Radiation Shielding for Fusion Reactor Tokamaks Atomkermenergie, 30, 308 (1977).

M. A. $A B D O U$

Radiation Considerations for Superconducting Fusion Magnets Joumal of Nuclear Materials, 72, 147 (March, 1978)

H. I. AVCI, Y. GOHAR, T. Y. SUNG, G. L. KULCINSKI AND C. W. MAYNARD

The Use and Performance of Graphtte and Metal ISSECS in Tokamak Fusion Reactors Nuclear Engineering and Design, 45(2) (February, 1978).

B. S. BROWN, R. C. BIRTCHER, R. T. KAMPWIRTH AND T. H. BLEWITT

Resistivity and $\mathrm{T}_{c}$ Measurements in Low Temperature Irradiated $\mathrm{Nb}_{3} \mathrm{Sn}$ and $\mathrm{Nb}_{3} \mathrm{Ge}$

Joumal of Nuclear Materials, 72, 76 (March, 1978).

S. K. DAS, M. KAMINSKY, V. M. GUSLV, M. I. GUSEVA, Yu, B. KRASULtN, Yu. G. MARTYNENKO AND I. A. ROSINA

Results of Joint Work on Surface Damage of N1 Caused by the Implantation of llelium Ions Having a Broad Energy Range

Piziko-Khimicheskaia Mekhaniva Materialov (Akado-Nauk URSR).

FUSION POWER PROGRAM

Recent Contributions to Fusion Reactor Design

Argonne National Laboratory, ANL/FPP/TM-103 (January, 1978).

E. M. GELBARD AND S. P. HIRSHMAN

Neoclassical Transport of a Multi-Species Plasma in a Mixed Regime with Several Collisional Species

Physics of Fluids, 21(1), 145 (January, 1978).

Y. GOHAR AND M. ABDOU

The MACK/MACKLIB System for Nuclear Response Functions Argonne National Laboratory, ANL/FPP/TM-104 (March, 1978).

J. JUNG AND M. A. ABDOU

Radiation Shielding of Major Penetrations in Tokamak Reactors Argonne National Laboratory, ANL/FPP/TM-107 (March, 1978).

M. KAMINSKY, S. DAS AND P. DUSZA

Sputtering and Surface Damage of TFTR Beam Dump Materlals (Mo, TZM, Graphite) by Energetic $D^{+}$Ion Irradiation Argonne National Laboratory, ANL/FPP/TM-105 (March, 1978).

M. KAMINSKY, S. K. DAS, R. EKERN AND D. C. HESS

An Accleerator System for Producing Two-Component Beams for Studies of Interactive Surface Effects

Inst. Phys. Sonf. Ser., No. 38 (1978), Chapter 7. 
J. MEADOWS, W. POENITZ, A. SMITH, D. SMITH AND J. WHALEN

Evaluated Nuclear Data File of Th-232

Argonne National Laboratory, ANL/NDM-35 (February, 1978).

D. I. POTTER AND D. G. RYDING

Precipitate Coarsening, Redistribution and Renucleation During Irradiation of $\mathrm{N} 1-6.35 \mathrm{wt} . \%$ Al

Joumal of Nuclear Materials, 71, 14 (December, 1977).

SAFETY PROJECT PERSONNEL

Fusion Reactor Safety Studies - FY 1977

Argonne National Laboratory, ANL/FPP/TM-111 (March, 1978)

M. K. SINHA, S. K. DAS AND M. KAMINSKY

Temperature Dependence of Helium Blistering in Nickel Monocrystals Joumal of Applied Physics, 49 (1) (January, 1978).

A. SMITH, R. McKNIGHT AND D. SMITH

Encrgy-Averaged Neutron Cross Sections of Fast-Reactor Structural

Materials

Argonne National Laboratory, ANL/NDM-41 (February, 1978)

W. M. STACEY, JR. AND M. A. ABDOU

Tokamak Fusion Power Reactors

Nuclear Technology, 37, 29 (January, 1978)

TNS PROJECT

General Atomic Company-Argonne National Laboratory TNS Scoping Studies,

Volume V - Support Engineering, Tritium and Neutronics

Argonne National Laboratory, ANL/FPP-77-6, and, General Atomic

Company, GA-A14614 (January, 1978) 
Distribution L1st for ANL/FPP-78-1

Internal

S. C. Agarwal

B. Ancker-Johnson

R. Avery

C. C. Baker

C. D. Boley

J. N. Brooks

L. Burrts

F. A. Cafasso

R. G. Clemmer

J. B. Darby

S. A. Davis

K. Evans

J. A. Fasolo

P. R. Fields

B. R. T. Frost

R. E. Fuja

G. T. Garvey

E. M, Gelbard

Y. M. Gohar

L. R. Greenwood

D. M. Gruen

S. D. Harkness

R. R. Helnrich

M. S. Kaminsky
$\mathrm{Y}-\mathrm{K}, \mathrm{KIm}$

M. A. Kirk

R. L. Kustom

R. V. Laney

V. A. Maront

R. L. Martin

M. V. Nevitt

F. V. Nolf1

J. H. Norem

P. J. Persiant

E. N. Pettitt

E. G. Pewitt

M. D. Rechtin

R. E. Rowland

R. G. Sachs

D. L. Smith

D. L. Smith

H. C. Stevens

C. E. T111

D. C. Weber

FP Program (20)

ANL Contract Copy

ANL Libraries (5)

TIS Files (5)

\section{External}

DOE-TIC, for distribution per UC-20, plus -20a through -20g (406)

Manager, Chicago Operations Office

Chief, Chicago Patent Group

President, Argonne Universities Association

Applied Physics Division Review Committee:

P. W. Dickson, Jr., Westinghouse Electric Corp.

R. L. Hellens, Combustion Englneering, Inc.

W. B. Loewensteln, Electrlc Power Research Inst.

R. F. Redmond, Ohio State U.

R. Sher, Stanford U.

D. B. Wehmeyer, Detroit Edison

S. A. Werner, U. Missour1

Chemical Engineering Division Review Committee:

C. B. Alcock, U. Toronto

R. C. Axtmann, Princeton U.

J. T. Banchero, U. Notre Dame

T. Cole, Ford Motor Co.

P. W. Gilles, U. Kansas

R. I. Newman, Allied Chemical Corp.

G. M. Rosenblatt, Pennsylvania State U. 
Chemistry Division Review Committee:

J. Bigeleisen, U, Rochester

W. H. Flygare, U. Illinois

H. F. Franzen, Iowa State U.

H. S. Gutowsky, U. Illinols

D. R. Herschbach, Harvard U.

E. L. Muetterties, Cosnell U.

J. 0. Rasmussen, Lawrence berkeley Lab.

F. S. Rowland, U. California, Irvine

J. H. Wang, State U. New York, Buffalo

Components Technology Division Review Committee:

P. F. Cunniff, U。 Maryland

W. E. Kessler, Commonwealth Assoctates

N. J. Palladino, Pennsylvania State U.

N. C. Rasmussen, Massachusetts Inst. Technology

M. A. Schultz, Pennsylvania State U.

A. Sesonske, Purdue U.

H. Thielsch, ITT Grinnell Corp.

Materials Sclence Division Review Committee:

G. S. Ansell, Rensselaer Molytechnic Inst.

R. W. Balluff1, Cornell U.

S. L. Cooper, U. Wisconsin

S. Donfach, Stanford U.

H. L. Falkenberry, Tennessee Valley Authority

C. Laird, U. Pennsylvania

D. Lazarus, U. Illinois

M. T. Simnad, General Atomic Co.

A. R. C. Westwood, Martin Marietta Labs.

Physics Division Review Committee:

B. Bederson, New York U.

D. A. Bromley, Yale U.

W. L. Brown, Bell Telephone Labs.

R. Middleton, U. Pennsylvania

D. E. Nagle, Los Alamos Scientific Lab.

J. W. Negele, Massachusetts Inst. Technology

H. B. Willard, Case Western Reserve U.

Reactor Analysis and Safety Division Review Committee:

S. Baron, Burns and Roe, Inc.

J. R。 Dietrich, Combustion Engineering, Inc.

W. Kerr, U。 Michigan

M. Levenson, Electric Power Research Inst。

S. Levy, S. Levy, Inc。

D. Okrent, U. California, Los Angeles

Solid State Science Division Review Committee:

C. P. Flynn, U. Illinols

D. M. Ginsberg, U. Illinols

K. L. Kllewer, Iowa State U.

G. A. Russell, U. Missour1

zGS Complex Review Committee:

R. L. Cool, Rockefeller U.

V. W. Hughes, Yale U.

J. D. Jackson, U. Calıfornia, Berkeley

W. Lee, Columbia U. 
H. A. Neal, Indiana U.

J. L. Rosen, Northwestern U.

L. C. Teng, Fermi National Accelerator Lab.

M. Abdou, Georgla Institute of Technology

S. J. Buchsbaum, Bell Telephone Laboratorles, Inc.

R. A. Carruthers, Culham Laboratory, United Kingdom

G. Casint, Commission of the European Community Joint Research Center, Italy

J. A. Casazza, Stone \& Webster Management Consultants, Inc.

R. Challender, United Kingdom Atomic Energy Authority

M. Clarke, Combustion Engineering

M. Collins, Engelhard Minerals \& Chemicals Corp.

J. A. Davis, McDonnell Douglas Astronautics Company-East

W. E. Drummond, University of Texas at Austin

A. M. Dupas, Centre A'Etudes Nucleaires, France

T. S. Elleman, Nortn Carolina State University

J. Feinstein, Varian Associates, Inc.

H. Finger, Center of Energy Systems

H. K. Forsen, Exxon Nuclear Company, Inc.

J. S. Foster, Jr., TRW

D. Grafstein, Exxon Research \& Engineering Co.

G. Hansen, Convair Division/General Dynamics

A. F. Haught, United Technologies Research Center

N. Hershkowitz, University of Iowa

I. Grant Hedrick, Grumman Aerospace Corporation

R. A. Huse, Public Service Electric \& Gas Company

H. Horwitz, General Electric Company

A. Kolb, Maxwel1 Laboratories

W. B. Kunkel, University of California, Berkeley

D. Kummer, McDonnell Douglas Astronautics Company-East

S. Hale Lul1, Northeast Ut1lity Service Company

R. Lengye, Bibliothek, Max-Planck Institute fur Plasmaphysik, West Germany

S. Naymark, Nuclear Services Corporation

R. Raeder, Max-Plaıck Institut fur Plasmaphysik, West Germany

K. H. Schmitter, Max-Planck Institut fur Plasmaphysik, West Germany

W. M. Stacey, Ir., Georgla Institute of Technology

Library, Centre de Recherches en Physique des Plasma, Switzerland

Library, Culham Laboratory

Bibliotheque, Service du Confinement des Plasmas, CEA, France

Library, FOM-Institut voor Plasma-Fysica, The Netherlands

Thermonuclear Library, Japan Atomic Energy Research Institute

Library, Kurchatov Institute of Atomic Energy, U.S.S.R.

Library, Laboratorio Gas Ionizata, Italy 